\title{
Structure-Based Optimization of a Small Molecule Antagonist of the Interaction Between WD Repeat-Containing Protein 5 (WDR5) and Mixed-Lineage Leukemia 1 (MLL1)
}

Matthäus Getlik, ${ }^{\dagger, \#}$ David Smil, ${ }^{\not, \#}$ Carlos Zepeda-Velázquez, ${ }^{\dagger}$ Yuri Bolshan, ${ }^{,}$Gennady Poda, ${ }^{\dagger, \&}$ Hong Wu, Aiping Dong, ${ }^{*}$ Ekaterina Kuznetsova, ${ }^{*}$ Richard Marcellus, ${ }^{\dagger}$ Guillermo Senisterra, ${ }^{*}$ Ludmila Dombrovski, ${ }^{*}$ Taraneh Hajian, ${ }^{+}$Taira Kiyota, ${ }^{\dagger}$ Matthieu Schapira, ${ }^{\ddagger}$, Cheryl H. Arrowsmith, ${ }^{*}$ Peter J. Brown, ${ }^{*}$ Masoud Vedadi, ${ }^{\hbar,}$ Rima Al-awar ${ }^{\dagger, \xi, *}$

${ }^{\dagger}$ Drug Discovery Program, Ontario Institute for Cancer Research, 661 University Avenue, MaRS Centre, West Tower, Toronto, Ontario, M5G 0A3, Canada

Structural Genomics Consortium, University of Toronto, 101 College Street, MaRS Centre, South Tower, Toronto, Ontario, M5G 1L7, Canada

\& Leslie Dan Faculty of Pharmacy, University of Toronto, 144 College Street, Toronto, Ontario, M5S 3M2, Canada

$\S$ Department of Pharmacology and Toxicology, University of Toronto, Medical Sciences Building, 1 King's College Circle, Toronto, Ontario, M5S 1A8, Canada

\section{- Supporting Information -}

1. General Information $\quad$ S1

2. Synthetic Procedures and Compound Characterization Data $\quad$ S4

3. NMR Spectra of Select Compounds $\quad$ S34

4. Focused Library Design and Molecular Docking — S55

5. Cloning, Expression, and Purification of Human WDR5

6. Fluorescence Polarization (FP) Binding Assays_—S56

7. Crystallization and Structure Determination $\quad$ S56

8. Pharmacokinetics $\quad$ S57 


\section{General Information}

All oxygen and/or moisture sensitive reactions were carried out under a nitrogen atmosphere. Solvent removal from reaction mixtures was performed by rotary evaporation under reduced pressure at $40{ }^{\circ} \mathrm{C}$ unless otherwise noted. All reagents and laboratory grade solvents were purchased from commercial vendors and used as received, without further purification. The yields given refer to chromatographically purified and spectroscopically pure compounds, unless stated otherwise.

Nuclear Magnetic Resonance (NMR)

${ }^{1} \mathrm{H},{ }^{13} \mathrm{C}\left\{{ }^{1} \mathrm{H}\right\}$, DEPTq, COSY, HSQC and HMBC NMR spectra were recorded on a Bruker Avance-III $500 \mathrm{MHz}$ spectrometer $\left(500 \mathrm{MHz}{ }^{1} \mathrm{H}, 125 \mathrm{MHz}{ }^{13} \mathrm{C}\right.$ ). All ${ }^{1} \mathrm{H}$ NMR spectra were referenced relative to $\mathrm{SiMe}_{4}$ through a resonance of the employed deuterated solvent or proteo impurity of the solvent; chloroform (7.26 ppm), acetone (2.05 ppm), DMSO (3.33 ppm) and methanol (3.31 ppm) for ${ }^{1} \mathrm{H}$ NMR; chloroform (77.00 ppm), acetone (29.84 ppm), DMSO (39.52 $\mathrm{ppm})$ and methanol (49.00 ppm) for ${ }^{13} \mathrm{C} \mathrm{NMR} .{ }^{1}$ Data are reported as follows: chemical shifts $(\delta)$, multiplicity $(\mathrm{br}=$ broad, $\mathrm{s}=$ singlet, $\mathrm{d}=$ doublet, $\mathrm{t}=$ triplet, $\mathrm{q}=$ quartet, $\mathrm{m}=$ multiplet $)$; coupling constant(s) $(J)$ in $\mathrm{Hz}$; integration. Unless otherwise noted, NMR data were collected at $25^{\circ} \mathrm{C}$.

\section{Flash Column Chromatography}

Performed using a Biotage SP1 system fitted with a KP-SIL SNAP Silica Gel (60 ̊̊ mesh) Flash Cartridge (FSKO-1107).

\section{Compound Purity Determination}

Conducted by UV absorbance at $254 \mathrm{~nm}$ during tandem liquid chromatography/mass spectrometry (LCMS) using a Waters Acquity separations module.

\section{Low Resolution Mass Spectrometry (LRMS)}

Conducted in positive ion mode using a Waters Acquity SQD mass spectrometer (electrospray ionization source) fitted with a PDA detector. Mobile phase A consisted of $0.1 \%$ formic acid in water, while mobile phase $\mathrm{B}$ consisted of $0.1 \%$ formic acid in acetonitrile. The gradient that was followed is presented in the table below.

\begin{tabular}{|l|l|l|l|}
\hline Time (min) & Flow (mL/min) & \%A & \%B \\
\hline Initial & 0.4 & 90 & 10 \\
\hline 1.8 & 0.4 & 5 & 95 \\
\hline 2.3 & 0.4 & 5 & 95 \\
\hline 2.5 & 0.4 & 90 & 10 \\
\hline 3 & 0.4 & 90 & 10 \\
\hline 5 & 0 & 90 & 10 \\
\hline
\end{tabular}


Column 1: Acquity UPLC CSH C18 (2.1 x $50 \mathrm{~mm}, 130 \AA$, $1.7 \mu \mathrm{m}$. Part No. 186005296) or Column 2: Acquity UPLC BEH C8 (2.1 x $50 \mathrm{~mm}, 130 \AA \AA, 1.7 \mu \mathrm{m}$. Part No. 186002877). Both were used with column temperature maintained at $25{ }^{\circ} \mathrm{C}$. The sample solution injection volume was $1 \mu \mathrm{L}$.

Analytical Thin-Layer Chromatography (TLC)

Performed on aluminum sheets, silica gel $60 \mathrm{~F}_{254}(0.2 \mathrm{~mm}$, VWR International, Darmstadt, Germany). Visualization was accomplished with UV light and aqueous potassium permanganate $\left(\mathrm{KMnO}_{4}\right)$ stain followed by heating.

High Resolution Mass Spectrometry (HRMS)

Conducted using a Waters Xevo quadrupole-time-of-flight (QTOF) hybrid mass spectrometer system coupled with an Acquity ultra-performance liquid chromatography (UPLC) system.

\section{Chromatographic Separations}

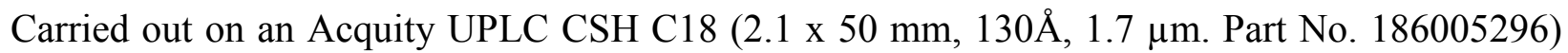
or Column 2: Acquity UPLC BEH C8 (2.1 x $50 \mathrm{~mm}, 130 \AA, 1.7 \mu \mathrm{m}$. Part No. 186002877). The mobile phase was $0.1 \%$ formic acid in water (solvent $\mathrm{A}$ ) and $0.1 \%$ formic acid in acetonitrile (solvent B). Leucine Enkephalin was used as lock mass. MassLynx 4.1 was used for data analysis.

${ }^{1}$ Gottlieb, H. E., Kotlyar, V., Nudelman, A. J. Org. Chem. 1997, 62 (21), 7512-7515. 


\section{Experimental Procedures and Compound Characterization Data}

\section{5-Bromo-2-(4-methylpiperazin-1-yl)aniline (7)}

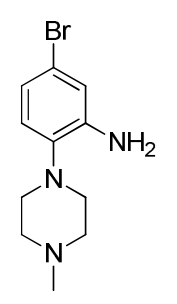

A $100 \mathrm{~mL}$ round bottom flask was charged with 4-bromo-1-fluoro-2-nitrobenzene (6) $(3.33 \mathrm{~mL}$, $26.5 \mathrm{mmol}), 1$-methylpiperazine $(3.28 \mathrm{~mL}, 29.2 \mathrm{mmol})$, and $N, N$-diisopropylethylamine $(9.12$ $\mathrm{mL}, 53.1 \mathrm{mmol})$ in DMSO $(20 \mathrm{~mL})$. The reaction turned red, and was stirred for $3 \mathrm{~h}$ at $80{ }^{\circ} \mathrm{C}$ during which time it gradually turned brown. After cooling to $23{ }^{\circ} \mathrm{C}$ and dilution with water (80 $\mathrm{mL})$, the aqueous layer was extracted with EtOAc $(4 \times 50 \mathrm{~mL})$. The combined organic extracts were dried $\left(\mathrm{Na}_{2} \mathrm{SO}_{4}\right)$, filtered, and concentrated under reduced pressure. The residue was purified by flash column chromatography on silica gel $(0-30 \% \mathrm{MeOH} / \mathrm{EtOAc})$ to afford the intermediate 1-(4-bromo-2-nitrophenyl)-4-methylpiperazine (8.22 g, 100\% yield) as a red oil. Subsequently, the 1-(4-bromo-2-nitrophenyl)-4-methylpiperazine (7.94 g, $27 \mathrm{mmol})$, iron powder (7.39 g, 132 mmol), and calcium chloride $(3.52 \mathrm{~g}, 32 \mathrm{mmol})$ were dissolved in a mixture of water and $\mathrm{MeOH}$ $(1: 1,100 \mathrm{~mL})$, and heated at reflux for $3 \mathrm{~h}$. The solution was then basified with $1 \mathrm{M} \mathrm{NaOH}$, diluted with brine, and extracted with EtOAc $(5 \times 50 \mathrm{~mL})$. The combined organic extracts were dried $\left(\mathrm{MgSO}_{4}\right)$, filtered, and concentrated under reduced pressure. The residue was purified by flash column chromatography on silica gel (5-30\% MeOH/EtOAc) to afford the title compound (2.75 g, 39\% yield). ${ }^{1} \mathrm{H}$ NMR $\left(500 \mathrm{MHz}, \mathrm{DMSO}-d_{6}\right) \delta 6.83(\mathrm{~d}, J=2.4 \mathrm{~Hz}, 1 \mathrm{H}), 6.80(\mathrm{~d}, J=8.3$ $\mathrm{Hz}, 1 \mathrm{H}), 6.65(\mathrm{dd}, J=2.4,8.3 \mathrm{~Hz}, 1 \mathrm{H}), 4.97$ (s, 2H), 2.76 (br s, 4H), 2.47 (br s, 4H), 2.22 (s, $3 \mathrm{H}) ;{ }^{13} \mathrm{C}$ NMR (125 MHz, DMSO- $\left.d_{6}\right) \delta 144.3,137.4,120.9,118.5,116.2,116.1,55.0$ (2), 50.1 (2), 45.8. HRMS (ESI) $m / z$ calcd for $\mathrm{C}_{11} \mathrm{H}_{17} \mathrm{BrN}_{3}[\mathrm{M}+\mathrm{H}]^{+}: 270.0606$, found: 270.0612 .

\section{N-(5-Bromo-2-(4-methylpiperazin-1-yl)phenyl)-3-methylbenzamide (8)}

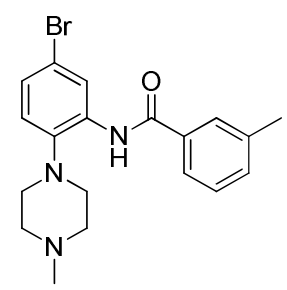

5-Bromo-2-(4-methylpiperazin-1-yl)aniline (7) (1.5 g, $5.55 \mathrm{mmol}$ ) was dissolved in $\mathrm{CH}_{2} \mathrm{Cl}_{2}$ (25 $\mathrm{mL})$ prior to the addition of pyridine $(584 \mu \mathrm{L}, 7 \mathrm{mmol})$ and 3-methylbenzoyl chloride $(807 \mu \mathrm{L}, 7$ mmol). After $1 \mathrm{~h}$ at $23{ }^{\circ} \mathrm{C}$ the reaction mixture was diluted with EtOAc and $1 \mathrm{M} \mathrm{NaOH}$, and the aqueous layer extracted with EtOAc $(3 \times 15 \mathrm{~mL})$. The organic layers were combined, dried $\left(\mathrm{MgSO}_{4}\right)$, filtered, and concentrated under reduced pressure to give a brown solid. This crude product was purified by flash column chromatography on silica gel (5-30\% $\mathrm{MeOH} / \mathrm{EtOAc})$ to 
afford the title compound (2.12 g, 93\% yield) as an off-white solid. ${ }^{1} \mathrm{H}$ NMR (500 MHz, DMSO$\left.d_{6}\right) \delta 9.58(\mathrm{~s}, 1 \mathrm{H}), 8.39(\mathrm{~d}, J=2.4 \mathrm{~Hz}, 1 \mathrm{H}), 7.74-7.71(\mathrm{~m}, 2 \mathrm{H}), 7.49-7.45(\mathrm{~m}, 2 \mathrm{H}), 7.30(\mathrm{dd}, J=$ 2.4, 8.6 Hz, 1H), $7.25(\mathrm{~d}, J=8.6 \mathrm{~Hz}, 1 \mathrm{H}), 2.86(\mathrm{t}, J=4.8 \mathrm{~Hz}, 4 \mathrm{H}), 2.51(\mathrm{br} \mathrm{s}, 4 \mathrm{H}), 2.43(\mathrm{~s}, 3 \mathrm{H})$, $2.24(\mathrm{~s}, 3 \mathrm{H}) ;{ }^{13} \mathrm{C}$ NMR $\left(125 \mathrm{MHz}, \mathrm{DMSO}-d_{6}\right) \delta 164.4,142.1,138.2,134.5,134.1,132.7,128.8$, $127.5,126.8,124.1,123.0,122.7,116.6,55.4$ (2), 51.3 (2), 45.8, 20.9. HRMS (ESI) $\mathrm{m} / z$ calcd for $\mathrm{C}_{19} \mathrm{H}_{23} \mathrm{BrN}_{3} \mathrm{O}[\mathrm{M}+\mathrm{H}]^{+}: 388.1025$, found: 388.1036 .

General Procedure A for the Synthesis of Compounds 9a-w. A $5 \mathrm{~mL}$ reaction vial was charged with $N$-(5-bromo-2-(4-methylpiperazin-1-yl)phenyl)-3-methylbenzamide (8) (50 mg, $0.13 \mathrm{mmol})$, the boronic acid/ester $(0.17 \mathrm{mmol})$, sodium carbonate $(68 \mathrm{mg}, 0.64 \mathrm{mmol})$, $\mathrm{Pd}\left(\mathrm{Ph}_{3} \mathrm{P}\right)_{4}(15 \mathrm{mg}, 0.01 \mathrm{mmol})$ and toluene/water $(1: 1,2 \mathrm{~mL})$. The reaction mixture was then heated at $115{ }^{\circ} \mathrm{C}$ overnight. After cooling to $23{ }^{\circ} \mathrm{C}$, the solution was diluted with EtOAc $(1 \mathrm{~mL})$ and water $(1 \mathrm{~mL})$, and the aqueous layer extracted with EtOAc $(3 \times 2 \mathrm{~mL})$. The combined organic layers were then dried $\left(\mathrm{MgSO}_{4}\right)$, filtered, and concentrated under reduced pressure. The crude product was purified by flash column chromatography on silica gel (5-50\% $\mathrm{MeOH} / \mathrm{EtOAc})$ to afford the desired compound.

\section{$N$-(5-Cyclopropyl-2-(4-methylpiperazin-1-yl)phenyl)-3-methylbenzamide (9a)}

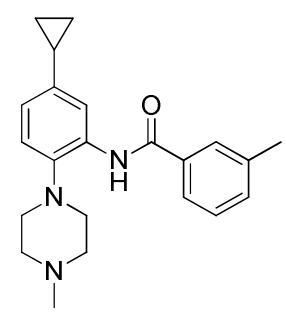

The title compound was prepared according to general procedure A (17 mg, 35\% yield). ${ }^{1} \mathrm{H}$ $\operatorname{NMR}\left(500 \mathrm{MHz}, \mathrm{CDCl}_{3}\right) \delta 9.25($ br s, $1 \mathrm{H}), 8.30(\mathrm{~s}, 1 \mathrm{H}), 7.76(\mathrm{~s}, 1 \mathrm{H}), 7.65(\mathrm{~d}, J=6.6 \mathrm{~Hz}, 1 \mathrm{H})$, 7.43-7.38 (m, 2H), $7.18(\mathrm{~d}, J=8.2 \mathrm{~Hz}, 1 \mathrm{H}), 6.84(\mathrm{dd}, J=2.0,4.3 \mathrm{~Hz}, 1 \mathrm{H}), 3.35-2.75(\mathrm{~m}, 8 \mathrm{H})$, 2.66 (br s, 3H), 2.47 (s, 3H), 1.95-1.89 (m, 1H), 0.99-0.95 (m, 2H), 0.76-0.72 (m, 2H); ${ }^{13} \mathrm{C} \mathrm{NMR}$ $\left(125 \mathrm{MHz}, \mathrm{CDCl}_{3}\right) \delta 165.1,142.7,139.0,138.1,135.4,133.9,132.7,129.0,128.1,123.9,121.4$, 121.1, 116.9, 56.0 (2), 51.5, 45.5, 21.7 (2), 15.7, 9.5. HRMS (ESI) $m / z$ calcd for $\mathrm{C}_{22} \mathrm{H}_{28} \mathrm{~N}_{3} \mathrm{O}$ $[\mathrm{M}+\mathrm{H}]^{+}:$350.2232, found: 350.2230 . 


\section{3-Methyl- $N$-(2-(4-methylpiperazin-1-yl)-5-(naphthalen-1-yl)phenyl)benzamide (9b)}

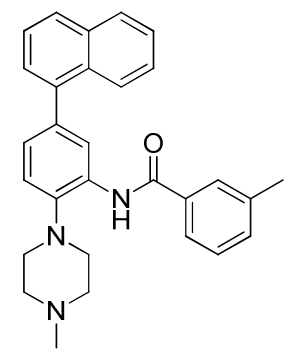

The title compound was prepared according to general procedure A (26 mg, 44\%yield). ${ }^{1} \mathrm{H}$ NMR $\left(500 \mathrm{MHz}, \mathrm{CDCl}_{3}\right) \delta 9.32($ br s, $1 \mathrm{H}), 8.71(\mathrm{~d}, J=1.5 \mathrm{~Hz}, 1 \mathrm{H}), 7.99(\mathrm{~d}, J=8.3 \mathrm{~Hz}, 1 \mathrm{H}), 7.90(\mathrm{~d}, J$ $=8.2 \mathrm{~Hz}, 1 \mathrm{H}), 7.86(\mathrm{~d}, J=8.2 \mathrm{~Hz}, 1 \mathrm{H}), 7.77(\mathrm{~s}, 1 \mathrm{H}), 7.68(\mathrm{~d}, J=7.3 \mathrm{~Hz}, 1 \mathrm{H}), 7.53-7.38(\mathrm{~m}, 7 \mathrm{H})$, 7.27 (dd, $J=1.9,8.1 \mathrm{~Hz}, 1 \mathrm{H}), 3.27$ (br s, 4H), 2.96 (br s, 4H), 2.64 (br s, 3H), $2.46(\mathrm{~s}, 3 \mathrm{H}) ;{ }^{13} \mathrm{C}$ NMR $\left(125 \mathrm{MHz}, \mathrm{CDCl}_{3}\right) \delta 165.2,139.7,139.5,139.2,139.1,135.2,134.0,133.6,132.9,131.7$, $129.0,128.5,128.1,128.0,127.3,126.3,126.1,126.1,125.9,125.5,123.8,121.8,121.0,55.5$ (2), 50.8, 45.0, 21.7 (2). HRMS (ESI) $m / z$ calcd for $\mathrm{C}_{29} \mathrm{H}_{30} \mathrm{~N}_{3} \mathrm{O}[\mathrm{M}+\mathrm{H}]^{+}$: 436.2389, found: 436.2397 .

\section{3-Methyl-N-(2-(4-methylpiperazin-1-yl)-5-(naphthalen-2-yl)phenyl)benzamide (9c)}

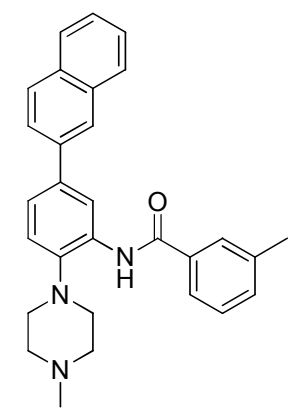

The title compound was prepared according to general procedure A ( $9 \mathrm{mg}, 15 \%$ yield). ${ }^{1} \mathrm{H}$ NMR $\left(500 \mathrm{MHz}, \mathrm{CDCl}_{3}\right) \delta 9.24($ br s, $1 \mathrm{H}), 8.98(\mathrm{~s}, 1 \mathrm{H}), 8.11(\mathrm{~d}, J=1.1 \mathrm{~Hz}, 1 \mathrm{H}), 7.91(\mathrm{~d}, J=8.1 \mathrm{~Hz}$, $1 \mathrm{H}), 7.86(\mathrm{~d}, J=8.1 \mathrm{~Hz}, 1 \mathrm{H}), 7.81-7.79(\mathrm{~m}, 2 \mathrm{H}), 7.69(\mathrm{~d}, J=7.1 \mathrm{~Hz}, 1 \mathrm{H}), 7.53-7.40(\mathrm{~m}, 6 \mathrm{H})$, 3.27 (br s, 4H), 2.97 (br s, 4H), 2.70 (br s, 3H), 2.49 (s, 3H); ${ }^{13} \mathrm{C} \mathrm{NMR}\left(125 \mathrm{MHz}, \mathrm{CDCl}_{3}\right) \delta$ $165.7,140.8,139.3,137.7,137.4,135.0,133.8,133.7,133.2,133.1,129.1,128.8,128.5,128.5$, 127.9, 126.6, 126.4, 126.2, 125.6, 124.0, 123.8, 121.8, 54.3, 49.5 (2), 43.9, 29.9, 21.8 (2). HRMS (ESI) $m / z$ calcd for $\mathrm{C}_{29} \mathrm{H}_{30} \mathrm{~N}_{3} \mathrm{O}[\mathrm{M}+\mathrm{H}]^{+}:$436.2389, found: 436.2389 . 

(9d)

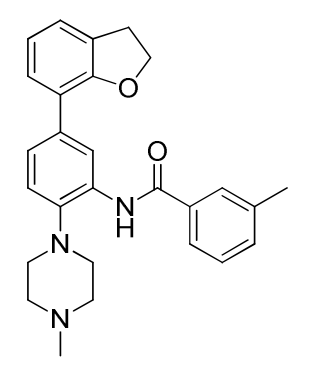

The title compound was prepared according to general procedure A (36 mg, 62\%yield). ${ }^{1} \mathrm{H}$ NMR $\left(500 \mathrm{MHz}, \mathrm{CDCl}_{3}\right) \delta 9.23(\mathrm{br} \mathrm{s}, 1 \mathrm{H}), 8.87(\mathrm{~d}, J=2.0 \mathrm{~Hz}, 1 \mathrm{H}), 7.78(\mathrm{~s}, 1 \mathrm{H}), 7.68(\mathrm{~d}, J=7.0 \mathrm{~Hz}$, $1 \mathrm{H}$ ), 7.50 (dd, $J=2.0,8.3 \mathrm{~Hz}, 1 \mathrm{H}), 7.44-7.38$ (m, 2H), 7.34-7.32 (m, 2H), 7.18 (dd, $J=1.1,7.3$ $\mathrm{Hz}, 1 \mathrm{H}), 6.93(\mathrm{t}, J=7.6 \mathrm{~Hz}, 1 \mathrm{H}), 4.64(\mathrm{t}, J=8.8 \mathrm{~Hz}, 2 \mathrm{H}), 3.35-2.80(\mathrm{~m}, 10 \mathrm{H}), 2.65(\mathrm{~s}, 3 \mathrm{H}), 2.47$ (s, 3H); ${ }^{13} \mathrm{C}$ NMR $\left(125 \mathrm{MHz}, \mathrm{CDCl}_{3}\right) \delta 165.3,157.4,139.3,138.1,136.7,135.4,133.4,133.0$, 129.0, 128.4, 128.1, 128.0, 124.9, 124.5, 123.6, 122.8, 121.4, 121.1, 120.7, 71.4, 54.7 (2), 49.3 (2), 43.8, 30.0, 21.7. HRMS (ESI) $\mathrm{m} / z$ calcd for $\mathrm{C}_{27} \mathrm{H}_{30} \mathrm{~N}_{3} \mathrm{O}_{2}[\mathrm{M}+\mathrm{H}]^{+}: 428.2338$, found: 428.2342 .

\section{$N$-(5-(2,3-Dihydrobenzofuran-5-yl)-2-(4-methylpiperazin-1-yl)phenyl)-3-methylbenzamide} (9e)

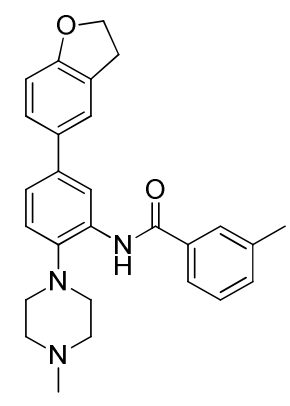

The title compound was prepared according to general procedure A (35 mg, 60\%yield). ${ }^{1} \mathrm{H}$ NMR $\left(500 \mathrm{MHz}, \mathrm{CDCl}_{3}\right) \delta 9.27(\mathrm{br} \mathrm{s}, 1 \mathrm{H}), 8.79(\mathrm{~s}, 1 \mathrm{H}), 7.79(\mathrm{~s}, 1 \mathrm{H}), 7.71-7.67(\mathrm{~m}, 1 \mathrm{H}), 7.51(\mathrm{~d}, J=$ $1.2 \mathrm{~Hz}, 1 \mathrm{H}), 7.44-7.38(\mathrm{~m}, 3 \mathrm{H}), 7.33-7.29(\mathrm{~m}, 2 \mathrm{H}), 6.84(\mathrm{~d}, J=8.3 \mathrm{~Hz}, 1 \mathrm{H}), 4.62(\mathrm{t}, J=8.5 \mathrm{~Hz}$, $2 \mathrm{H}), 3.32-2.82(\mathrm{~m}, 10 \mathrm{H}), 2.66(\mathrm{~s}, 3 \mathrm{H}), 2.48(\mathrm{~s}, 3 \mathrm{H}) ;{ }^{13} \mathrm{C} \mathrm{NMR}\left(125 \mathrm{MHz}, \mathrm{CDCl}_{3}\right) \delta 165.3,160.2$, 140.3, 139.3, 138.0, 135.3, 133.8, 133.1, 133.0, 129.0, 128.3, 128.0, 127.3, 124.0, 123.6, 122.7, 121.7, 118.6, 109.6, 71.7, 55.0 (2), 49.7 (2), 44.1, 29.9, 21.8. HRMS (ESI) $\mathrm{m} / z$ calcd for $\mathrm{C}_{27} \mathrm{H}_{30} \mathrm{~N}_{3} \mathrm{O}_{2}[\mathrm{M}+\mathrm{H}]^{+}: 428.2338$, found: 428.2353 . 


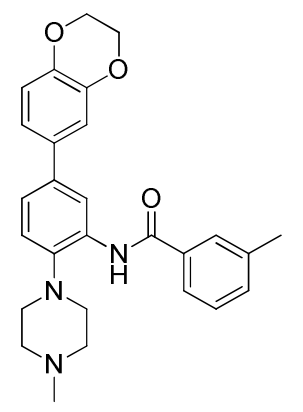

The title compound was prepared according to general procedure A ( $8 \mathrm{mg}, 13 \%$ yield). ${ }^{1} \mathrm{H}$ NMR $\left(500 \mathrm{MHz}, \mathrm{CDCl}_{3}\right) \delta 9.24($ br s, $1 \mathrm{H}), 8.77(\mathrm{~d}, J=1.5 \mathrm{~Hz}, 1 \mathrm{H}), 7.77(\mathrm{~s}, 1 \mathrm{H}), 7.67(\mathrm{~d}, J=7.1 \mathrm{~Hz}$, 1H), 7.44-7.39 (m, 3H), 7.32-7.27 (m, 2H), 7.17 (d, $J=2.2 \mathrm{~Hz}, 1 \mathrm{H}), 7.14$ (dd, $J=2.3,8.2 \mathrm{~Hz}$, 1H), 6.92 (d, $J=8.4 \mathrm{~Hz}, 1 \mathrm{H}), 4.30$ (s, 4H), 3.21 (br s, 4H), 2.96 (br s, 4H), 2.66 (br s, 3H), 2.47 (s, 3H); ${ }^{13} \mathrm{C}$ NMR $\left(125 \mathrm{MHz}, \mathrm{CDCl}_{3}\right) \delta 165.8,143.9,143.9,139.2,136.7,136.5,134.8,133.4$, 133.4, 133.2, 129.0, 129.6, 123.9, 123.6. 121.5, 121.1, 120.6, 117.8, 116.2, 64.7, 64.6, 53.8 (2), 49.6, 43.8, 21.7 (2). HRMS (ESI) $\mathrm{m} / z$ calcd for $\mathrm{C}_{27} \mathrm{H}_{30} \mathrm{~N}_{3} \mathrm{O}_{3}[\mathrm{M}+\mathrm{H}]^{+}$: 444.2287, found: 444.2294 .

\section{$N$-(5-(Isoquinolin-4-yl)-2-(4-methylpiperazin-1-yl)phenyl)-3-methylbenzamide (9g)}

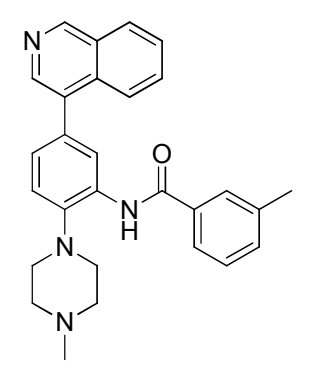

The title compound was prepared according to general procedure A (31 mg, 52\%yield). ${ }^{1} \mathrm{H}$ NMR $\left(500 \mathrm{MHz}, \mathrm{CD}_{3} \mathrm{OD}\right) \delta 9.21(\mathrm{br} \mathrm{s}, 1 \mathrm{H}), 8.61(\mathrm{~d}, J=1.9 \mathrm{~Hz}, 1 \mathrm{H}), 8.36(\mathrm{~s}, 1 \mathrm{H}), 8.14(\mathrm{~d}, J=8.0 \mathrm{~Hz}$, $1 \mathrm{H}), 8.01(\mathrm{~d}, J=8.5 \mathrm{~Hz}, 1 \mathrm{H}), 7.77-7.67(\mathrm{~m}, 4 \mathrm{H}), 7.44-7.41(\mathrm{~m}, 3 \mathrm{H}), 7.29(\mathrm{dd}, J=2.0,8.1 \mathrm{~Hz}$, 1H), 3.03 (t, $J=4.9 \mathrm{~Hz}, 4 \mathrm{H}), 2.68$ (br s, 4H), 2.43 (s, 3H), 2.38 (s, 3H); ${ }^{13} \mathrm{C}$ NMR $(125 \mathrm{MHz}$, $\left.\mathrm{CD}_{3} \mathrm{OD}\right) \delta 167.7,152.9,144.4,142.7,140.3,136.0,135.7,135.1,134.8,134.6,134.1,132.8$, 130.2, 130.1, 129.6, 129.1, 128.9, 127.7, 125.9, 125.4, 124.0, 122.5, 57.0 (2), 52.9, 46.3, 21.6 (2). HRMS (ESI) $m / z$ calcd for $\mathrm{C}_{28} \mathrm{H}_{29} \mathrm{~N}_{4} \mathrm{O}[\mathrm{M}+\mathrm{H}]^{+}: 437.2341$, found: 437.2339 . 


\section{3-Methyl- $N$-(2-(4-methylpiperazin-1-yl)-5-(quinolin-3-yl)phenyl)benzamide (9h)}

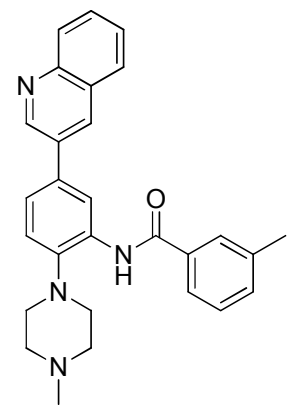

The title compound was prepared according to general procedure A (26 mg, 44\%yield). ${ }^{1} \mathrm{H}$ NMR $\left(500 \mathrm{MHz}, \mathrm{CD}_{3} \mathrm{OD}\right) \delta 9.01(\mathrm{~d}, J=2.3 \mathrm{~Hz}, 1 \mathrm{H}), 8.61(\mathrm{~d}, J=2.2 \mathrm{~Hz}, 1 \mathrm{H}), 8.36(\mathrm{~d}, J=2.2 \mathrm{~Hz}$, 1H), 7.99 (d, $J=8.5 \mathrm{~Hz}, 1 \mathrm{H}), 7.89$ (d, $J=7.9 \mathrm{~Hz}, 1 \mathrm{H}), 7.72-7.67(\mathrm{~m}, 3 \mathrm{H}), 7.57-7.47$ (m, 1H), 7.43-7.37 (m, 3H), $7.29(\mathrm{~d}, J=8.2 \mathrm{~Hz}, 1 \mathrm{H}), 2.90$ (t, $J=4.8 \mathrm{~Hz}, 4 \mathrm{H}), 2.60$ (br s, 4H), 2.40 (s, $3 \mathrm{H}), 2.33(\mathrm{~s}, 3 \mathrm{H}) ;{ }^{13} \mathrm{C}$ NMR $\left(125 \mathrm{MHz}, \mathrm{CD}_{3} \mathrm{OD}\right) \delta 167.5,150.4,147.9,144.4,140.3,135.9$, $135.4,135.1,135.0,134.9,134.2,131.2,130.1,129.8,129.7,129.1,128.9,128.7,125.4,124.8$, 122.7, 120.8, 57.0 (2), 52.8, 46.4, 21.6 (2). HRMS (ESI) $m / z$ calcd for $\mathrm{C}_{28} \mathrm{H}_{29} \mathrm{~N}_{4} \mathrm{O}[\mathrm{M}+\mathrm{H}]^{+}$: 437.2341, found: 437.2336 .

\section{$N$-(5-(Benzo[b]thiophen-3-yl)-2-(4-methylpiperazin-1-yl)phenyl)-3-methylbenzamide (9i)}

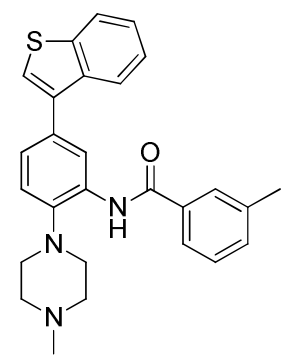

The title compound was prepared according to general procedure A (11 mg, 15\%yield). ${ }^{1} \mathrm{H}$ NMR $\left(500 \mathrm{MHz}, \mathrm{CDCl}_{3}\right) \delta 9.30($ br s, $1 \mathrm{H}), 8.82(\mathrm{~s}, 1 \mathrm{H}), 8.03(\mathrm{~d}, J=8.1 \mathrm{~Hz}, 1 \mathrm{H}), 7.92(\mathrm{~d}, J=7.8 \mathrm{~Hz}$, 1H), $7.79(\mathrm{~s}, 1 \mathrm{H}), 7.69(\mathrm{~d}, J=7.7 \mathrm{~Hz}, 1 \mathrm{H}), 7.47(\mathrm{~s}, 1 \mathrm{H}), 7.44-7.36(\mathrm{~m}, 6 \mathrm{H}), 3.25$ (br s, 4H), 2.98 (br s, 4H), 2.64 (s, 3H), 2.48 (s, 3H); $\left.{ }^{13} \mathrm{C} \mathrm{NMR} \mathrm{(125} \mathrm{MHz,} \mathrm{CDCl}_{3}\right) \delta 165.3,140.9,139.2,139.2$, $137.8,137.4,135.2,134.7,133.9,133.0,129.0,128.3,124.7,124.6$ (2C), 124.1, 123.7, 123.1 (2C), 121.7, 120.6, 55.1 (2), 50.0, 44.4, 21.7 (2). HRMS (ESI) $\mathrm{m} / z$ calcd for $\mathrm{C}_{27} \mathrm{H}_{28} \mathrm{~N}_{3} \mathrm{OS}$ $[\mathrm{M}+\mathrm{H}]^{+}:$442.1953, found: 442.1962 . 


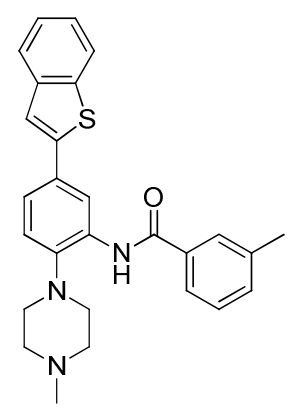

The title compound was prepared according to general procedure A (9 mg, 13\%yield). ${ }^{1} \mathrm{H}$ NMR $\left(500 \mathrm{MHz}, \mathrm{CDCl}_{3}\right) \delta 9.18(\mathrm{br} \mathrm{s}, 1 \mathrm{H}), 9.01(\mathrm{~s}, 1 \mathrm{H}), 7.84-7.77(\mathrm{~m}, 3 \mathrm{H}), 7.68(\mathrm{~d}, J=5.6 \mathrm{~Hz}, 1 \mathrm{H})$, $7.63(\mathrm{~s}, 1 \mathrm{H}), 7.48-7.42(\mathrm{~m}, 3 \mathrm{H}), 7.38-7.30(\mathrm{~m}, 3 \mathrm{H}), 3.59-2.86(\mathrm{~m}, 8 \mathrm{H}), 2.70($ br s, $3 \mathrm{H}), 2.49(\mathrm{~s}$, $3 \mathrm{H}) ;{ }^{13} \mathrm{C}$ NMR $\left(125 \mathrm{MHz}, \mathrm{CDCl}_{3}\right) \delta 165.6,143.1,140.8,139.9,139.4,138.0,134.9,133.9$, 133.6, 133.2, 129.1, 128.5, 125.4, 124.8, 123.7, 123.0, 122.6, 122.5, 122.0, 121.7, 120.7, 54.4 (2), 49.4, 44.0 (2), 21.8. HRMS (ESI) $m / z$ calcd for $\mathrm{C}_{27} \mathrm{H}_{28} \mathrm{~N}_{3} \mathrm{OS}[\mathrm{M}+\mathrm{H}]^{+}: 442.1953$, found: 442.1961 .

3-Methyl- $N$-(5-(5-methylbenzo[b]thiophen-2-yl)-2-(4-methylpiperazin-1yl)phenyl)benzamide (9k)

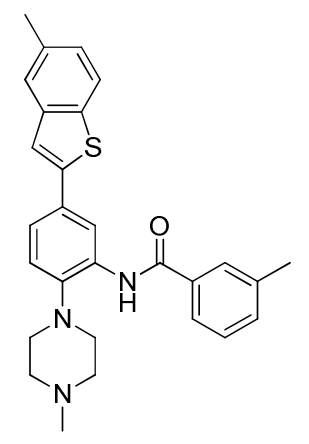

The title compound was prepared according to general procedure A (14 mg, 23\% yield). ${ }^{1} \mathrm{H}$ NMR $\left(500 \mathrm{MHz}, \mathrm{CDCl}_{3}\right) \delta 9.06(\mathrm{~s}, 1 \mathrm{H}), 8.96(\mathrm{~s}, 1 \mathrm{H}), 7.78(\mathrm{~s}, 1 \mathrm{H}), 7.70-7.64(\mathrm{~m}, 2 \mathrm{H}), 7.59-7.53$ $(\mathrm{m}, 2 \mathrm{H}), 7.47-7.41(\mathrm{~m}, 3 \mathrm{H}), 7.34(\mathrm{~d}, J=8.2 \mathrm{~Hz}, 1 \mathrm{H}), 7.15(\mathrm{dd}, J=1.3,8.2 \mathrm{~Hz}, 1 \mathrm{H}), 3.95-2.64$ $(\mathrm{m}, 11 \mathrm{H}), 2.48(\mathrm{~s}, 3 \mathrm{H}), 2.47(\mathrm{~s}, 3 \mathrm{H}) ;{ }^{13} \mathrm{C} \mathrm{NMR}\left(125 \mathrm{MHz}, \mathrm{CDCl}_{3}\right) \delta 165.3,143.8,141.2,139.2$, 137.0, 135.1, 134.5, 134.1, 133.0, 133.0, 129.0, 129.0, 128.2, 126.4, 123.8, 123.8, 122.3, 122.1, 121.7, 120.0, 117.8, 55.3 (2), 50.5, 44.5, 21.7 (2), 21.6. HRMS (ESI) $m / z$ calcd for $\mathrm{C}_{28} \mathrm{H}_{30} \mathrm{~N}_{3} \mathrm{OS}$ $[\mathrm{M}+\mathrm{H}]^{+}: 456.2110$, found: 456.2115 . 


\section{$N$-(5-(Dibenzo[b,d]thiophen-2-yl)-2-(4-methylpiperazin-1-yl)phenyl)-3-methylbenzamide}

(9l)

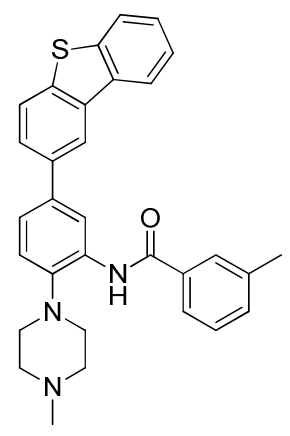

The title compound was prepared according to general procedure A (26 mg, 39\%yield). ${ }^{1} \mathrm{H}$ NMR $\left(500 \mathrm{MHz}, \mathrm{CDCl}_{3}\right) \delta 9.27(\mathrm{~s}, 1 \mathrm{H}), 8.97(\mathrm{~d}, J=1.4 \mathrm{~Hz}, 1 \mathrm{H}), 8.40(\mathrm{~d}, J=1.5 \mathrm{~Hz}, 1 \mathrm{H}), 8.28-8.24$ $(\mathrm{m}, 1 \mathrm{H}), 7.91(\mathrm{~d}, J=8.6 \mathrm{~Hz}, 1 \mathrm{H}), 7.88-7.85(\mathrm{~m}, 1 \mathrm{H}), 7.81(\mathrm{br} \mathrm{s}, 1 \mathrm{H}), 7.75(\mathrm{dd}, J=1.9,8.4 \mathrm{~Hz}$, $1 \mathrm{H}), 7.70(\mathrm{~d}, J=7.1 \mathrm{~Hz}, 1 \mathrm{H}), 7.50-7.46(\mathrm{~m}, 3 \mathrm{H}), 7.45-7.40(\mathrm{~m}, 3 \mathrm{H}), 3.26(\mathrm{br} \mathrm{s}, 4 \mathrm{H}), 3.00(\mathrm{br} \mathrm{s}$, $4 \mathrm{H}), 2.70(\mathrm{~s}, 3 \mathrm{H}), 2.49(\mathrm{~s}, 3 \mathrm{H}) ;{ }^{13} \mathrm{C}$ NMR $\left(125 \mathrm{MHz}, \mathrm{CDCl}_{3}\right) \delta 165.3,140.1,140.1,139.3,139.1$, 138.8, 137.4, 136.3, 135.8, 135.3, 134.3, 132.9, 129.0, 128.1, 127.0, 126.4, 124.6, 124.0, 123.2, 123.1, 123.0, 122.0, 121.6, 120.2, 118.6, 55.9 (2), 51.5, 45.7, 21.7 (2). HRMS (ESI) $m / z$ calcd for $\mathrm{C}_{31} \mathrm{H}_{30} \mathrm{~N}_{3} \mathrm{OS}[\mathrm{M}+\mathrm{H}]^{+}:$492.2110, found: 492.2115 .

\section{3-Methyl- $N$-(5-(1-methyl-1H-indol-4-yl)-2-(4-methylpiperazin-1-yl)phenyl)benzamide (9m)}

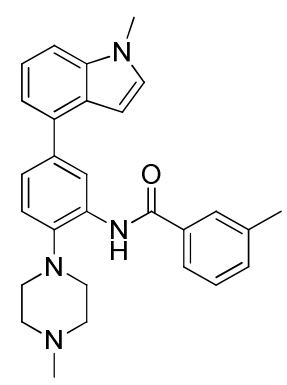

The title compound was prepared according to general procedure A (30 mg, $51 \%$ yield). ${ }^{1} \mathrm{H}$ $\operatorname{NMR}\left(500 \mathrm{MHz}, \mathrm{CDCl}_{3}\right) \delta 9.17(\mathrm{br} \mathrm{s}, 1 \mathrm{H}), 8.86(\mathrm{~s}, 1 \mathrm{H}), 7.73(\mathrm{~s}, 1 \mathrm{H}), 7.61(\mathrm{~d}, J=7.0 \mathrm{~Hz}, 1 \mathrm{H})$, 7.42 (dd, $J=1.9,8.3 \mathrm{~Hz}, 1 \mathrm{H}), 7.36-7.30$ (m, 3H), 7.27-7.22 (m, 2H), 7.19 (dd, $J=1.5,7.0 \mathrm{~Hz}$, $1 \mathrm{H}), 7.06(\mathrm{~d}, J=3.2 \mathrm{~Hz}, 1 \mathrm{H}), 6.74(\mathrm{~d}, J=3.0 \mathrm{~Hz}, 1 \mathrm{H}), 3.77(\mathrm{~s}, 3 \mathrm{H}), 3.18(\mathrm{br} \mathrm{s}, 4 \mathrm{H}), 2.91(\mathrm{br} \mathrm{s}$, 4H), 2.58 (br s, 3H), 2.40 (br s, 3H); ${ }^{13} \mathrm{C}$ NMR $\left(125 \mathrm{MHz}, \mathrm{CDCl}_{3}\right) \delta 165.2,139.9,139.9,138.9$, 137.5, 135.4, 133.7, 133.6, 132.8, 129.6, 129.0, 128.3, 126.8, 124.8, 123.7, 122.0, 121.4, 120.8, 119.6, 108.8, 100.8, 55.3, 50.4, 44.7, 33.2, 21.7. HRMS (ESI) $\mathrm{m} / z$ calcd for $\mathrm{C}_{28} \mathrm{H}_{31} \mathrm{~N}_{4} \mathrm{O}[\mathrm{M}+\mathrm{H}]^{+}$: 439.2498, found: 439.2496 . 


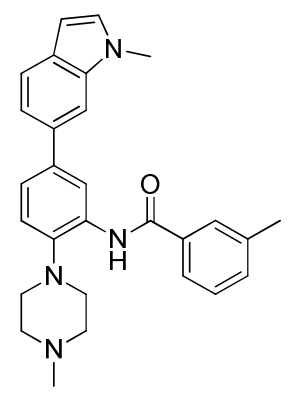

The title compound was prepared according to general procedure A (39 mg, 66\%yield). ${ }^{1} \mathrm{H}$ NMR $\left(500 \mathrm{MHz}, \mathrm{CDCl}_{3}\right) \delta 9.26($ br s, $1 \mathrm{H}), 8.86(\mathrm{~s}, 1 \mathrm{H}), 7.74(\mathrm{~s}, 1 \mathrm{H}), 7.64(\mathrm{~d}, J=6.5 \mathrm{~Hz}, 1 \mathrm{H}), 7.60(\mathrm{~d}$, $J=8.5 \mathrm{~Hz}, 1 \mathrm{H}), 7.52(\mathrm{~s}, 1 \mathrm{H}), 7.39-7.33(\mathrm{~m}, 4 \mathrm{H}), 7.29(\mathrm{~d}, J=8.2 \mathrm{~Hz}, 1 \mathrm{H}), 7.02(\mathrm{~d}, J=3.0 \mathrm{~Hz}$, 1H), $6.43(\mathrm{~d}, J=3.0 \mathrm{~Hz}, 1 \mathrm{H}), 3.79$ (s, 3H), 3.14 (br s, 4H), 2.85 (br s, 4H), 2.57 (br s, 3H), 2.41 (br s, 3H); ${ }^{13} \mathrm{C}$ NMR $\left(125 \mathrm{MHz}, \mathrm{CDCl}_{3}\right) \delta 165.3,41.0,139.1,139.0,137.4,135.4,134.5,134.0$, $132.9,129.8,129.0,128.1,128.2,123.8,123.2,121.5,121.2,119.4,118.9,108.0,101.0,56.5$ (2), 50.8, 45.0, 33.1 (2), 21.7. HRMS (ESI) $m / z$ calcd for $\mathrm{C}_{28} \mathrm{H}_{31} \mathrm{~N}_{4} \mathrm{O}[\mathrm{M}+\mathrm{H}]^{+}:$439.2498, found: 439.2496.

\section{$N-(5-(1 H$-Indol-5-yl)-2-(4-methylpiperazin-1-yl)phenyl)-3-methylbenzamide (9o)}

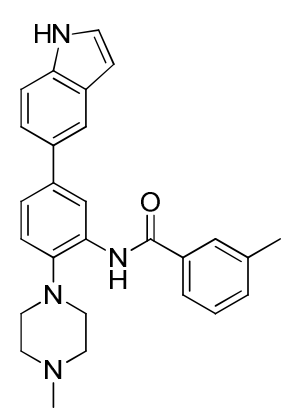

The title compound was prepared according to general procedure A (27 mg, 47\% yield). ${ }^{1} \mathrm{H}$ $\operatorname{NMR}\left(500 \mathrm{MHz}, \mathrm{CDCl}_{3}\right) \delta 9.54(\mathrm{~s}, 1 \mathrm{H}), 8.91(\mathrm{~d}, J=1.9 \mathrm{~Hz}, 1 \mathrm{H}), 8.35(\mathrm{~s}, 1 \mathrm{H}), 7.87(\mathrm{~s}, 1 \mathrm{H}), 7.78$ $(\mathrm{s}, 1 \mathrm{H}), 7.72(\mathrm{~d}, J=7.4 \mathrm{~Hz}, 1 \mathrm{H}), 7.46(\mathrm{dd}, J=1.6,8.5 \mathrm{~Hz}, 1 \mathrm{H}), 7.39-7.32(\mathrm{~m}, 4 \mathrm{H}), 7.24(\mathrm{~d}, J=$ $8.2 \mathrm{~Hz}, 1 \mathrm{H}), 7.16(\mathrm{~d}, J=2.6 \mathrm{~Hz}, 1 \mathrm{H}), 6.54-6.53(\mathrm{~m}, 1 \mathrm{H}), 2.97(\mathrm{~s}, 4 \mathrm{H}), 2.61$ (br s, 4H), 2.43 (s, 3H), $2.35(\mathrm{~s}, 3 \mathrm{H}) ;{ }^{13} \mathrm{C} \mathrm{NMR}\left(125 \mathrm{MHz}, \mathrm{CDCl}_{3}\right) \delta 165.9,141.0,139.0,138.9,135.7,134.8$, 133.2, 132.8, 131.8, 128.8, 128.4, 128.3, 127.9, 125.2, 125.1, 123.6, 123.3, 121.2, 118.9, 111.4, 102.1, 55.0 (2), 50.2, 29.6, 21.2 (2). HRMS (ESI) $m / z$ calcd for $\mathrm{C}_{27} \mathrm{H}_{28} \mathrm{~N}_{4} \mathrm{O}[\mathrm{M}+\mathrm{H}]^{+}: 425.2341$, found: 425.2328 . 

(9p)

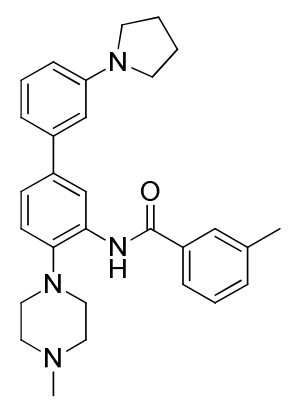

The title compound was prepared according to general procedure A (9 mg, 15\%yield). ${ }^{1} \mathrm{H}$ NMR $\left(500 \mathrm{MHz}, \mathrm{CDCl}_{3}\right) \delta 9.45($ br s, $1 \mathrm{H}), 8.85(\mathrm{~d}, J=1.6 \mathrm{~Hz}, 1 \mathrm{H}), 7.77(\mathrm{~s}, 1 \mathrm{H}), 7.70(\mathrm{~d}, J=7.1 \mathrm{~Hz}$, $1 \mathrm{H}), 7.40-7.32(\mathrm{~m}, 3 \mathrm{H}), 7.27-7.23(\mathrm{~m}, 2 \mathrm{H}), 6.91(\mathrm{~d}, J=7.6 \mathrm{~Hz}, 1 \mathrm{H}), 6.79(\mathrm{~s}, 1 \mathrm{H}), 6.53(\mathrm{dd}, J=$ 2.0, 8.2 Hz, 1H), 3.34-3.32 (m, 4H), 3.03 (br s, 4H), 2.71 (br s, 3H), 2.44-2.42 (m, 7H), 2.02$1.97(\mathrm{~m}, 4 \mathrm{H}) ;{ }^{13} \mathrm{C} \mathrm{NMR}\left(125 \mathrm{MHz}, \mathrm{CDCl}_{3}\right) \delta 165.2,148.5,141.7,140.6,139.6,139.0,135.3$, $133.9,132.8,129.6,129.0,129.0,128.1,128.1,123.8,123.1,121.3,118.8,114.8,111.1,110.6$, 55.6, 51.0 (2), 47.9, 45.2, 25.6 (2), 21.7. HRMS (ESI) $\mathrm{m} / z$ calcd for $\mathrm{C}_{29} \mathrm{H}_{35} \mathrm{~N}_{4} \mathrm{O}[\mathrm{M}+\mathrm{H}]^{+}$: 455.2811, found: 455.2811 .

3-Methyl-N-(4-(4-methylpiperazin-1-yl)-4'-(pyrrolidin-1-yl)-[1,1'-biphenyl]-3-yl)benzamide (9q)

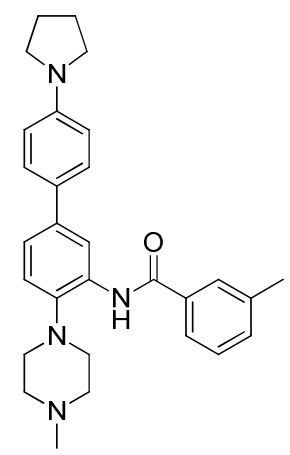

The title compound was prepared according to general procedure A (18 mg, 29\% yield). ${ }^{1} \mathrm{H}$ $\operatorname{NMR}\left(500 \mathrm{MHz}, \mathrm{CDCl}_{3}\right) \delta 9.45($ br s, $1 \mathrm{H}), 8.82(\mathrm{~d}, J=1.4 \mathrm{~Hz}, 1 \mathrm{H}), 7.80(\mathrm{~s}, 1 \mathrm{H}), 7.72(\mathrm{~d}, J=7.7$ $\mathrm{Hz}, 1 \mathrm{H}), 7.57-7.54(\mathrm{~m}, 2 \mathrm{H}), 7.44-7.37(\mathrm{~m}, 2 \mathrm{H}), 7.30(\mathrm{dd}, J=2.0,8.4 \mathrm{~Hz}, 1 \mathrm{H}), 7.27-7.25(\mathrm{~m}$, 1H), 6.63-6.60 (m, 2H), 3.33-3.31 (m, 4H), 3.08 (br s, 4H), 2.78 (br s, 3H), 2.49 (br s, 3H), 2.47 (s, 4H), 2.03-2.00 (m, 4H); ${ }^{13} \mathrm{C}$ NMR (125 MHz, $\left.\mathrm{CDCl}_{3}\right) \delta 165.0,147.6,139.7,138.9,138.6$, $135.4,134.1,132.7,128.9,128.1,128.0,127.5,123.9,121.6,121.3,117.3,112.1,55.9,51.5$, 47.8 (2), 45.6, 25.7 (2), 21.7. HRMS (ESI) $m / z$ calcd for $\mathrm{C}_{29} \mathrm{H}_{35} \mathrm{~N}_{4} \mathrm{O}[\mathrm{M}+\mathrm{H}]^{+}: 455.2811$, found: 455.2815 . 
3-Methyl- $N$-(4-(4-methylpiperazin-1-yl)-2'-(morpholinomethyl)-[1,1'-biphenyl]-3yl)benzamide (9r)

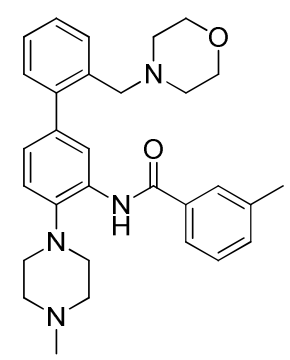

The title compound was prepared according to general procedure A ( $27 \mathrm{mg}, 42 \%$ yield). ${ }^{1} \mathrm{H}$ $\operatorname{NMR}\left(500 \mathrm{MHz}, \mathrm{CDCl}_{3}\right) \delta 9.37(\mathrm{br} \mathrm{s}, 1 \mathrm{H}), 8.55(\mathrm{~s}, 1 \mathrm{H}), 7.77(\mathrm{~s}, 1 \mathrm{H}), 7.70(\mathrm{~s}, 1 \mathrm{H}), 7.44-7.28(\mathrm{~m}$, $7 \mathrm{H}), 7.13(\mathrm{~d}, J=6.7 \mathrm{~Hz}, 1 \mathrm{H}), 3.73(\mathrm{br} \mathrm{s}, 4 \mathrm{H}), 3.36-2.97(\mathrm{~m}, 20 \mathrm{H}) ;{ }^{13} \mathrm{C} \mathrm{NMR}\left(125 \mathrm{MHz}, \mathrm{CDCl}_{3}\right)$ $\delta 165.0,142.6,140.1,139.2,138.9,135.3,133.5,132.8,130.5,130.3,129.0,128.0,127.5,127.3$, 125.2, 124.0, 120.8, 120.5, 67.0, 60.1, 56.2 (2), 53.4 (2), 52.1 (2), 46.1, 21.7 (2). HRMS (ESI) $m / z$ calcd for $\mathrm{C}_{30} \mathrm{H}_{37} \mathrm{~N}_{4} \mathrm{O}_{2}[\mathrm{M}+\mathrm{H}]^{+}: 485.2917$, found: 485.2924 .

\section{3-Methyl- $N$-(4-(4-methylpiperazin-1-yl)-3'-(morpholinomethyl)-[1,1'-biphenyl]-3- yl)benzamide (9s)}

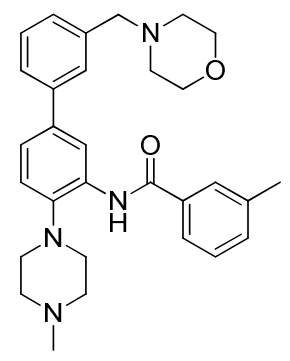

The title compound was prepared according to general procedure A (15 mg, 23\% yield). ${ }^{1} \mathrm{H}$ NMR $\left(500 \mathrm{MHz}, \mathrm{CDCl}_{3}\right) \delta 9.44(\mathrm{br} \mathrm{s}, 1 \mathrm{H}), 8.87(\mathrm{~d}, J=1.9 \mathrm{~Hz}, 1 \mathrm{H}), 7.80(\mathrm{~s}, 1 \mathrm{H}), 7.73(\mathrm{~d}, J=7.3$ $\mathrm{Hz}, 1 \mathrm{H}), 7.63(\mathrm{~s}, 1 \mathrm{H}), 7.57$ (d, $J=7.3 \mathrm{~Hz}, 1 \mathrm{H}), 7.45-7.31(\mathrm{~m}, 6 \mathrm{H}), 3.78$ (s, 4H), $3.65(\mathrm{~s}, 3 \mathrm{H})$, 3.11 (s, 4H), 2.82 (br s, 3H), 2.56 (br s, 4H), 2.52 (br s, 3H), 2.48 (s, 3H) ${ }^{13} \mathrm{C}$ NMR $(125 \mathrm{MHz}$, DMSO- $\left.d_{6}\right) \delta 165.1,140.9,139.6,139.0,138.8,135.0,133.9,132.8,129.2,128.9,128.0,127.4$, 123.6, 123.0, 121.5, 118.7, 77.3, 77.0, 76.8, 65.6, 62.6, 55.2 (2), 52.8 (2), 50.4 (2), 44.7, 21.5 (2). HRMS (ESI) $m / z$ calcd for $\mathrm{C}_{30} \mathrm{H}_{37} \mathrm{~N}_{4} \mathrm{O}_{2}[\mathrm{M}+\mathrm{H}]^{+}: 485.2917$, found: 485.2924 . 
3-Methyl- $N$-(4-(4-methylpiperazin-1-yl)-4'-(morpholinomethyl)-[1,1'-biphenyl]-3yl)benzamide (9t)

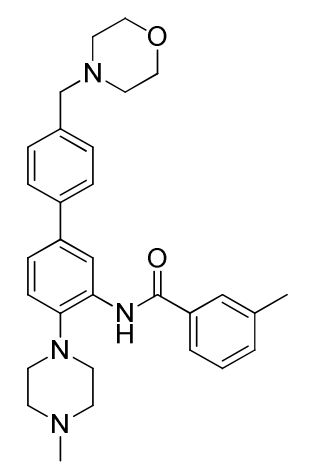

The title compound was prepared according to general procedure A $\left(17 \mathrm{mg}, 27 \%\right.$ yield). ${ }^{1} \mathrm{H}$ NMR $\left(500 \mathrm{MHz}, \mathrm{CDCl}_{3}\right) \delta 9.30(\mathrm{br} \mathrm{s}, 1 \mathrm{H}), 8.85(\mathrm{~s}, 1 \mathrm{H}), 7.79(\mathrm{~s}, 1 \mathrm{H}), 7.69(\mathrm{~d}, J=7.2 \mathrm{~Hz}, 1 \mathrm{H})$, 7.64 (d, $J=7.9 \mathrm{~Hz}, 2 \mathrm{H}), 7.49$ (br s, 2H), 7.45-7.40 (m, 2H), 7.35 (s, 2H), 3.94-3.64 (m, 7H), 3.36-2.97 (m, 8H), 2.62 (br s, 6H), $2.48(\mathrm{~s}, 3 \mathrm{H}) ;{ }^{13} \mathrm{C} \mathrm{NMR}\left(125 \mathrm{MHz}, \mathrm{CDCl}_{3}\right) \delta 165.2,139.9$, $139.1,138.9,135.2,134.1,132.9,130.6,129.2,129.0,128.1,127.7,127.6,123.9,122.8,121.6$, 118.6, 66.1, 62.7, 55.7 (2), 53.1 (2), 51.0 (2), 45.3, 21.8 (2). HRMS (ESI) $\mathrm{m} / z$ calcd for $\mathrm{C}_{30} \mathrm{H}_{37} \mathrm{~N}_{4} \mathrm{O}_{2}[\mathrm{M}+\mathrm{H}]^{+}: 485.2917$, found: 485.2920 .

\section{3-Methyl- $N$-(5-(5-methyl-1-phenyl-1 $H$-pyrazol-4-yl)-2-(4-methylpiperazin-1- yl)phenyl)benzamide (9u)}

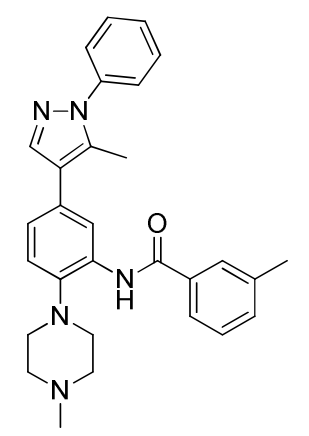

The title compound was prepared according to general procedure A (13 mg, 21\% yield). ${ }^{1} \mathrm{H}$ NMR $\left(500 \mathrm{MHz}, \mathrm{CDCl}_{3}\right) \delta 9.29(\mathrm{~s}, 1 \mathrm{H}), 8.70(\mathrm{~d}, J=1.9 \mathrm{~Hz}, 1 \mathrm{H}), 7.83(\mathrm{~s}, 1 \mathrm{H}), 7.79(\mathrm{~s}, 1 \mathrm{H}), 7.68$ (d, $J=6.8 \mathrm{~Hz}, 1 \mathrm{H}), 7.51(\mathrm{~s}, 2 \mathrm{H}), 7.50(\mathrm{~s}, 2 \mathrm{H}), 7.44-7.39$ (m, 3H), $7.34(\mathrm{~d}, J=8.1 \mathrm{~Hz}, 1 \mathrm{H}), 7.22$ (dd, $J=2.0,8.2 \mathrm{~Hz}, 1 \mathrm{H}), 3.23$ (br s, 4H), 2.98 (br s, 4H), 2.65 (s, 3H), $2.51(\mathrm{~s}, 3 \mathrm{H}), 2.47$ (s, 3H); ${ }^{13} \mathrm{C}$ NMR $\left(125 \mathrm{MHz}, \mathrm{CDCl}_{3}\right) \delta 165.3,139.6,139.2,139.6,137.1,135.8,135.0,133.5,132.9$, 132.6, 129.3, 129.2, 128.8, 128.2, 128.0, 125.2, 123.7, 123.3, 121.6, 121.2, 54.5, 49.7 (2), 43.7, 21.5 (2), 12.1. HRMS (ESI) $m / z$ calcd for $\mathrm{C}_{29} \mathrm{H}_{32} \mathrm{~N}_{5} \mathrm{O}$ [M+H] $]^{+}: 466.2607$, found: 466.2608 . 


\section{$N$-(5-(1-Isopentyl-1H-pyrazol-4-yl)-2-(4-methylpiperazin-1-yl)phenyl)-3-methylbenzamide}

(9v)

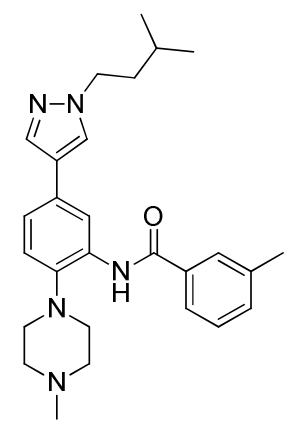

The title compound was prepared according to general procedure A (11 mg, $18 \%$ yield). ${ }^{1} \mathrm{H}$ $\operatorname{NMR}\left(500 \mathrm{MHz}, \mathrm{CDCl}_{3}\right) \delta 9.28($ br s, $1 \mathrm{H}), 8.72(\mathrm{~d}, J=1.8 \mathrm{~Hz}, 1 \mathrm{H}), 7.79(\mathrm{~d}, J=0.6 \mathrm{~Hz}, 1 \mathrm{H})$, 7.78 (br s, 1H), $7.71(\mathrm{~s}, 1 \mathrm{H}), 7.67(\mathrm{~d}, J=7.2 \mathrm{~Hz}, 1 \mathrm{H}), 7.45-7.40(\mathrm{~m}, 2 \mathrm{H}), 7.28(\mathrm{~d}, J=8.3 \mathrm{~Hz}$, $1 \mathrm{H}), 7.25(\mathrm{dd}, J=2.0,8.4 \mathrm{~Hz}, 1 \mathrm{H}), 4.16(\mathrm{t}, J=7.6 \mathrm{~Hz}, 2 \mathrm{H}), 3.26$ (br s, 4H), 2.94 (br s, 4H), 2.67 (br s, 3H), $2.48(\mathrm{~s}, 3 \mathrm{H}), 1.81(\mathrm{q}, J=7.1 \mathrm{~Hz}, 2 \mathrm{H}), 1.65-1.58(\mathrm{~m}, 1 \mathrm{H}), 0.98(\mathrm{~s}, 3 \mathrm{H}), 0.96(\mathrm{~s}, 3 \mathrm{H})$; ${ }^{13} \mathrm{C}$ NMR $\left(125 \mathrm{MHz}, \mathrm{CDCl}_{3}\right) \delta 165.3,139.3,137.3,136.6,135.3,134.0,133.1,132.1,129.1$, 128.3, 126.5, 123.5, 123.1, 122.3, 122.0, 121.5, 117.3, 54.8, 51.0, 49.4, 43.9, 39.4, 25.8, 22.5, 21.8. HRMS (ESI) $m / z$ calcd for $\mathrm{C}_{27} \mathrm{H}_{35} \mathrm{~N}_{5} \mathrm{O}[\mathrm{M}+\mathrm{H}]^{+}: 446.2920$, found: 446.2926 .

\section{$N$-(5-(6-Acetamidopyridin-3-yl)-2-(4-methylpiperazin-1-yl)phenyl)-3-methylbenzamide} (9w)

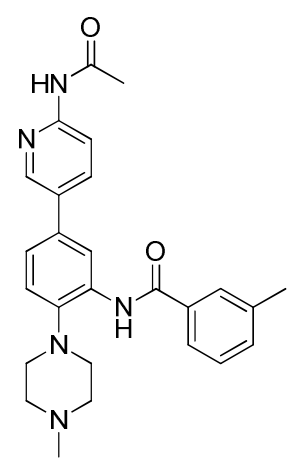

The title compound was prepared according to general procedure A (14 mg, $23 \%$ yield). ${ }^{1} \mathrm{H}$ $\operatorname{NMR}\left(500 \mathrm{MHz}, \mathrm{CDCl}_{3}\right) \delta 9.21(\mathrm{br} \mathrm{s}, 1 \mathrm{H}), 9.01(\mathrm{~s}, 1 \mathrm{H}), 8.74(\mathrm{~s}, 1 \mathrm{H}), 8.47(\mathrm{~s}, 1 \mathrm{H}), 8.34(\mathrm{~d}, J=$ $8.8 \mathrm{~Hz}, 1 \mathrm{H}), 8.04(\mathrm{dd}, J=2.0,8.9 \mathrm{~Hz}, 1 \mathrm{H}), 7.76(\mathrm{~s}, 1 \mathrm{H}), 7.63(\mathrm{q}, J=6.2 \mathrm{~Hz}, 1 \mathrm{H}), 7.46-7.40(\mathrm{~m}$, $3 \mathrm{H}), 7.31$ (dd, $J=1.8,8.5 \mathrm{~Hz}, 1 \mathrm{H}), 3.78(\mathrm{t}, J=11.5 \mathrm{~Hz}, 2 \mathrm{H}), 3.67(\mathrm{~d}, J=11.5 \mathrm{~Hz}, 2 \mathrm{H}), 3.15$ (d, $J=13.0 \mathrm{~Hz}, 2 \mathrm{H}), 3.08(\mathrm{t}, J=11.5 \mathrm{~Hz}, 2 \mathrm{H}), 2.91(\mathrm{~s}, 3 \mathrm{H}), 2.47(\mathrm{~s}, 3 \mathrm{H}), 2.29(\mathrm{~s}, 3 \mathrm{H}) ;{ }^{13} \mathrm{C} \mathrm{NMR}$ $\left(125 \mathrm{MHz}, \mathrm{CDCl}_{3}\right) \delta 165.6,148.1,144.9,140.8,139.6,134.8,134.6,133.8,133.5,131.9,129.2$, 128.4, 123.6, 123.0, 122.7, 118.8, 117.6, 54.6 (2), 53.6, 49.2 (2), 43.9, 29.9, 25.1, 21.8. HRMS (ESI) $m / z$ calcd for $\mathrm{C}_{26} \mathrm{H}_{30} \mathrm{~N}_{5} \mathrm{O}_{2}[\mathrm{M}+\mathrm{H}]^{+}: 444.2400$, found: 444.2394 . 
General Procedure $B$ for the Synthesis of Compounds 12a,c,f,h,k,q,s. To a solution of commercially available 2-fluoro-5-nitroaniline (10) $(0.100 \mathrm{~g}, 0.64 \mathrm{mmol})$ in $\mathrm{CH}_{2} \mathrm{Cl}_{2}(3 \mathrm{~mL})$ was added the commercial acid chloride $(0.83 \mathrm{mmol})$ at $23{ }^{\circ} \mathrm{C}$. This was followed by the addition of pyridine $(0.07 \mathrm{~mL}, 0.83 \mathrm{mmol})$, and the resulting solution was stirred at $23{ }^{\circ} \mathrm{C}$ for $4 \mathrm{~h}$. The reaction was subsequently diluted with $\mathrm{CH}_{2} \mathrm{Cl}_{2}(5 \mathrm{~mL})$, and washed with water $(10 \mathrm{~mL})$. The organic phase was then separated, dried $\left(\mathrm{Na}_{2} \mathrm{SO}_{4}\right)$, filtered, and concentrated. The residue was purified by flash column chromatography on silica gel using an appropriate EtOAc/hexanes gradient as the eluent, providing the intermediate fluoro-benzamide 11. To a solution of the fluoro-benzamide $11(0.50 \mathrm{mmol})$ in DMF $(4 \mathrm{~mL})$ at $23{ }^{\circ} \mathrm{C}$ was added 1 -methylpiperazine $(0.072$ $\mathrm{mL}, 0.65 \mathrm{mmol})$, followed by $N, N$-diisopropylethylamine $(0.113 \mathrm{~mL}, 0.881 \mathrm{mmol})$. The resulting solution was then heated at $80{ }^{\circ} \mathrm{C}$ for $1 \mathrm{~h}$, and subsequently cooled to $23{ }^{\circ} \mathrm{C}$. Following dilution with ethyl acetate $(40 \mathrm{~mL})$, the organic phase was washed with water $(2 \times 20 \mathrm{~mL})$, separated, dried $\left(\mathrm{Na}_{2} \mathrm{SO}_{4}\right)$, filtered, and concentrated. The residue was purified by trituration from EtOAc with hexanes, or by flash column chromatography on silica gel using a common 5-20\% $\mathrm{MeOH} /$ EtOAc gradient to afford the desired product.

General Procedure $C$ for the Synthesis of Compounds 12d,e,g,j,o,p,t. To a solution of the benzoic acid $(0.530 \mathrm{mmol})$ in toluene $(2 \mathrm{~mL})$ was added $\mathrm{SOCl}_{2}(0.20 \mathrm{~mL}, 2.65 \mathrm{mmol})$ at $23{ }^{\circ} \mathrm{C}$. The resulting solution was stirred vigorously and heated at $70{ }^{\circ} \mathrm{C}$ for $2 \mathrm{~h}$, and subsequently cooled back down to $23{ }^{\circ} \mathrm{C}$. All of the solvent was then removed under reduced pressure, and the crude acid chloride used in the subsequent reaction with no further purification. To a solution of commercially available 2-fluoro-5-nitroaniline (10) $(0.100 \mathrm{~g}, 0.64 \mathrm{mmol})$ in $\mathrm{CH}_{2} \mathrm{Cl}_{2}(3 \mathrm{~mL})$ was added the freshly prepared acid chloride $(0.83 \mathrm{mmol})$ at $23{ }^{\circ} \mathrm{C}$. This was followed by the addition of pyridine $(0.07 \mathrm{~mL}, 0.83 \mathrm{mmol})$, and stirring of the resulting solution at $23{ }^{\circ} \mathrm{C}$ for $4 \mathrm{~h}$. The reaction mixture was subsequently diluted with $\mathrm{CH}_{2} \mathrm{Cl}_{2}(5 \mathrm{~mL})$ and washed with water (10 $\mathrm{mL})$. The organic phase was then separated, dried $\left(\mathrm{Na}_{2} \mathrm{SO}_{4}\right)$, filtered, and concentrated. The residue was purified by flash column chromatography on silica gel using an appropriate EtOAc/hexanes gradient as the eluent, providing the intermediate fluoro-benzamide 11. To a solution of the fluoro-benzamide $11(0.500 \mathrm{mmol})$ in DMF $(4 \mathrm{~mL})$ at $23{ }^{\circ} \mathrm{C}$ was added 1methylpiperazine $(0.072 \mathrm{~mL}, 0.650 \mathrm{mmol})$ followed by $N, N$-diisopropylethylamine $(0.113 \mathrm{~mL}$, $0.881 \mathrm{mmol})$. The resulting solution was heated at $80{ }^{\circ} \mathrm{C}$ for $1 \mathrm{~h}$, and subsequently cooled to 23 ${ }^{\circ} \mathrm{C}$. Following dilution with ethyl acetate $(40 \mathrm{~mL})$, the organic phase was washed with water $(2 \mathrm{x}$ $20 \mathrm{~mL})$, separated, dried $\left(\mathrm{Na}_{2} \mathrm{SO}_{4}\right)$, filtered, and concentrated. The residue was purified by trituration from EtOAc with hexanes, or byflash column chromatography on silica gel using a common 5-20\% MeOH/EtOAc gradient to afford the desired product.

General Procedure D for the Synthesis of Compounds 12b,i,l,m,n,r. Identical to general procedure $\mathrm{C}$, but using $\mathrm{POCl}_{3}$ in place of $\mathrm{SOCl}_{2}$. 


\section{5-Fluoro- $N$-(2-(4-methylpiperazin-1-yl)-5-nitrophenyl)-2-(trifluoromethyl)benzamide (12a)}<smiles>CN1CCN(c2ccc([N+](=O)[O-])cc2NC(=O)c2cc(F)ccc2C(F)(F)F)CC1</smiles>

The title compound was prepared according to general procedure B (74 mg, 90\% yield). ${ }^{1} \mathrm{H}$ NMR $\left(500 \mathrm{MHz}, \mathrm{DMSO}-d_{6}\right) \delta 10.06(\mathrm{~s}, 1 \mathrm{H}), 8.60(\mathrm{~d}, J=3.0 \mathrm{~Hz}, 1 \mathrm{H}), 8.06(\mathrm{dd}, J=9.0,2.5 \mathrm{~Hz}$, $1 \mathrm{H}), 7.96(\mathrm{dd}, J=8.5,5.0 \mathrm{~Hz}, 1 \mathrm{H}), 7.69(\mathrm{~d}, J=7.0 \mathrm{~Hz}, 1 \mathrm{H}), 7.59(\mathrm{t}, J=8.5 \mathrm{~Hz}, 1 \mathrm{H}), 7.27(\mathrm{~d}, J=$ $9.0 \mathrm{~Hz}, 1 \mathrm{H}), 3.10$ (br t, $4 \mathrm{H}), 2.48$ (br s, 4H), $2.22(\mathrm{~s}, 3 \mathrm{H}) .{ }^{13} \mathrm{C}$ NMR $\left(125 \mathrm{MHz}, \mathrm{DMSO}-d_{6}\right) \delta$ $165.2,164.0\left(\mathrm{~d},{ }^{\mathrm{a} 1} J_{\mathrm{C}-\mathrm{F}}=250.0 \mathrm{~Hz}\right), 152.0,141.7,138.7\left(\mathrm{~d},{ }^{\mathrm{a} 4} J_{\mathrm{C}-\mathrm{F}}=6.3 \mathrm{~Hz}\right), 130.3,130.1\left(\mathrm{q},{ }^{\mathrm{b} 3} J_{\mathrm{C}-\mathrm{F}}\right.$ $=5.0 \mathrm{~Hz}), 124.0\left(\mathrm{q},{ }^{\mathrm{b} 1} J_{\mathrm{C}-\mathrm{F}}=271.3 \mathrm{~Hz}\right), 122.9\left(\mathrm{q},{ }^{\mathrm{b} 2} J_{\mathrm{C}-\mathrm{F}}=28.8 \mathrm{~Hz}\right), 122.2,120.7,120.0,117.6(\mathrm{~d}$, $\left.{ }^{\mathrm{a} 3} J_{\mathrm{C}-\mathrm{F}}=21.3 \mathrm{~Hz}\right), 116.6\left(\mathrm{~d},{ }^{\mathrm{a} 2} J_{\mathrm{C}-\mathrm{F}}=25.0 \mathrm{~Hz}\right), 54.5(2), 50.5(2), 46.2$. HRMS (ESI) $\mathrm{m} / z$ calcd for $\mathrm{C}_{19} \mathrm{H}_{18} \mathrm{~F}_{4} \mathrm{~N}_{4} \mathrm{O}_{3}[\mathrm{M}+\mathrm{H}]^{+}$: 427.1393, found: 427.1389 .

\section{4-Hydroxy- $N$-(2-(4-methylpiperazin-1-yl)-5-nitrophenyl)-2-(trifluoromethyl)benzamide} (12b)

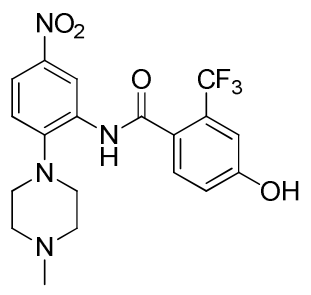

The title compound was prepared according to general procedure D (14 mg, 15\% yield). ${ }^{1} \mathrm{H}$ NMR (500 MHz, DMSO- $\left.d_{6}\right) \delta 10.59$ (br s, 1H), 9.68 (s, 1H), 8.58 (s, 1H), 8.04 (dd, $J=9.0,2.5$ $\mathrm{Hz}, 1 \mathrm{H}), 7.58(\mathrm{~d}, J=8.5 \mathrm{~Hz}, 1 \mathrm{H}), 7.28(\mathrm{~d}, J=9.0 \mathrm{~Hz}, 1 \mathrm{H}), 7.18(\mathrm{~s}, 1 \mathrm{H}), 7.13(\mathrm{~d}, J=8.0 \mathrm{~Hz}, 1 \mathrm{H})$, 3.10 (br s, 4H), 2.51 (br s, 4H), 2.25 (s, 3H). ${ }^{13} \mathrm{C}$ NMR $(125 \mathrm{MHz}$, DMSO-d $) \delta 166.6,159.4$, 151.6, 141.9, 131.1, 130.9, $127.4\left(\mathrm{q},{ }^{1} J_{\mathrm{C}-\mathrm{F}}=193.8 \mathrm{~Hz}\right), 121.8(2), 120.2,120.1,119.0(2), 113.7$, 54.6 (2), 50.4 (2), 46.0. HRMS (ESI) $m / z$ calcd for $\mathrm{C}_{19} \mathrm{H}_{19} \mathrm{~F}_{3} \mathrm{~N}_{4} \mathrm{O}_{4}[\mathrm{M}+\mathrm{H}]^{+}:$425.1437, found: 425.1438 . 


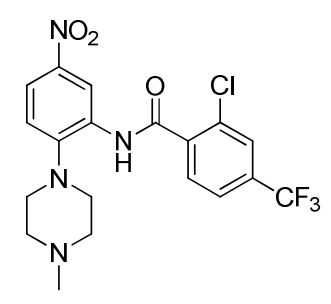

The title compound was prepared according to general procedure B $(72 \mathrm{mg}, 85 \%$ yield $) .{ }^{1} \mathrm{H}$ NMR (500 MHz, DMSO-d $\left.d_{6}\right) 10.10($ br s, $1 \mathrm{H}), 8.71(\mathrm{~d}, J=2.5 \mathrm{~Hz}, 1 \mathrm{H}), 8.12(\mathrm{~s}, 1 \mathrm{H}), 8.07$ (dd, $J=9.0,2.5 \mathrm{~Hz}, 1 \mathrm{H}), 7.89(\mathrm{~d}, J=8.0 \mathrm{~Hz}, 1 \mathrm{H}), 7.83(\mathrm{~d}, J=8.5 \mathrm{~Hz}, 1 \mathrm{H}), 7.27(\mathrm{~d}, J=9.0 \mathrm{~Hz}, 1 \mathrm{H})$, 3.11 (br t, 4H), 2.49 (br s, 4H), $2.21(\mathrm{~s}, 3 \mathrm{H}) .{ }^{13} \mathrm{C}$ NMR (125 MHz, DMSO-d $) \delta 164.7,152.2$, $141.8,137.7,134.8,131.3,130.3,128.3\left(\mathrm{q},{ }^{2} J_{\mathrm{C}-\mathrm{F}}=32.5 \mathrm{~Hz}\right), 128.3\left(\mathrm{~d},{ }^{4} J_{\mathrm{C}-\mathrm{F}}=2.5 \mathrm{~Hz}\right), 126.7(\mathrm{~d}$, $\left.{ }^{3} J_{\mathrm{C}-\mathrm{F}}=3.8 \mathrm{~Hz}\right), 124.1\left(\mathrm{q},{ }^{1} J_{\mathrm{C}-\mathrm{F}}=271.3 \mathrm{~Hz}\right), 122.2,121.2,120.0,54.6$ (2), 50.6 (2), 46.2. HRMS (ESI) $m / z$ calcd for $\mathrm{C}_{19} \mathrm{H}_{18} \mathrm{ClF}_{3} \mathrm{~N}_{4} \mathrm{O}_{3}[\mathrm{M}+\mathrm{H}]^{+}: 443.1098$, found: 443.1105 .

\section{2-Chloro- $N$-(2-(4-methylpiperazin-1-yl)-5-nitrophenyl)-5-(trifluoromethyl)benzamide (12d)}<smiles>CN1CCN(c2ccc([N+](=O)[O-])cc2NC(=O)c2cc(C(F)(F)F)ccc2Cl)CC1</smiles>

The title compound was prepared according to general procedure $\mathrm{C}(65 \mathrm{mg}, 71 \%$ yield $) .{ }^{1} \mathrm{H}$ NMR $\left(500 \mathrm{MHz}\right.$, DMSO- $\left.d_{6}\right) \delta 10.11(\mathrm{~s}, 1 \mathrm{H}), 8.71(\mathrm{~d}, J=2.5 \mathrm{~Hz}, 1 \mathrm{H}), 8.12(\mathrm{~s}, 1 \mathrm{H}), 8.07(\mathrm{dd}, J=$ 9.0, $2.5 \mathrm{~Hz}, 1 \mathrm{H}), 7.90(\mathrm{~d}, J=8.5 \mathrm{~Hz}, 1 \mathrm{H}), 7.83(\mathrm{~d}, J=8.5 \mathrm{~Hz}, 1 \mathrm{H}), 7.28(\mathrm{~d}, J=8.5 \mathrm{~Hz}, 1 \mathrm{H}), 3.12$ (br t, 4H), 2.50 (br t, 4H), 2.22 (s, 3H). ${ }^{13} \mathrm{C}$ NMR (125 MHz, DMSO-d 6 ) $\delta 164.7,152.2,141.7$, $137.7,134.8,131.3,130.2,128.3\left(\mathrm{q},{ }^{2} J_{\mathrm{C}-\mathrm{F}}=32.5 \mathrm{~Hz}\right), 128.3\left(\mathrm{q},{ }^{3} J_{\mathrm{C}-\mathrm{F}}=3.8 \mathrm{~Hz}\right), 126.7\left(\mathrm{q},{ }^{3} J_{\mathrm{C}-\mathrm{F}}=\right.$ $3.8 \mathrm{~Hz}), 124.1\left(\mathrm{q},{ }^{1} J_{\mathrm{C}-\mathrm{F}}=395.0 \mathrm{~Hz}\right), 122.3,121.3,120.0,54.6$ (2), 50.6 (2), 46.2. HRMS (ESI) $\mathrm{m} / z$ calcd for $\mathrm{C}_{19} \mathrm{H}_{18} \mathrm{ClF}_{3} \mathrm{~N}_{4} \mathrm{O}_{3}[\mathrm{M}+\mathrm{H}]^{+}: 443.1098$, found: 443.1107 .

\section{2-Chloro-5-methyl- $N$-(2-(4-methylpiperazin-1-yl)-5-nitrophenyl)benzamide (12e)}<smiles>Cc1ccc(Cl)c(C(=O)Nc2cc([N+](=O)[O-])ccc2N2CCN(C)CC2)c1</smiles> 
The title compound was prepared according to general procedure $\mathrm{C}$ (66 $\mathrm{mg}, 88 \%$ yield). ${ }^{1} \mathrm{H}$ NMR $\left(500 \mathrm{MHz}, \mathrm{DMSO}-d_{6}\right) \delta 9.83(\mathrm{~s}, 1 \mathrm{H}), 8.67$ (br s, $\left.1 \mathrm{H}\right), 8.05(\mathrm{dd}, J=8.5,3.0 \mathrm{~Hz}, 1 \mathrm{H}), 7.48(\mathrm{~s}, 1 \mathrm{H})$, $7.46(\mathrm{~d}, J=8.5 \mathrm{~Hz}, 1 \mathrm{H}), 7.34(\mathrm{~d}, J=8.0 \mathrm{~Hz}, 1 \mathrm{H}), 7.29$ (d, $J=9.0 \mathrm{~Hz}, 1 \mathrm{H}), 3.10$ (br t, 4H), 2.49 (br t, 4H), $2.36(\mathrm{~s}, 3 \mathrm{H}), 2.22(\mathrm{~s}, 3 \mathrm{H}) .{ }^{13} \mathrm{C}$ NMR (125 MHz, DMSO-d $) \delta 165.8,151.8,141.9$, 137.4, 136.2, 132.4, 130.8, 130.6, 130.0 (2) 127.2, 121.9, 120.2, 54.76 (2), 50.6 (2), 46.2, 20.7. HRMS (ESI) $m / z$ calcd for $\mathrm{C}_{19} \mathrm{H}_{21} \mathrm{ClN}_{4} \mathrm{O}_{3}[\mathrm{M}+\mathrm{H}]^{+}: 389.1392$, found: 389.1390 .

\section{2-Chloro-6-fluoro- $N$-(2-(4-methylpiperazin-1-yl)-5-nitrophenyl)benzamide (12f)}

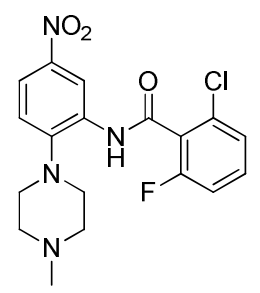

The title compound was prepared according to general procedure $\mathrm{B}(51 \mathrm{mg}, 68 \%$ yield $) .{ }^{1} \mathrm{H}$ NMR $\left(500 \mathrm{MHz}, \mathrm{DMSO}-d_{6}\right) \delta 10.33(\mathrm{~s}, 1 \mathrm{H}), 8.54(\mathrm{~d}, J=2.5 \mathrm{~Hz}, 1 \mathrm{H}), 8.07(\mathrm{dd}, J=9.0,2.5 \mathrm{~Hz}$, $1 \mathrm{H}), 7.59-7.53(\mathrm{~m}, 1 \mathrm{H}), 7.46(\mathrm{~d}, J=8.0 \mathrm{~Hz}, 1 \mathrm{H}), 7.40(\mathrm{t}, J=9.0 \mathrm{~Hz}, 1 \mathrm{H}), 7.26(\mathrm{~d}, J=9.0 \mathrm{~Hz}$, 1H), 3.11 (br t, 4H), 2.49 (br s, 4H), 2.22 (s, 3H). ${ }^{13} \mathrm{C}$ NMR (125 MHz, DMSO-d 6 ) $\delta 161.7$, $159.3\left(\mathrm{~d},{ }^{1} J_{\mathrm{C}-\mathrm{F}}=246.3 \mathrm{~Hz}\right), 152.2,141.5,132.3\left(\mathrm{~d},{ }^{3} J_{\mathrm{C}-\mathrm{F}}=10.0 \mathrm{~Hz}\right), 131.4\left(\mathrm{~d},{ }^{4} J_{\mathrm{C}-\mathrm{F}}=5.0 \mathrm{~Hz}\right)$, $129.8,126.2,126.0\left(\mathrm{~d},{ }^{5} J_{\mathrm{C}-\mathrm{F}}=3.8 \mathrm{~Hz}\right), 122.4,120.9,119.9,115.2\left(\mathrm{~d},{ }^{2} J_{\mathrm{C}-\mathrm{F}}=21.3 \mathrm{~Hz}\right), 54.5(2)$, 50.5 (2), 46.2. HRMS (ESI) $m / z$ calcd for $\mathrm{C}_{18} \mathrm{H}_{18} \mathrm{ClFN}_{4} \mathrm{O}_{3}[\mathrm{M}+\mathrm{H}]^{+}$: 393.1130, found: 393.1129.

\section{4-Methoxy-N-(2-(4-methylpiperazin-1-yl)-5-nitrophenyl)-3-(trifluoromethyl)benzamide (12g)}

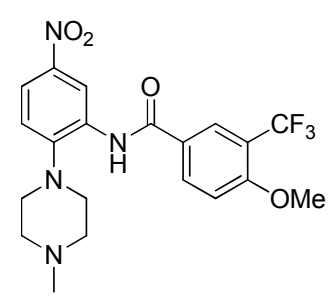

The title compound was prepared according to general procedure $\mathrm{C}$ (71 mg, 82\% yield). ${ }^{1} \mathrm{H}$ NMR $\left(500 \mathrm{MHz}, \mathrm{DMSO}-d_{6}\right) \delta 9.86(\mathrm{~s}, 1 \mathrm{H}), 8.64(\mathrm{~d}, J=2.5 \mathrm{~Hz}, 1 \mathrm{H}), 8.28(\mathrm{~d}, J=9.0 \mathrm{~Hz}, 1 \mathrm{H})$, $8.24(\mathrm{~s}, 1 \mathrm{H}), 8.05(\mathrm{dd}, J=9.0,2.5 \mathrm{~Hz}, 1 \mathrm{H}), 7.48(\mathrm{~d}, J=8.5 \mathrm{~Hz}, 1 \mathrm{H}), 7.31(\mathrm{~d}, J=9.0 \mathrm{~Hz}, 1 \mathrm{H})$, $4.01(\mathrm{~s}, 3 \mathrm{H}), 3.08$ (br t, 4H), 2.49 (br s, 4H), 2.22 (s, 3H). ${ }^{13} \mathrm{C}$ NMR (125 MHz, DMSO- $\left.d_{6}\right) \delta$ $163.9,160.2,151.9,142.0,134.4,131.1,126.9\left(\mathrm{q},{ }^{3} J_{\mathrm{C}-\mathrm{F}}=5.0 \mathrm{~Hz}\right), 123.9\left(\mathrm{q},{ }^{1} J_{\mathrm{C}-\mathrm{F}}=270.0 \mathrm{~Hz}\right)$, 121.7, 120.5, 120.2, $117.2\left(\mathrm{q},{ }^{2} J_{\mathrm{C}-\mathrm{F}}=30.0 \mathrm{~Hz}\right), 113.6(2), 57.2(2), 55.0(2), 50.5,46.2$. HRMS (ESI) $m / z$ calcd for $\mathrm{C}_{20} \mathrm{H}_{21} \mathrm{~F}_{3} \mathrm{~N}_{4} \mathrm{O}_{4}[\mathrm{M}+\mathrm{H}]^{+}:$439.1593, found: 439.1595 . 


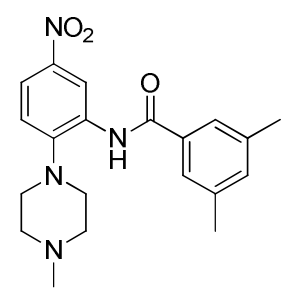

The title compound was prepared according to general procedure B $(70 \mathrm{mg}, 90 \%$ yield $) .{ }^{1} \mathrm{H}$ NMR $\left(500 \mathrm{MHz}, \mathrm{DMSO}-d_{6}\right) \delta 9.60(\mathrm{~s}, 1 \mathrm{H}), 8.76(\mathrm{~d}, J=2.5 \mathrm{~Hz}, 1 \mathrm{H}), 8.03(\mathrm{dd}, J=9.0,2.5 \mathrm{~Hz}$, 1H), $7.58(\mathrm{~s}, 2 \mathrm{H}), 7.36(\mathrm{~d}, J=9.0 \mathrm{~Hz}, 1 \mathrm{H}), 3.07$ (br t, 4H), 2.51 (br s, 4H), $2.38(\mathrm{~s}, 6 \mathrm{H}), 2.24$ (s, 3H). ${ }^{13} \mathrm{C}$ NMR $\left(125 \mathrm{MHz}, \mathrm{DMSO}-d_{6}\right) \delta 165.5,151.0,142.5,138.5,134.4,133.9,131.9,125.5$ (2), 121.2, 120.6, 118.7, 55.3 (2), 50.7 (2), 46.3, 21.3 (2). HRMS (ESI) $m / z$ calcd for $\mathrm{C}_{20} \mathrm{H}_{24} \mathrm{~N}_{4} \mathrm{O}_{3}$ $[\mathrm{M}+\mathrm{H}]^{+}:$369.1927, found: 369.1927 .

\section{3-Methyl-N-(2-(4-methylpiperazin-1-yl)-5-nitrophenyl)-5-(trifluoromethyl)benzamide (12i)}<smiles>Cc1cc(C(=O)Nc2cc([N+](=O)[O-])ccc2N2CCN(C)CC2)cc(C(F)(F)F)c1</smiles>

The title compound was prepared according to general procedure D (4 mg, 4\% yield). ${ }^{1} \mathrm{H}$ NMR $\left(500 \mathrm{MHz}, \mathrm{DMSO}-d_{6}\right) \delta 9.98(\mathrm{br} \mathrm{s}, 1 \mathrm{H}), 8.63(\mathrm{~d}, J=2.5 \mathrm{~Hz}, 1 \mathrm{H}), 8.09(\mathrm{~s}, 2 \mathrm{H}), 8.06(\mathrm{dd}, J=9.5$, $3.0 \mathrm{~Hz}, 1 \mathrm{H}), 7.84(\mathrm{~s}, 1 \mathrm{H}), 7.32(\mathrm{~d}, J=9.0 \mathrm{~Hz}, 1 \mathrm{H}), 4.01(\mathrm{~s}, 3 \mathrm{H}), 3.09$ (br t, 4H), 2.48 (br s, 4H), $2.21(\mathrm{~s}, 3 \mathrm{H}) .{ }^{13} \mathrm{C}$ NMR $\left(125 \mathrm{MHz}, \mathrm{DMSO}-d_{6}\right) \delta 164.4,152.0,142.0,140.5,135.4,132.7,130.9$, $129.7\left(\mathrm{q},{ }^{2} J_{\mathrm{C}-\mathrm{F}}=32.5 \mathrm{~Hz}\right), 129.3,124.4\left(\mathrm{q},{ }^{1} J_{\mathrm{C}-\mathrm{F}}=271.3 \mathrm{~Hz}\right), 122.0,121.7,120.6,120.3,55.0$ (2), 50.5 (2), 46.2, 21.2. HRMS (ESI) $\mathrm{m} / z$ calcd for $\mathrm{C}_{20} \mathrm{H}_{21} \mathrm{~F}_{3} \mathrm{~N}_{4} \mathrm{O}_{3}[\mathrm{M}+\mathrm{H}]^{+}:$423.1644, found: 423.1640 .

3-Fluoro- $N$-(2-(4-methylpiperazin-1-yl)-5-nitrophenyl)-5-(trifluoromethyl)benzamide (12j)<smiles>CN1CCN(c2ccc([N+](=O)[O-])cc2NC(=O)c2cc(F)cc(C(F)(F)F)c2)CC1</smiles>

The title compound was prepared according to general procedure $\mathrm{C}$ (78 $\mathrm{mg}, 80 \%$ yield). ${ }^{1} \mathrm{H}$ NMR $\left(500 \mathrm{MHz}, \mathrm{DMSO}_{6}\right) \delta 10.15(\mathrm{~s}, 1 \mathrm{H}), 8.56(\mathrm{~d}, J=2.0 \mathrm{~Hz}, 1 \mathrm{H}), 8.18(\mathrm{~s}, 1 \mathrm{H}), 8.11(\mathrm{~d}, J=$ 
$8.5 \mathrm{~Hz}, 1 \mathrm{H}), 8.07(\mathrm{dd}, J=9.0,3.0 \mathrm{~Hz}, 1 \mathrm{H}), 8.02(\mathrm{~d}, J=8.5 \mathrm{~Hz}, 1 \mathrm{H}), 7.30(\mathrm{~d}, J=9.0 \mathrm{~Hz}, 1 \mathrm{H})$, 3.12 (br t, 4H), 2.48 (br t, 4H), 2.21 (s, 3H). ${ }^{13} \mathrm{C}$ NMR (125 MHz, DMSO-d 6 ) $\delta 163.2,162.4$ (d, $\left.{ }^{\mathrm{a} 1} J_{\mathrm{C}-\mathrm{F}}=246.3 \mathrm{~Hz}\right), 152.5,141.6,118.1\left(\mathrm{~d},{ }^{\mathrm{a} 3} J_{\mathrm{C}-\mathrm{F}}=11.3 \mathrm{~Hz}\right), 131.7\left(\mathrm{q},{ }^{\mathrm{b} 2} J_{\mathrm{C}-\mathrm{F}}=33.8 \mathrm{~Hz}\right), 130.16$, 124.6, 122.5, 121.7, $121.0(\mathrm{~m}), 120.1,119.5\left(\mathrm{~d},{ }^{\mathrm{a} 2} J_{\mathrm{C}-\mathrm{F}}=22.5 \mathrm{~Hz}\right), 116.7\left(\mathrm{q},{ }^{\mathrm{b} 3} J_{\mathrm{C}-\mathrm{F}}=21.3 \mathrm{~Hz}\right)$, 54.9 (2), 50.4 (2), 46.1. HRMS (ESI) $m / z$ calcd for $\mathrm{C}_{19} \mathrm{H}_{18} \mathrm{~F}_{4} \mathrm{~N}_{4} \mathrm{O}_{3}[\mathrm{M}+\mathrm{H}]^{+}:$427.1393, found: 427.1400 .

\section{3,5-Dichloro- $N$-(2-(4-methylpiperazin-1-yl)-5-nitrophenyl)benzamide (12k)}

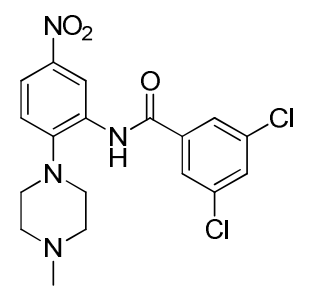

The title compound was prepared according to general procedure B (61 mg, 77\% yield). ${ }^{1} \mathrm{H}$ NMR $\left(500 \mathrm{MHz}, \mathrm{DMSO}-d_{6}\right) \delta 10.01(\mathrm{~s}, 1 \mathrm{H}), 8.51(\mathrm{~d}, J=2.5 \mathrm{~Hz}, 1 \mathrm{H}), 8.05(\mathrm{dd}, J=9.0,2.5 \mathrm{~Hz}$, 1H), $7.97(\mathrm{~s}, 1 \mathrm{H}), 7.90(\mathrm{~s}, 1 \mathrm{H}), 7.28(\mathrm{~d}, J=9.0 \mathrm{~Hz}, 1 \mathrm{H}), 3.10(\mathrm{br} \mathrm{t}, 4 \mathrm{H}), 2.47$ (br t, 4H), 2.21 (s, $3 \mathrm{H}) .{ }^{13} \mathrm{C}$ NMR $\left(125 \mathrm{MHz}, \mathrm{DMSO}-d_{6}\right) \delta 163.1,152.4,141.6,137.8,134.9$ (2), 131.7, $130.2,126.9$ (2), 122.4, 121.5, 120.1, 54.9 (2), 50.4 (2), 46.2. HRMS (ESI) $m / z$ calcd for $\mathrm{C}_{18} \mathrm{H}_{18} \mathrm{Cl}_{2} \mathrm{~N}_{4} \mathrm{O}_{3}$ $[\mathrm{M}+\mathrm{H}]^{+}:$409.0834, found: 409.0844 .

\section{3-Hydroxy-N-(2-(4-methylpiperazin-1-yl)-5-nitrophenyl)-5-(trifluoromethyl)benzamide} (12l)

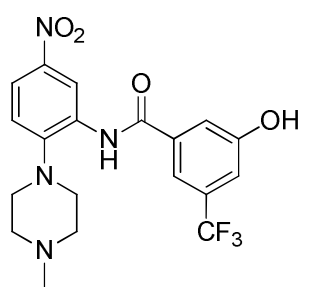

The title compound was prepared according to general procedure D ( $8 \mathrm{mg}, 14 \%$ yield $).{ }^{1} \mathrm{H}$ NMR $\left(500 \mathrm{MHz}, \mathrm{CD}_{3} \mathrm{OD}\right) \delta 10.96$ (br s, $\left.1 \mathrm{H}\right), 9.91(\mathrm{~s}, 1 \mathrm{H}), 8.64(\mathrm{~d}, J=2.9 \mathrm{~Hz}, 1 \mathrm{H}), 8.07$ (dd, $J=2.7$, $8.9 \mathrm{~Hz}, 1 \mathrm{H}), 7.72(\mathrm{~s}, 1 \mathrm{H}), 7.64(\mathrm{~s}, 1 \mathrm{H}), 7.33(\mathrm{~d}, J=9.1 \mathrm{~Hz}, 2 \mathrm{H}), 3.10(\mathrm{t}, J=4.7 \mathrm{~Hz}, 4 \mathrm{H}), 2.50(\mathrm{~s}$, 4H), $2.23(\mathrm{~s}, 3 \mathrm{H}) ;{ }^{13} \mathrm{C}$ NMR $\left(125 \mathrm{MHz}, \mathrm{CD}_{3} \mathrm{OD}\right) \delta 163.6,158.4,151.4,141.5,136.5,130.6$, $130.4,130.3,123.7\left(\mathrm{~d},{ }^{1} J_{\mathrm{C}-\mathrm{F}}=272.7 \mathrm{~Hz}, 1 \mathrm{C}\right), 121.4,119.9\left(\mathrm{~d},{ }^{3} J_{\mathrm{C}-\mathrm{F}}=10.0 \mathrm{~Hz}, 1 \mathrm{C}\right), 118.5,115.0$, $114.2\left(\mathrm{~d},{ }^{4} J_{\mathrm{C}-\mathrm{F}}=3.7 \mathrm{~Hz}, 1 \mathrm{C}\right), 54.5$ (2), 50.0 (2), 45.6. HRMS (ESI) $\mathrm{m} / z$ calcd for $\mathrm{C}_{19} \mathrm{H}_{20} \mathrm{~F}_{3} \mathrm{~N}_{4} \mathrm{O}_{4}$ $[\mathrm{M}+\mathrm{H}]^{+}:$425.1437, found: 425.1438 . 


\section{2-Fluoro- $N$-(2-(4-methylpiperazin-1-yl)-5-nitrophenyl)-5-sulfamoylbenzamide (12m)}

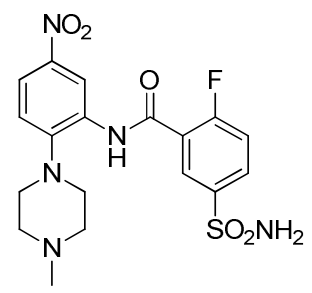

The title compound was prepared according to general procedure $\mathrm{D}$ (26 $\mathrm{mg}, 23 \%$ yield). ${ }^{1} \mathrm{H}$ NMR $\left(500 \mathrm{MHz}, \mathrm{CDCl}_{3}\right) \delta 9.96(\mathrm{~d}, J=6.9 \mathrm{~Hz}, 1 \mathrm{H}), 8.96(\mathrm{~d}, J=1.7 \mathrm{~Hz}, 1 \mathrm{H}), 8.37(\mathrm{dd}, J=2.0$, 6.7 Hz, 1H), 8.07-8.02 (m, 2H), 7.68-7.64 (m, 1H), $7.57(\mathrm{~s}, 2 \mathrm{H}), 7.41(\mathrm{~d}, J=9.0 \mathrm{~Hz}, 1 \mathrm{H}), 3.10-$ $3.07(\mathrm{~m}, 4 \mathrm{H}), 2.60$ (br s, 4H), $2.30(\mathrm{~s}, 3 \mathrm{H}) ;{ }^{13} \mathrm{C} \mathrm{NMR}\left(125 \mathrm{MHz}, \mathrm{CDCl}_{3}\right) \delta 160.9,160.7\left(\mathrm{~d},{ }^{1} J_{\mathrm{C}-\mathrm{F}}\right.$ $=255.8 \mathrm{~Hz}, 1 \mathrm{C}), 150.0,142.3,141.0,131.3,131.1\left(\mathrm{~d},{ }^{3} J_{\mathrm{C}-\mathrm{F}}=10.4 \mathrm{~Hz}, 1 \mathrm{C}\right), 128.9\left(\mathrm{~d},{ }^{4} J_{\mathrm{C}-\mathrm{F}}=3.6\right.$ $\mathrm{Hz}, 1 \mathrm{C}), 122.9$ (d, $\left.{ }^{3} J_{\mathrm{C}-\mathrm{F}}=14.8 \mathrm{~Hz}, 1 \mathrm{C}\right), 120.9,120.5,117.7,117.5\left(\mathrm{~d},{ }^{2} J_{\mathrm{C}-\mathrm{F}}=25.0 \mathrm{~Hz}, 1 \mathrm{C}\right), 54.2$ (2), 50.3 (2), 45.4. HRMS (ESI) $m / z$ calcd for $\mathrm{C}_{18} \mathrm{H}_{21} \mathrm{FN}_{5} \mathrm{O}_{5} \mathrm{~S}[\mathrm{M}+\mathrm{H}]^{+}$: 438.1247, found: 438.1240 .

\section{2,3-Difluoro-5-hydroxy-N-(2-(4-methylpiperazin-1-yl)-5-nitrophenyl)benzamide (12n)}<smiles>CN1CCN(c2ccc([N+](=O)[O-])cc2NC(=O)c2cc(O)cc(F)c2F)CC1</smiles>

The title compound was prepared according to general procedure D (11 mg, 13\%yield). ${ }^{1} \mathrm{H}$ NMR $\left(500 \mathrm{MHz}, \mathrm{DMSO}-d_{6}\right) \delta 10.60(\mathrm{br} \mathrm{s}, 1 \mathrm{H}), 8.88(\mathrm{~d}, \mathrm{~J}=2.5 \mathrm{~Hz}, 1 \mathrm{H}), 8.01(\mathrm{dd}, \mathrm{J}=9.0,2.5 \mathrm{~Hz}, 1 \mathrm{H})$, $7.35(\mathrm{q}, J=10.0 \mathrm{~Hz}, 1 \mathrm{H}), 7.31(\mathrm{~d}, J=9.0 \mathrm{~Hz}, 1 \mathrm{H}), 6.73(\mathrm{~m}, 1 \mathrm{H}), 3.08$ (br t, 4H), 2.60 (br s, 4H), $2.29(\mathrm{~s}, 3 \mathrm{H}) .{ }^{13} \mathrm{C}$ NMR $\left(125 \mathrm{MHz}, \mathrm{DMSO}-d_{6}\right) \delta 161.3,155.6,150.0,141.8(2), 131.1,120.5$, $119.8(2), 118.8\left(\mathrm{~d},{ }^{2} J_{\mathrm{C}-\mathrm{F}}=18.9 \mathrm{~Hz}\right), 117.9,113.2\left(\mathrm{~d},{ }^{3} J_{\mathrm{C}-\mathrm{F}}=12.3 \mathrm{~Hz}\right), 111.9,54.1(2), 50.0(2)$, 45.3. HRMS (ESI) $m / z$ calcd for $\mathrm{C}_{18} \mathrm{H}_{18} \mathrm{~F}_{2} \mathrm{~N}_{4} \mathrm{O}_{4}[\mathrm{M}+\mathrm{H}]^{+}:$393.1374, found: 393.1387.

\section{3-Chloro-2-fluoro- $N$-(2-(4-methylpiperazin-1-yl)-5-nitrophenyl)-5-} (trifluoromethyl)benzamide (120)<smiles>CN1CCN(c2ccc([N+](=O)[O-])cc2NC(=O)c2cc(C(F)(F)F)cc(Cl)c2F)CC1</smiles> 
The title compound was prepared according to general procedure $\mathrm{C}\left(31 \mathrm{mg}, 51 \%\right.$ yield). ${ }^{1} \mathrm{H}$ NMR (500 MHz, DMSO- $\left.d_{6}\right) \delta 10.12$ (br s, $\left.1 \mathrm{H}\right), 8.83$ (br s, $\left.1 \mathrm{H}\right), 8.35$ (d, $\left.J=9.0 \mathrm{~Hz}, 1 \mathrm{H}\right), 8.19$ (d, $J=2.8 \mathrm{~Hz}, 1 \mathrm{H}), 8.07$ (dd, $J=9.0,2.8 \mathrm{~Hz}, 1 \mathrm{H}), 7.36$ (d, $J=9.0 \mathrm{~Hz}, 1 \mathrm{H}), 3.10$ (br s, 4H), 2.56 (br $\mathrm{s}, 4 \mathrm{H}), 2.27(\mathrm{~s}, 3 \mathrm{H}) .{ }^{13} \mathrm{C}$ NMR $\left(125 \mathrm{MHz}, \mathrm{DMSO}-d_{6}\right) \delta 161.0,157.2\left(\mathrm{~d},{ }^{\mathrm{a} 1} J_{\mathrm{C}-\mathrm{F}}=250.0 \mathrm{~Hz}\right)$, $151.5,142.2,130.8,127.1,126.8\left(\mathrm{q},{ }^{\mathrm{b} 2} J_{\mathrm{C}-\mathrm{F}}=50.0 \mathrm{~Hz}\right), 126.6,126.5,123.2\left(\mathrm{q},{ }^{\mathrm{b} 1} J_{\mathrm{C}-\mathrm{F}}=295.1 \mathrm{~Hz}\right)$, 122.5, 122.1, 120.5, 119.8, 54.7 (2), 50.7 (2), 46.2. HRMS (ESI) $m / z$ calcd for $\mathrm{C}_{19} \mathrm{H}_{17} \mathrm{ClF}_{4} \mathrm{~N}_{4} \mathrm{O}_{3}$ $[\mathrm{M}+\mathrm{H}]^{+}:$461.1004, found: 461.1003 .

\section{2-Chloro-6-fluoro-3-methyl- $N$-(2-(4-methylpiperazin-1-yl)-5-nitrophenyl)benzamide (12p)}

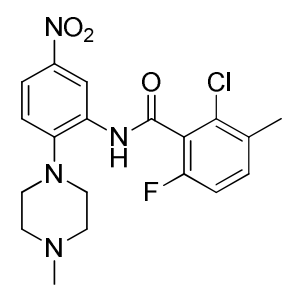

The title compound was prepared according to general procedure $\mathrm{C}\left(55 \mathrm{mg}, 59 \%\right.$ yield). ${ }^{1} \mathrm{H}$ NMR $\left(500 \mathrm{MHz}, \mathrm{DMSO}-d_{6}\right) \delta 10.29(\mathrm{~s}, 1 \mathrm{H}), 8.54(\mathrm{~d}, J=2.5 \mathrm{~Hz}, 1 \mathrm{H}), 8.07(\mathrm{dd}, J=9.0,2.5 \mathrm{~Hz}$, 1H), $7.52(\mathrm{~m}, 1 \mathrm{H}), 7.31(\mathrm{t}, J=9.0 \mathrm{~Hz}, 1 \mathrm{H}), 7.26(\mathrm{~d}, J=9.0 \mathrm{~Hz}, 1 \mathrm{H}), 3.11$ (br t, $4 \mathrm{H}), 2.49$ (br s, 4H), $2.37(\mathrm{~s}, 3 \mathrm{H}), 2.22(\mathrm{~s}, 3 \mathrm{H}) .{ }^{13} \mathrm{C}$ NMR $\left(125 \mathrm{MHz}, \mathrm{DMSO}-d_{6}\right) \delta 162.0,157.4\left(\mathrm{~d},{ }^{1} J_{\mathrm{C}-\mathrm{F}}=243.8\right.$ $\mathrm{Hz}), 152.2,141.5,132.8,132.7\left(\mathrm{~d},{ }^{4} J_{\mathrm{C}-\mathrm{F}}=13.8 \mathrm{~Hz}\right), 131.1\left(\mathrm{~d},{ }^{5} J_{\mathrm{C}-\mathrm{F}}=6.3 \mathrm{~Hz}\right), 129.8,126.1\left(\mathrm{~d},{ }^{2} J_{\mathrm{C}-}\right.$ $\mathrm{F}=22.5 \mathrm{~Hz}), 122.1,120.9,119.9,114.8\left(\mathrm{~d},{ }^{3} J_{\mathrm{C}-\mathrm{F}}=21.3 \mathrm{~Hz}\right), 54.6(2), 50.4(2), 46.2,19.5$. HRMS (ESI) $m / z$ calcd for $\mathrm{C}_{19} \mathrm{H}_{20} \mathrm{ClFN}_{4} \mathrm{O}_{3}[\mathrm{M}+\mathrm{H}]^{+}:$407.1286, found: 407.1293.

\section{2,4-Difluoro-3-methyl- $N$-(2-(4-methylpiperazin-1-yl)-5-nitrophenyl)benzamide (12q)}

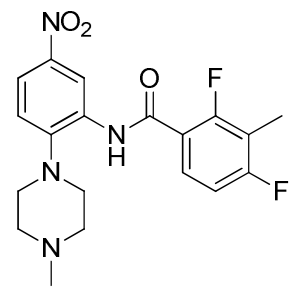

The title compound was prepared according to general procedure B (34 mg, 86\% yield). ${ }^{1} \mathrm{H}$ NMR $\left(500 \mathrm{MHz}, \mathrm{DMSO}-d_{6}\right) \delta 9.78(\mathrm{~s}, 1 \mathrm{H}), 9.00(\mathrm{~s}, 1 \mathrm{H}), 8.02(\mathrm{dd}, J=9.0,2.5 \mathrm{~Hz}, 1 \mathrm{H}), 7.85(\mathrm{q}$, $J=7.0 \mathrm{~Hz}, 1 \mathrm{H}), 7.41(\mathrm{~d}, J=9.0 \mathrm{~Hz}, 1 \mathrm{H}), 7.27$ (t, $J=8.5 \mathrm{~Hz}, 1 \mathrm{H}), 3.02$ (br t, 4H), 2.51 (br s, 4H), $2.25(\mathrm{~s}, 3 \mathrm{H}) .{ }^{13} \mathrm{C}$ NMR $\left(125 \mathrm{MHz}, \mathrm{DMSO}-d_{6}\right) \delta 163.1\left(\mathrm{dd},{ }^{1} J_{\mathrm{C}-\mathrm{F}}=248.8,8.8 \mathrm{~Hz}\right), 161.7,158.9$ $\left(\mathrm{dd},{ }^{1} J_{\mathrm{C}-\mathrm{F}}=247.3,8.8 \mathrm{~Hz}\right), 150.1,143.0,132.5,129.8\left(\mathrm{dd},{ }^{3} J_{\mathrm{C}-\mathrm{F}}=11.3,3.8 \mathrm{~Hz}\right), 121.2,120.9$, $118.9\left(\mathrm{dd},{ }^{3} J_{\mathrm{C}-\mathrm{F}}=11.3,3.8 \mathrm{~Hz}\right), 117.2,114.0\left(\mathrm{t},{ }^{2} J_{\mathrm{C}-\mathrm{F}}=21.3 \mathrm{~Hz}\right), 112.3\left(\mathrm{dd},{ }^{2} J_{\mathrm{C}-\mathrm{F}}=22.5,2.5 \mathrm{~Hz}\right)$, 55.0 (2), 51.2 (2), 46.3, 7.4. HRMS (ESI) $m / z$ calcd for $\mathrm{C}_{19} \mathrm{H}_{20} \mathrm{~F}_{2} \mathrm{~N}_{4} \mathrm{O}_{3}[\mathrm{M}+\mathrm{H}]^{+}: 391.1582$, found: 391.1585 . 


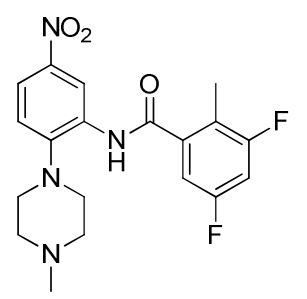

The title compound was prepared according to general procedure $\mathrm{D}(71 \mathrm{mg}, 68 \%$ yield $) .{ }^{1} \mathrm{H}$ NMR $\left(500 \mathrm{MHz}, \mathrm{DMSO}-d_{6}\right) \delta 9.39(\mathrm{~s}, 1 \mathrm{H}), 8.62(\mathrm{~s}, 1 \mathrm{H}), 8.05(\mathrm{dd}, J=2.7,8.8 \mathrm{~Hz}, 1 \mathrm{H}), 7.33(\mathrm{~d}$, $J=8.8 \mathrm{~Hz}, 1 \mathrm{H}), 7.06-7.04(\mathrm{~m}, 1 \mathrm{H}), 7.01-6.97(\mathrm{~m}, 1 \mathrm{H}), 3.06(\mathrm{~s}, 4 \mathrm{H}), 2.67(\mathrm{~s}, 4 \mathrm{H}), 2.43(\mathrm{~s}, 6 \mathrm{H})$; ${ }^{13} \mathrm{C}$ NMR $\left(125 \mathrm{MHz}, \mathrm{DMSO}-d_{6}\right) \delta 165.4\left(\mathrm{t},{ }^{4} J_{\mathrm{C}-\mathrm{F}}=2.9,3.5 \mathrm{~Hz}, 1 \mathrm{C}\right), 162.0\left(\mathrm{dd},{ }^{1,3} J_{\mathrm{C}-\mathrm{F}}=11.4\right.$, $249.3 \mathrm{~Hz}, 1 \mathrm{C}), 160.9\left(\mathrm{dd},{ }^{1,3} J_{\mathrm{C}-\mathrm{F}}=12.7,249.3 \mathrm{~Hz}, 1 \mathrm{C}\right), 147.1,145.2,138.5(\mathrm{~m}), 133.6,121.0$, $120.7\left(\mathrm{dd},{ }^{2,4} J_{\mathrm{C}-\mathrm{F}}=4.1,18.2 \mathrm{~Hz}, 1 \mathrm{C}\right), 120.1,115.3,109.5\left(\mathrm{dd},{ }^{2,4} J_{\mathrm{C}-\mathrm{F}}=3.7,22.7 \mathrm{~Hz}, 1 \mathrm{C}\right), 106.2$ (m), 55.4 (2), 51.8 (2), 46.0, 11.4. HRMS (ESI) $m / z$ calcd for $\mathrm{C}_{19} \mathrm{H}_{21} \mathrm{~F}_{2} \mathrm{~N}_{4} \mathrm{O}_{3}[\mathrm{M}+\mathrm{H}]^{+}: 391.1582$, found: 391.1589 .

\section{4-Fluoro-3,5-dimethyl- $N$-(2-(4-methylpiperazin-1-yl)-5-nitrophenyl)benzamide (12s)}

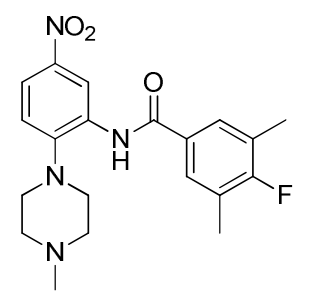

The title compound was prepared according to general procedure $\mathrm{C}\left(49 \mathrm{mg}, 52 \%\right.$ yield). ${ }^{1} \mathrm{H}$ NMR $\left(500 \mathrm{MHz}, \mathrm{DMSO}-d_{6}\right) \delta 9.63(\mathrm{~s}, 1 \mathrm{H}), 8.66(\mathrm{~d}, J=2.5 \mathrm{~Hz}, 1 \mathrm{H}), 8.04(\mathrm{dd}, J=8.5,2.5 \mathrm{~Hz}$, 1H), $7.74(\mathrm{~d}, J=6.5 \mathrm{~Hz}, 1 \mathrm{H}), 7.33$ (d, $J=9.0 \mathrm{~Hz}, 1 \mathrm{H}), 3.08$ (br t, 4H), 2.50 (br s, 4H), 2.32 (s, $3 \mathrm{H}), 2.19(\mathrm{~s}, 6 \mathrm{H}) .{ }^{13} \mathrm{C}$ NMR $\left(125 \mathrm{MHz}, \mathrm{DMSO}-d_{6}\right) \delta 164.7,161.9\left(\mathrm{~d},{ }^{1} J_{\mathrm{C}-\mathrm{F}}=247.5 \mathrm{~Hz}\right), 151.4$, $142.2,131.4,129.9\left(\mathrm{~d},{ }^{4} J_{\mathrm{C}-\mathrm{F}}=2.5 \mathrm{~Hz}\right), 129.1(2), 129.0,124.8\left(\mathrm{~d},{ }^{2} J_{\mathrm{C}-\mathrm{F}}=18.9 \mathrm{~Hz}\right), 121.5,120.4$, 119.6, 55.2 (2), 50.6 (2), 46.3, 14.8 (2) (d, $\left.{ }^{3} J_{\mathrm{C}-\mathrm{F}}=3.8 \mathrm{~Hz}\right)$. HRMS (ESI) $\mathrm{m} / \mathrm{z}$ calcd for $\mathrm{C}_{20} \mathrm{H}_{23} \mathrm{FN}_{4} \mathrm{O}_{3}[\mathrm{M}+\mathrm{H}]^{+}: 387.1832$, found: 387.1834 . 


\section{2,4,6-Trifluoro-3,5-dimethyl- $N$-(2-(4-methylpiperazin-1-yl)-5-nitrophenyl)benzamide (12t)}

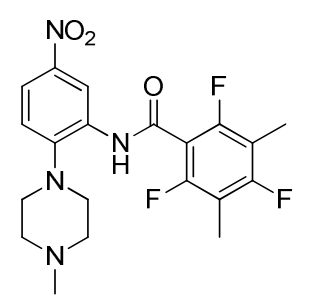

The title compound was prepared according to general procedure $\mathrm{C}\left(17 \mathrm{mg}, 22 \%\right.$ yield). ${ }^{1} \mathrm{H}$ NMR $\left(500 \mathrm{MHz}\right.$, DMSO- $\left.d_{6}\right) \delta 10.19(\mathrm{~s}, 1 \mathrm{H}), 8.55(\mathrm{~d}, J=2.5 \mathrm{~Hz}, 1 \mathrm{H}), 8.06(\mathrm{dd}, J=8.5,3.0 \mathrm{~Hz}$, $1 \mathrm{H}), 7.29(\mathrm{~d}, J=8.5 \mathrm{~Hz}, 1 \mathrm{H}), 3.09$ (br t, $4 \mathrm{H}), 2.51$ (br s, $4 \mathrm{H}), 2.23(\mathrm{~s}, 3 \mathrm{H}), 2.18(\mathrm{~s}, 6 \mathrm{H}) .{ }^{13} \mathrm{C}$ NMR $\left(125 \mathrm{MHz}\right.$, DMSO- $\left.d_{6}\right) \delta 160.7,159.3,158.8,156.5\left(\mathrm{~d},{ }^{3} J_{\mathrm{C}-\mathrm{F}}=12.5 \mathrm{~Hz}\right), 154.5\left(\mathrm{~d},{ }^{3} J_{\mathrm{C}-\mathrm{F}}=\right.$ $11.3 \mathrm{~Hz}), 151.9,141.6,129.9,122.3,120.5,120.1,111.5\left(\mathrm{t},{ }^{2} J_{\mathrm{C}-\mathrm{F}}=21.1 \mathrm{~Hz}\right), 109.4\left(\mathrm{t},{ }^{2} J_{\mathrm{C}-\mathrm{F}}=\right.$ $21.3 \mathrm{~Hz}$ ), 54.4 (2), 50.5 (2), 46.2, 7.2 (2). HRMS (ESI) $m / z$ calcd for $\mathrm{C}_{20} \mathrm{H}_{21} \mathrm{~F}_{3} \mathrm{~N}_{4} \mathrm{O}_{3}[\mathrm{M}+\mathrm{H}]^{+}$: 423.1644, found: 423.1653 .

\section{2-(4-Methylpiperazin-1-yl)-5-nitroaniline (13)}

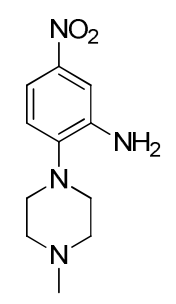

A mixture of 2-fluoro-5-nitroaniline (10) $(2.13 \mathrm{~g}, 13.7 \mathrm{mmol}), 1$-methylpiperazine $(5 \mathrm{~mL}, 45$ mmol) and $N, N$-diisopropylethylamine $(3.6 \mathrm{~mL}, 20 \mathrm{mmol})$ was heated at $80^{\circ} \mathrm{C}$ for $3 \mathrm{~h}$. After cooling to $23{ }^{\circ} \mathrm{C}$, the yellow precipitate was filtered off, washed with $\mathrm{CH}_{2} \mathrm{Cl}_{2}$, and dried under reduced pressure to afford the title compound $\left(2.42 \mathrm{~g}, 75 \%\right.$ yield). ${ }^{1} \mathrm{H} \mathrm{NMR}\left(500 \mathrm{MHz}, \mathrm{CDCl}_{3}\right) \delta$ $7.62(\mathrm{dd}, J=2.6,8.7 \mathrm{~Hz}, 1 \mathrm{H}), 7.55(\mathrm{~d}, J=2.6 \mathrm{~Hz}, 1 \mathrm{H}), 6.99(\mathrm{~d}, J=8.7 \mathrm{~Hz}, 1 \mathrm{H}), 4.11(\mathrm{br} \mathrm{s}, 2 \mathrm{H})$, $3.03(\mathrm{br} \mathrm{s}, 4 \mathrm{H}), 2.61$ (br s, $4 \mathrm{H}), 2.38(\mathrm{~s}, 3 \mathrm{H}) ;{ }^{13} \mathrm{C}$ NMR $\left(125 \mathrm{MHz}, \mathrm{CDCl}_{3}\right) \delta$ 145.2, 144.4, 14.6, 119.2, 114.6, 109.7, 55.6 (2), 50.3 (2), 46.3. HRMS (ESI) $m / z$ calcd for $\mathrm{C}_{11} \mathrm{H}_{17} \mathrm{~N}_{4} \mathrm{O}_{2}[\mathrm{M}+\mathrm{H}]^{+}$: 237.1352, found: 237.1357 .

General Procedure E for the Synthesis of Compounds 14c,d,e,f,g,i,j. A solution of 2-(4methylpiperazin-1-yl)-5-nitroaniline (13) $(50 \mathrm{mg}, 0.21 \mathrm{mmol})$ and the desired carboxylic acid $(0.24 \mathrm{mmol})$ in xylene $(2 \mathrm{~mL})$ was heated at $120{ }^{\circ} \mathrm{C}$ for $5 \mathrm{~min}$ before $\mathrm{POCl}_{3}(14 \mu \mathrm{L}, 0.16 \mathrm{mmol})$ and DMAP $(2.9 \mathrm{mg}, 0.02 \mathrm{mmol})$ were added. The reaction mixture was heated at $120^{\circ} \mathrm{C}$ for a further $2 \mathrm{~h}$ before cooling to $23{ }^{\circ} \mathrm{C}$. The solvent was evaporated, and saturated aqueous sodium bicarbonate solution $(2 \mathrm{~mL})$ along with EtOAc $(2 \mathrm{~mL})$ were added to the residue. The aqueous layer was extracted with EtOAc $(3 \times 15 \mathrm{~mL})$, and the combined organic extracts dried $\left(\mathrm{MgSO}_{4}\right)$, filtered, and concentrated. The residue was purified by flash column chromatography on silica 
gel $(5-30 \% \mathrm{MeOH} / \mathrm{EtOAc})$ or precipitation from EtOAc with hexanes to afford the desired product.

\section{N-(2-(4-Methylpiperazin-1-yl)-5-nitrophenyl)-6-oxo-4-(trifluoromethyl)-1,6- dihydropyridine-3-carboxamide (14a)}

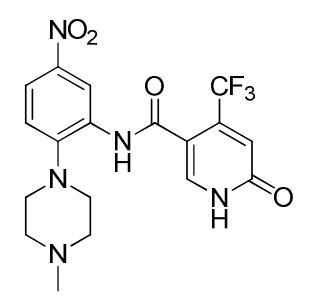

The 6-hydroxy-4-(trifluoromethyl)nicotinic acid (117 mg, $0.554 \mathrm{mmol}$ ) was suspended in $\mathrm{SOCl}_{2}$ $(1.506 \mathrm{ml}, 20.76 \mathrm{mmol})$ to form a white slurry. The suspension was stirred at $70{ }^{\circ} \mathrm{C}$ for $2 \mathrm{~h}$ until the solution went clear. The remaining $\mathrm{SOCl}_{2}$ was removed under reduced pressure, and the residue dried under high vacuum for $1 \mathrm{~h}$. Thedried residue was subsequently dissolved in $\mathrm{CH}_{2} \mathrm{Cl}_{2}$ $(10 \mathrm{~mL})$ and added drop wise over 20-30 min to a solution of 2-(4-methylpiperazin-1-yl)-5nitroaniline (13) $(109 \mathrm{mg}, 0.461 \mathrm{mmol})$ and pyridine $(0.074 \mathrm{ml}, 0.923 \mathrm{mmol})$ in $\mathrm{CH}_{2} \mathrm{Cl}_{2}(5.00$ $\mathrm{mL})$. After $2 \mathrm{~h}$ the reaction mixture was diluted with saturated aqueous sodium bicarbonate solution $(10 \mathrm{~mL})$ and extracted with $\mathrm{CH}_{2} \mathrm{Cl}_{2}(5 \times 10 \mathrm{~mL})$ (sonication was necessary to dissolve the black solid formed). The combined organic extracts were dried $\left(\mathrm{Na}_{2} \mathrm{SO}_{4}\right)$, filtered, and concentrated under reduced pressure. The residue was purified by flash column chromatography on silica gel $\left(0-90 \% \mathrm{MeOH} / \mathrm{CH}_{2} \mathrm{Cl}_{2}, 1 \% \mathrm{NH}_{4} \mathrm{Ac}\right)$ to afford the title compound $(59 \mathrm{mg}, 30 \%$ yield) as a white solid. ${ }^{1} \mathrm{H}$ NMR $\left(500 \mathrm{MHz}, \mathrm{DMSO}-d_{6}\right) \delta 9.77(\mathrm{~s}, 1 \mathrm{H}), 8.53(\mathrm{~d}, J=2.7 \mathrm{~Hz}, 1 \mathrm{H})$, $8.04(\mathrm{dd}, J=9.0,2.8 \mathrm{~Hz}, 1 \mathrm{H}), 7.98(\mathrm{~s}, 1 \mathrm{H}), 7.26(\mathrm{~d}, J=9.0 \mathrm{~Hz}, 1 \mathrm{H}), 6.82(\mathrm{~s}, 1 \mathrm{H}), 3.34(\mathrm{~s}, 4 \mathrm{H})$, 3.10-3.04 (m, 4H), $2.24(\mathrm{~s}, 3 \mathrm{H}) ;{ }^{13} \mathrm{C}$ NMR (126 MHz,DMSO- $\left.d_{6}\right) \delta 163.06,161.06,151.62$, $141.28,139.55,138.64\left(\mathrm{q},{ }^{2} J_{C-F}=32.4 \mathrm{~Hz}\right), 130.24,121.97\left(\mathrm{q},{ }^{1} J_{C-F}=275.2 \mathrm{~Hz}\right), 121.48$, 120.64, 119.49, $118.95\left(\mathrm{q},{ }^{3} J_{C-F}=5.6 \mathrm{~Hz}\right), 110.99,54.03,49.89,45.57 ;{ }^{19} \mathrm{~F} \mathrm{NMR}(471 \mathrm{MHz}$, DMSO- $d_{6}$ ) $\delta$-61.51. HRMS (ESI) $m / z$ calcd for $\mathrm{C}_{18} \mathrm{H}_{19} \mathrm{~F}_{3} \mathrm{~N}_{5} \mathrm{O}_{4}[\mathrm{M}+\mathrm{H}]^{+}:$426.1389, found: 426.1380 .

\section{3-Hydroxy-2-methyl- $N$-(2-(4-methylpiperazin-1-yl)-5-nitrophenyl)quinoline-4-carboxamide} (14b)

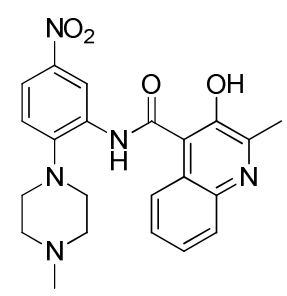

To a solution of 3-hydroxy-2-methylquinoline-4-carboxylic acid (100 $\mathrm{mg}, 0.48 \mathrm{mmol})$ and triethlyamine $(233 \mu \mathrm{L}, 1.67 \mathrm{mmol})$ in EtOAc $(5 \mathrm{~mL})$ was added $\mathrm{SOCl}_{2}(35 \mu \mathrm{L}, 0.48 \mathrm{mmol})$ at 0 
${ }^{\circ} \mathrm{C}$. The ice bath was then removed, and the solution allowed to stir at $23{ }^{\circ} \mathrm{C}$ for $1.5 \mathrm{~h}$. Subsequently, 2-(4-methylpiperazin-1-yl)-5-nitroaniline (13) (90 mg, $0.382 \mathrm{mmol}$ ) was added, and the temperature was raised to $80^{\circ} \mathrm{C}$. After stirring for $1.5 \mathrm{~h}$, the reaction mixture was cooled to $23{ }^{\circ} \mathrm{C}$, and diluted with water $(5 \mathrm{~mL})$. The aqueous phase was extracted with EtOAc $(3 \mathrm{x} 10$ $\mathrm{mL})$, and the combined organic extracts were dried $\left(\mathrm{MgSO}_{4}\right)$, filtered, and concentrated under reduced pressure. The residue was purified by flash column chromatography on silica gel (5-30\% $\mathrm{MeOH} / \mathrm{EtOAc})$ to afford the title compound (25 mg, $11 \%$ yield). ${ }^{1} \mathrm{H}$ NMR (500 MHz, CD $\left.3 \mathrm{OD}\right) \delta$ $9.32(\mathrm{~d}, J=2.7 \mathrm{~Hz}, 1 \mathrm{H}), 9.26(\mathrm{~d}, J=8.6 \mathrm{~Hz}, 1 \mathrm{H}), 7.96(\mathrm{dd}, J=2.7,9.0 \mathrm{~Hz}, 1 \mathrm{H}), 7.74(\mathrm{dd}, J=$ 1.1, 8.2 Hz, 1H), 7.56-7.48 (m, 1H), 7.39-7.35 (m, 1H), 7.27-7.22 (m, 2H), 3.18 (br s, 4H), 2.98 $(\mathrm{t}, J=4.6 \mathrm{~Hz}, 4 \mathrm{H}), 2.65(\mathrm{~s}, 3 \mathrm{H}), 2.50(\mathrm{~s}, 3 \mathrm{H}) ;{ }^{13} \mathrm{C} \mathrm{NMR}\left(125 \mathrm{MHz}, \mathrm{CD}_{3} \mathrm{OD}\right) \delta 170.8,165.2$, $161.5,150.7,144.8,139.4,135.3,130.6,128.1,127.5,127.3,125.7,124.3,123.5,120.2,120.2$, 118.9, 111.6, 55.5 (2), 51.3 (2), 46.1, 45.8. HRMS (ESI) $m / z$ calcd for $\mathrm{C}_{22} \mathrm{H}_{23} \mathrm{~N}_{5} \mathrm{O}_{4}[\mathrm{M}+\mathrm{H}]^{+}$: 422.1828, found: 422.1830 .

\section{3-Hydroxy-N-(2-(4-methylpiperazin-1-yl)-5-nitrophenyl)quinoline-4-carboxamide (14c)}

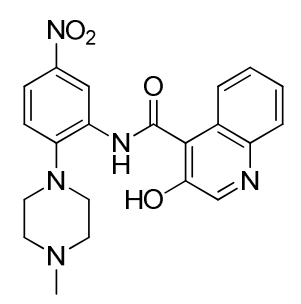

The title compound was prepared according to general procedure E (4 mg, 6\%yield). ${ }^{1} \mathrm{H}$ NMR $\left(500 \mathrm{MHz}, \mathrm{CD}_{3} \mathrm{OD}\right) \delta 9.41(\mathrm{~d}, J=2.7 \mathrm{~Hz}, 1 \mathrm{H}), 9.19(\mathrm{~d}, J=8.8 \mathrm{~Hz}, 1 \mathrm{H}), 8.52(\mathrm{~s}, 1 \mathrm{H}), 7.97(\mathrm{dd}, J$ $=2.7 \mathrm{~Hz}, 1 \mathrm{H}), 7.80(\mathrm{dd}, J=1.3,8.2 \mathrm{~Hz}, 1 \mathrm{H}), 7.48-7.45(\mathrm{~m}, 1 \mathrm{H}), 7.35-7.30(\mathrm{~m}, 2 \mathrm{H}), 3.35(\mathrm{~s}, 1 \mathrm{H})$, 3.20 (br s, 4H), 3.19 (br s, 4H), 2.70 (s, 3H); ${ }^{13} \mathrm{C} \mathrm{NMR} \mathrm{(125} \mathrm{MHz,} \mathrm{CD} 3$ OD) $\delta 169.6,163.0$, $152.1,149.6,145.4,141.1,135.5,130.4,129.3,128.7,126.1,124.6,120.9,120.2,118.4,114.8$, 55.4 (2), 51.0 (2), 45.0. HRMS (ESI) $\mathrm{m} / z$ calcd for $\mathrm{C}_{21} \mathrm{H}_{22} \mathrm{~N}_{5} \mathrm{O}_{4}[\mathrm{M}+\mathrm{H}]^{+}:$408.1672, found: 408.1666 .

6-Hydroxy-2-methyl- $N$-(2-(4-methylpiperazin-1-yl)-5-nitrophenyl)quinoline-4-carboxamide (14d)

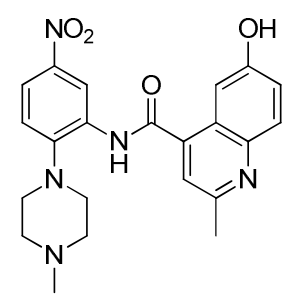

The title compound was prepared according to general procedure E ( $25 \mathrm{mg}, 23 \%$ yield $).{ }^{1} \mathrm{H}$ NMR $\left(500 \mathrm{MHz}, \mathrm{DMSO}-d_{6}\right) \delta 11.31(\mathrm{br} \mathrm{s}, 1 \mathrm{H}), 10.13(\mathrm{~s}, 1 \mathrm{H}), 10.11(\mathrm{~s}, 1 \mathrm{H}), 8.84(\mathrm{~s}, 1 \mathrm{H}), 8.11(\mathrm{dd}, J=$ 2.7, $9.0 \mathrm{~Hz}, 1 \mathrm{H}), 7.87(\mathrm{~d}, J=9.0 \mathrm{~Hz}, 1 \mathrm{H}), 7.57(\mathrm{~s}, 1 \mathrm{H}), 7.43(\mathrm{~d}, J=2.6 \mathrm{~Hz}, 1 \mathrm{H}), 7.34(\mathrm{dd}, J=$ 
2.7, $9.0 \mathrm{~Hz}, 1 \mathrm{H}), 3.35$ (br s, 4H), 3.07 (br s, 4H), 2.66 (s, 3H), 2.63 (br s, 3H); ${ }^{13} \mathrm{C}$ NMR $(125$ MHz, DMSO- $\left.d_{6}\right) \delta 166.3,155.7,154.5,150.2,143.0,141.9,139.6,130.6,130.2,123.6,122.2$, 121.6, 120.2, 120.0, 119.9, 105.6, 52.4 (2), 47.7 (2), 24.4 (2). HRMS (ESI) $\mathrm{m} / z$ calcd for $\mathrm{C}_{22} \mathrm{H}_{24} \mathrm{~N}_{5} \mathrm{O}_{4}[\mathrm{M}+\mathrm{H}]^{+}: 422.1828$, found: 422.1829 .

\section{$N$-(2-(4-Methylpiperazin-1-yl)-5-nitrophenyl)pyrazolo[1,5-a]pyridine-7-carboxamide (14e)}

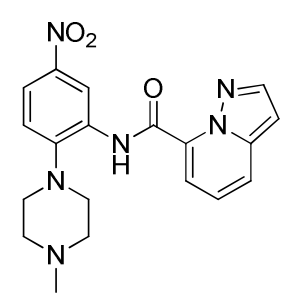

The title compound was prepared according to general procedure $\mathrm{E}$ (12 $\mathrm{mg}, 24 \%$ yield). ${ }^{1} \mathrm{H}$ NMR $\left(500 \mathrm{MHz}, \mathrm{DMSO}-d_{6}\right) \delta 13.17(\mathrm{~s}, 1 \mathrm{H}), 9.39(\mathrm{~d}, J=2.7 \mathrm{~Hz}, 1 \mathrm{H}), 8.35(\mathrm{~d}, J=2.4 \mathrm{~Hz}, 1 \mathrm{H}), 8.10$ (dd, $J=1.3,8.8 \mathrm{~Hz}, 1 \mathrm{H}), 8.05$ (dd, $J=2.9,8.9 \mathrm{~Hz}, 1 \mathrm{H}$ ), 8.03 (dd, $J=1.3,7.1 \mathrm{~Hz}, 1 \mathrm{H}$ ), 7.53-7.50 (m, 1H), 7.47 (d, $J=8.9 \mathrm{~Hz}, 1 \mathrm{H}), 7.01(\mathrm{~d}, J=2.5 \mathrm{~Hz}, 1 \mathrm{H}), 3.03$ (br s, 4H), 2.61 (br s, 4H), 2.30 $(\mathrm{s}, 3 \mathrm{H}) ;{ }^{13} \mathrm{C}$ NMR $\left(125 \mathrm{MHz}\right.$, DMSO- $\left.d_{6}\right) \delta 158.2,149.3,142.9,141.3,140.9,132.9,130.7$, 123.8, 122.6, 120.7, 120.2, 118.2, 115.6, 98.9, 54.5 (2), 50.8 (2), 45.7. HRMS (ESI) $\mathrm{m} / z$ calcd for $\mathrm{C}_{19} \mathrm{H}_{21} \mathrm{~N}_{6} \mathrm{O}_{3}[\mathrm{M}+\mathrm{H}]^{+}: 381.1675$, found: 381.1688 .

\section{5-Fluoro- $N$-(2-(4-methylpiperazin-1-yl)-5-nitrophenyl)-1H-benzo[d]imidazole-7- carboxamide (14f)}

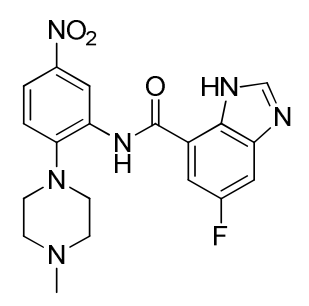

The title compound was prepared according to general procedure $\mathrm{E}$ (7 mg, 11\%yield). ${ }^{1} \mathrm{H}$ NMR $\left(500 \mathrm{MHz}, \mathrm{DMSO}-d_{6}\right) \delta 13.24(\mathrm{br} \mathrm{s}, 1 \mathrm{H}), 12.26(\mathrm{~s}, 1 \mathrm{H}), 9.37(\mathrm{~s}, 1 \mathrm{H}), 8.64(\mathrm{~s}, 1 \mathrm{H}), 8.01(\mathrm{dd}, J=$ $2.6,8.8 \mathrm{~Hz}, 1 \mathrm{H}), 7.77(\mathrm{dd}, J=2.3,10.6 \mathrm{~Hz}, 1 \mathrm{H}), 7.71$ (dd, $J=2.4,8.5 \mathrm{~Hz}, 1 \mathrm{H}), 7.43$ (d, $J=9.0$ $\mathrm{Hz}, 1 \mathrm{H}), 3.02$ (br s, 4H), 2.61 (br s, 4H), 2.28 (s, 3H); ${ }^{13} \mathrm{C}$ NMR (125 MHz, DMSO-d $\left.d_{6}\right) \delta 162.4$, $158.5\left(\mathrm{~d},{ }^{1} J_{\mathrm{C}-\mathrm{F}}=237.3 \mathrm{~Hz}, 1 \mathrm{C}\right), 149.3,144.4,142.8,136.8,134.2\left(\mathrm{~d},{ }^{3} J_{\mathrm{C}-\mathrm{F}}=11.5 \mathrm{~Hz}, 1 \mathrm{C}\right), 133.2$, $122.6\left(\mathrm{~d},{ }^{3} J_{\mathrm{C}-\mathrm{F}}=9.2 \mathrm{~Hz}, 1 \mathrm{C}\right), 120.5,119.7,115.6,110.6\left(\mathrm{~d},{ }^{2} J_{\mathrm{C}-\mathrm{F}}=27.1 \mathrm{~Hz}, 1 \mathrm{C}\right), 103.1\left(\mathrm{~d},{ }^{2} J_{\mathrm{C}-\mathrm{F}}=\right.$ $27.1 \mathrm{~Hz}, 1 \mathrm{C}$ ), 54.3 (2), 50.9 (2), 45.8. HRMS (ESI) $\mathrm{m} / z$ calcd for $\mathrm{C}_{19} \mathrm{H}_{20} \mathrm{FN}_{6} \mathrm{O}_{3}[\mathrm{M}+\mathrm{H}]^{+}$: 399.1581, found: 399.1582 . 


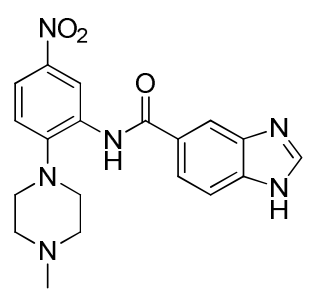

The title compound was prepared according to general procedure $\mathrm{E}$ (15 mg, 19\%yield). ${ }^{1} \mathrm{H}$ NMR $\left(500 \mathrm{MHz}, \mathrm{DMSO}-d_{6}\right) \delta 12.85(\mathrm{br} \mathrm{s}, 1 \mathrm{H}), 9.67(\mathrm{br} \mathrm{s}, 1 \mathrm{H}), 8.75(\mathrm{~d}, J=2.5 \mathrm{~Hz}, 1 \mathrm{H}), 8.41(\mathrm{~s}, 1 \mathrm{H})$, $8.30(\mathrm{br} \mathrm{s}, 1 \mathrm{H}), 8.04$ (dd, $J=9.0,2.5 \mathrm{~Hz}, 1 \mathrm{H}), 7.87(\mathrm{~d}, J=8.5 \mathrm{~Hz}, 1 \mathrm{H}), 7.74(\mathrm{~d}, J=8.5 \mathrm{~Hz}, 1 \mathrm{H})$, $7.35(\mathrm{~d}, J=9.0 \mathrm{~Hz}, 1 \mathrm{H}), 3.09$ (br t, 4H), $2.51(\mathrm{br} \mathrm{s}, 4 \mathrm{H}), 2.24(\mathrm{~s}, 3 \mathrm{H}) .{ }^{13} \mathrm{C}$ NMR $(125 \mathrm{MHz}$, DMSO- $\left.d_{6}\right) \delta 165.9,151.4,144.9,143.9,142.3,140.0,131.9,128.0,121.2,120.4(2), 119.5$, 113.6, 110.1, 55.1 (2), 50.7 (2), 46.2. HRMS (ESI) $m / z$ calcd for $\mathrm{C}_{19} \mathrm{H}_{20} \mathrm{~N}_{6} \mathrm{O}_{3}[\mathrm{M}+\mathrm{H}]^{+}: 381.1675$, found: 381.1671 .

\section{3-Methyl- $N$-(2-(4-methylpiperazin-1-yl)-5-nitrophenyl)-[1,2,4]triazolo[4,3-a]pyridine-6- carboxamide (14h)}

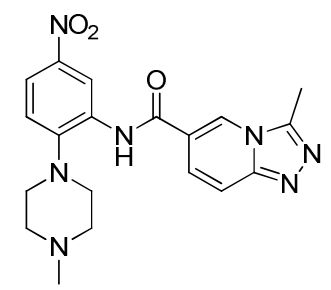

3-Methyl-[1,2,4]triazolo[4,3-a]pyridine-6-carboxylic acid (48.7 $\mathrm{mg}, 0.275 \mathrm{mmol})$ was suspended in $\mathrm{SOCl}_{2}(1 \mathrm{~mL})$ and stirred at $60{ }^{\circ} \mathrm{C}$ for $1 \mathrm{~h}$. Excess $\mathrm{SOCl}_{2}$ was removed under reduced pressure, and the residue was dried under high vacuum for $1 \mathrm{~h}$. The dried residue was then dissolved in $\mathrm{CH}_{2} \mathrm{Cl}_{2}(3 \mathrm{~mL})$, and added dropwise to a solution of 2-(4-methylpiperazin-1-yl)-5nitroaniline (13) $(50 \mathrm{mg}, 0.21 \mathrm{mmol})$ and pyridine $(22 \mu \mathrm{L}, 0.28 \mathrm{mmol})$ in $\mathrm{CH}_{2} \mathrm{Cl}_{2}(2 \mathrm{~mL})$. After $1.5 \mathrm{~h}$, the reaction mixture was diluted with saturated aqueous sodium bicarbonate solution ( 5 $\mathrm{mL})$ and extracted with $\mathrm{CH}_{2} \mathrm{Cl}_{2}(3 \times 5 \mathrm{~mL})$. The combined organic extracts were dried $\left(\mathrm{MgSO}_{4}\right)$, filtered, and concentrated under reduced pressure. The residue was purified by flash column chromatography on silica gel $(5-30 \% \mathrm{MeOH} / \mathrm{EtOAc})$ to afford the title compound $(6 \mathrm{mg}, 6 \%$ yield). ${ }^{1} \mathrm{H}$ NMR $\left(500 \mathrm{MHz}, \mathrm{CD}_{3} \mathrm{OD}\right) \delta 9.14(\mathrm{t}, J=1.3 \mathrm{~Hz}, 1 \mathrm{H}), 8.82(\mathrm{~d}, J=2.8 \mathrm{~Hz}, 1 \mathrm{H}), 8.19$ (dd, $J=2.7,8.9 \mathrm{~Hz}, 1 \mathrm{H}), 8.01$ (dd, $J=1.7,9.7 \mathrm{~Hz}, 1 \mathrm{H}), 7.88$ (dd, $J=1.0,9.5 \mathrm{~Hz}, 1 \mathrm{H}), 7.49$ (d, $J$ $=8.9 \mathrm{~Hz}, 1 \mathrm{H}), 3.62(\mathrm{br} \mathrm{s}, 4 \mathrm{H}), 3.43(\mathrm{br} \mathrm{s}, 2 \mathrm{H}), 3.30(\mathrm{br} \mathrm{s}, 2 \mathrm{H}), 3.01(\mathrm{~s}, 3 \mathrm{H}), 2.93(\mathrm{~s}, 3 \mathrm{H}) ;{ }^{13} \mathrm{C}$ NMR (125 MHz, CD $\left.{ }_{3} \mathrm{OD}\right) \delta 165.2,150.8,150.6,147.5,145.5,133.1,129.0,127.7,123.5,123.0$, 122.1, 121.9, 115.8, 115.5, 54.9 (2), 43.8 (2), 10.2. HRMS (ESI) $\mathrm{m} / z$ calcd for $\mathrm{C}_{19} \mathrm{H}_{21} \mathrm{~N}_{7} \mathrm{O}_{3}$ $[\mathrm{M}+\mathrm{H}]^{+}: 396.1784$, found: 396.1779 . 


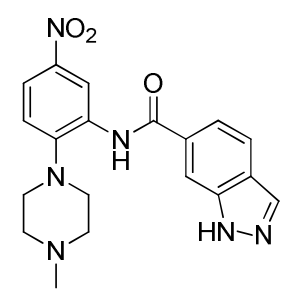

The title compound was prepared according to general procedure E ( $8 \mathrm{mg}, 8 \%$ yield $).{ }^{1} \mathrm{H}$ NMR $\left(500 \mathrm{MHz}, \mathrm{DMSO}-d_{6}\right) \delta 13.51(\mathrm{br} \mathrm{s}, 1 \mathrm{H}), 9.80(\mathrm{~s}, 1 \mathrm{H}), 8.70(\mathrm{~d}, J=2.8 \mathrm{~Hz}, 1 \mathrm{H}), 8.20(\mathrm{~d}, J=7.5$ $\mathrm{Hz}, 2 \mathrm{H}), 8.06(\mathrm{dd}, J=2.7,8.9 \mathrm{~Hz}, 1 \mathrm{H}), 7.94(\mathrm{~d}, J=8.4 \mathrm{~Hz}, 1 \mathrm{H}), 7.70(\mathrm{dd}, J=1.3,8.4 \mathrm{~Hz}, 1 \mathrm{H})$, $7.34(\mathrm{~d}, J=9.0 \mathrm{~Hz}, 1 \mathrm{H}), 3.10(\mathrm{t}, J=5.0 \mathrm{~Hz}, 4 \mathrm{H}), 2.51(\mathrm{br} \mathrm{s}, 4 \mathrm{H}), 2.23(\mathrm{~s}, 3 \mathrm{H}) ;{ }^{13} \mathrm{C} \mathrm{NMR}(125$ MHz, DMSO- $\left.d_{6}\right) \delta 165.3,151.2,141.6,139.3,133.7,131.6,130.9,124.7,121.1,120.9,119.9$, 119.5, 119.0, 111.0, 54.6 (2), 50.1 (2), 45.7. HRMS (ESI) $m / z$ calcd for $\mathrm{C}_{19} \mathrm{H}_{22} \mathrm{~N}_{6} \mathrm{O}_{3}[\mathrm{M}+\mathrm{H}]^{+}$: 381.1675, found: 381.1670 .

\section{1-Methyl- $N$-(2-(4-methylpiperazin-1-yl)-5-nitrophenyl)-1H-indazole-3-carboxamide (14j)}

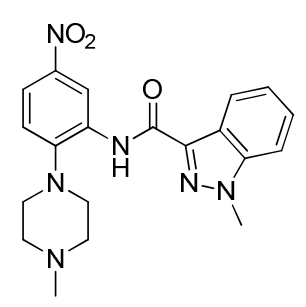

The title compound was prepared according to general procedure E (31 mg, 41\%yield). ${ }^{1} \mathrm{H}$ NMR $\left(500 \mathrm{MHz}, \mathrm{DMSO}-d_{6}\right) \delta 9.87$ (br s, $\left.1 \mathrm{H}\right), 9.26(\mathrm{~d}, J=2.5 \mathrm{~Hz}, 1 \mathrm{H}), 8.26(\mathrm{~d}, J=8.0 \mathrm{~Hz}, 1 \mathrm{H}), 8.01$ $(\mathrm{dd}, J=9.0,3.0 \mathrm{~Hz}, 1 \mathrm{H}), 7.83(\mathrm{~d}, J=8.5 \mathrm{~Hz}, 1 \mathrm{H}), 7.56(\mathrm{t}, J=7.5 \mathrm{~Hz}, 1 \mathrm{H}), 7.45(\mathrm{~d}, J=8.5 \mathrm{~Hz}$, 1H), $7.40(\mathrm{t}, J=7.5 \mathrm{~Hz}, 1 \mathrm{H}), 4.23(\mathrm{~s}, 3 \mathrm{H}), 3.04$ (br t, $4 \mathrm{H}), 2.51$ (br s, 4H), $2.33(\mathrm{~s}, 3 \mathrm{H}) .{ }^{13} \mathrm{C} \mathrm{NMR}$ $\left(125 \mathrm{MHz}, \mathrm{DMSO}-d_{6}\right) \delta 160.2,148.3,143.7,141.9,136.3,133.0,127.6,123.8,122.5,121.8$, $121.2,119.6,123.8,111.4,55.4$ (2), 51.4 (2), 46.4, 36.9. HRMS (ESI) $m / z$ calcd for $\mathrm{C}_{20} \mathrm{H}_{22} \mathrm{~N}_{6} \mathrm{O}_{3}$ $[\mathrm{M}+\mathrm{H}]^{+}:$395.1832, found: 395.1828 .

N-(5-Bromo-2-(4-methylpiperazin-1-yl)phenyl)-6-oxo-4-(trifluoromethyl)-1,6dihydropyridine-3-carboxamide (15)<smiles>CN1CCN(c2ccc(Br)cc2NC(=O)c2c[nH]c(=O)cc2C(F)(F)F)CC1</smiles> 
The 6-hydroxy-4-(trifluoromethyl)nicotinic acid $(1.890 \mathrm{~g}, 8.94 \mathrm{mmol})$ was suspended in $\mathrm{SOCl}_{2}$ $(24.33 \mathrm{~mL}, 335 \mathrm{mmol})$ and stirred at $80{ }^{\circ} \mathrm{C}$ for $2 \mathrm{~h}$. The solution become clear, and was then cooled to $23{ }^{\circ} \mathrm{C}$. The excess $\mathrm{SOCl}_{2}$ was removed under reduced pressure, and the resulting solid was dried under vacuum for $2 \mathrm{~h}$. The dry residue was dissolved in $\mathrm{CH}_{2} \mathrm{Cl}_{2}(10 \mathrm{~mL})$ and added over a $30 \mathrm{~min}$ period to a solution of 5-bromo-2-(4-methylpiperazin-1-yl)aniline (7) (2.013 g, $7.45 \mathrm{mmol})$ and pyridine $(1.801 \mathrm{~mL}, 22.36 \mathrm{mmol})$ in $\mathrm{CH}_{2} \mathrm{Cl}_{2}(20 \mathrm{~mL})$. The resulting mixture was then stirred for $12 \mathrm{~h}$. The reaction was diluted with saturated aqueous sodium bicarbonate solution $(100 \mathrm{~mL})$, sonicated to dissolve any solid particles, and extracted with $\mathrm{CH}_{2} \mathrm{Cl}_{2}(4 \times 50$ $\mathrm{mL})$. The combined organic extracts were dried $\left(\mathrm{Na}_{2} \mathrm{SO}_{4}\right)$, filtered, and concentrated under reduced pressure. The residue was purified by flash column chromatography on silica gel (0$100 \%, 89 \% \mathrm{CH}_{2} \mathrm{Cl}_{2}, 10 \% \mathrm{MeOH}, 1 \% \mathrm{NH}_{4} \mathrm{Ac} / \mathrm{CH}_{2} \mathrm{Cl}_{2}$ ) to afford the title compound (366 mg, $10 \%$ yield) as a yellow solid. ${ }^{1} \mathrm{H}$ NMR $(500 \mathrm{MHz}, \mathrm{MeOD}) \delta 8.20(\mathrm{~d}, J=2.3 \mathrm{~Hz}, 1 \mathrm{H}), 7.95(\mathrm{~s}$, $1 \mathrm{H}), 7.32(\mathrm{dd}, J=8.6,2.3 \mathrm{~Hz}, 1 \mathrm{H}), 7.18(\mathrm{~d}, J=8.6 \mathrm{~Hz}, 1 \mathrm{H}), 6.91(\mathrm{~s}, 1 \mathrm{H}), 2.95(\mathrm{t}, J=4.8 \mathrm{~Hz}$, $4 \mathrm{H}), 2.69$ (s, 4H), $2.40(\mathrm{~s}, 3 \mathrm{H}) ;{ }^{13} \mathrm{C}$ NMR $(126 \mathrm{MHz}, \mathrm{MeOD}) \delta 164.7,164.1,144.2,141.4\left(\mathrm{q},{ }^{2} J_{C-}\right.$ $F=33.2 \mathrm{~Hz}, 1 \mathrm{C}), 139.7,135.1,129.6,126.4,123.5,123.3\left(\mathrm{q},{ }^{1} J_{C-F}=274.7 \mathrm{~Hz}, 1 \mathrm{C}\right), 120.48(\mathrm{q}$, $\left.{ }^{3} J_{C-F}=5.4 \mathrm{~Hz}, 1 \mathrm{C}\right), 118.5,114.5,56.1,52.3,45.9 ;{ }^{19} \mathrm{~F}$ NMR $(471 \mathrm{MHz}, \mathrm{MeOD}) \delta-63.94$. HRMS (ESI) $m / z$ calcd for $\mathrm{C}_{18} \mathrm{H}_{19} \mathrm{BrF}_{3} \mathrm{~N}_{4} \mathrm{O}_{2}[\mathrm{M}+\mathrm{H}]^{+}: 459.0643$, found: 459.0647 .

General Procedure F for Synthesis of Compounds 16a-h. The N-(5-bromo-2-(4methylpiperazin-1-yl)phenyl)-6-oxo-4-(trifluoromethyl)-1,6-dihydropyridine-3-carboxamide

(15) (1 eqiv.), boronic acid/ester ( 3 equiv.), sodium carbonate (10 equiv.), XPhos ( 0.2 equiv.), and XPhos Pd G2 (0.2 equiv.) in 1,4-dioxane and water (5:3, $0.02 \mathrm{M})$ were mixed in a $5 \mathrm{~mL}$ microwave vial. The mixture was stirred for 5 min, degassed, purged with $\mathrm{N}_{2}$, and irradiated for $60 \mathrm{~min}$ at $120^{\circ} \mathrm{C}$. After cooling to $23^{\circ} \mathrm{C}$, all solvents were removed under reduced pressure, and the crude material purified using by flash column chromatography on silica gel $(0-100 \%, 89 \%$ $\mathrm{CH}_{2} \mathrm{Cl}_{2}, 10 \% \mathrm{MeOH}, 1 \% \mathrm{NH}_{4} \mathrm{Ac} / \mathrm{CH}_{2} \mathrm{Cl}_{2}$ ) to afford the desired compound.

\section{$\mathrm{N}$-(5-(2,3-Dihydrobenzofuran-5-yl)-2-(4-methylpiperazin-1-yl)phenyl)-6-oxo-4- (trifluoromethyl)-1,6-dihydropyridine-3-carboxamide (16a)}

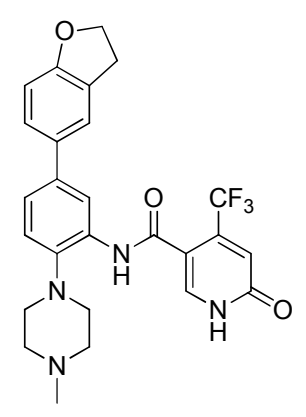

The title compound was prepared according to general procedure $\mathrm{F}$ (50 $\mathrm{mg}, 44 \%$ yield) as a white solid. ${ }^{1} \mathrm{H}$ NMR $\left(500 \mathrm{MHz}, \mathrm{DMSO}-d_{6}\right) \delta 9.39(\mathrm{~s}, 1 \mathrm{H}), 8.05(\mathrm{~s}, 1 \mathrm{H}), 7.97(\mathrm{~s}, 1 \mathrm{H}), 7.45(\mathrm{~s}$, $1 \mathrm{H}), 7.36(\mathrm{dd}, J=8.3,1.8 \mathrm{~Hz}, 1 \mathrm{H}), 7.31(\mathrm{~d}, J=8.2 \mathrm{~Hz}, 1 \mathrm{H}), 7.21(\mathrm{~d}, J=8.3 \mathrm{~Hz}, 1 \mathrm{H}), 6.83(\mathrm{~d}, J$ $=8.4 \mathrm{~Hz}, 1 \mathrm{H}), 6.82(\mathrm{~s}, 1 \mathrm{H}), 4.56(\mathrm{t}, J=8.7 \mathrm{~Hz}, 2 \mathrm{H}), 3.24(\mathrm{t}, J=8.6 \mathrm{~Hz}, 2 \mathrm{H}), 2.87(\mathrm{~s}, 4 \mathrm{H}), 2.48$ 
(s, 4H), 2.23 (s, 3H); ${ }^{13} \mathrm{C}$ NMR (126 MHz, DMSO- $\left.d_{6}\right) 161.0,159.6,157.6,141.5,137.5,137.0$ $\left(\mathrm{q},{ }^{2} J_{C-F}=32.5 \mathrm{~Hz}, 1 \mathrm{C}\right), 134.3,130.7,126.6,124.5,121.5,121.4,120.4\left(\mathrm{q},{ }^{1} J_{C-F}=275.1 \mathrm{~Hz}\right.$, 1C), 119.5, 118.8, 117.3 (q, $\left.{ }^{3} J_{C-F}=5.5 \mathrm{~Hz}, 1 \mathrm{C}\right), 110.26,107.54,69.51,53.20,49.61,44.11$, $27.45 ;{ }^{19} \mathrm{~F}$ NMR (471 MHz, DMSO- $d_{6}$ ) $\delta-61.43$. HRMS (ESI) $m / z$ calcd for $\mathrm{C}_{26} \mathrm{H}_{26} \mathrm{~F}_{3} \mathrm{~N}_{4} \mathrm{O}_{3}$ $[\mathrm{M}+\mathrm{H}]^{+}:$499.1957, found: 499.1955 .

\section{$N$-(2-(4-Methylpiperazin-1-yl)-5-(quinolin-3-yl)phenyl)-6-oxo-4-(trifluoromethyl)-1,6- dihydropyridine-3-carboxamide (16b)}

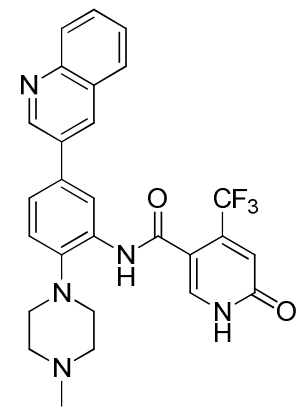

The title compound was prepared according to general procedure $\mathrm{F}$ ( $31 \mathrm{mg}, 97 \%$ yield). ${ }^{1} \mathrm{H}$ NMR $\left(500 \mathrm{MHz}, \mathrm{DMSO}-d_{6}\right) \delta 9.55(\mathrm{~s}, 1 \mathrm{H}), 9.19(\mathrm{~d}, J=2.0 \mathrm{~Hz}, 1 \mathrm{H}), 8.54(\mathrm{~d}, J=1.7 \mathrm{~Hz}, 1 \mathrm{H}), 8.24(\mathrm{~d}$, $J=1.5 \mathrm{~Hz}, 1 \mathrm{H}), 8.08(\mathrm{~d}, J=8.1 \mathrm{~Hz}, 1 \mathrm{H}), 8.05(\mathrm{~d}, J=8.4 \mathrm{~Hz}, 1 \mathrm{H}), 8.01(\mathrm{~s}, 1 \mathrm{H}), 7.76(\mathrm{t}, J=7.6$ $\mathrm{Hz}, 1 \mathrm{H}), 7.69(\mathrm{dd}, J=8.3,1.9 \mathrm{~Hz}, 1 \mathrm{H}), 7.64(\mathrm{t}, J=7.5 \mathrm{~Hz}, 1 \mathrm{H}), 7.33(\mathrm{~d}, J=8.3 \mathrm{~Hz}, 1 \mathrm{H}), 6.82(\mathrm{~s}$, $1 \mathrm{H}), 3.35(\mathrm{~s}, 4 \mathrm{H}), 2.94(\mathrm{~s}, 4 \mathrm{H}), 2.24(\mathrm{~s}, 3 \mathrm{H}) ;{ }^{13} \mathrm{C}$ NMR $\left(126 \mathrm{MHz}, \mathrm{DMSO}-d_{6}\right) \delta 163.4,161.8$, $149.7,147.2,145.7,140.0,139.1\left(\mathrm{q},{ }^{2} J_{C-F}=32.7 \mathrm{~Hz}, 1 \mathrm{C}\right), 132.9,132.6,132.5,129.9,129.1$, $128.8,128.2,127.5,124.9,123.3,122.5\left(\mathrm{q},{ }^{1} J_{C-F}=275.2 \mathrm{~Hz}, 1 \mathrm{C}\right), 121.2,119.3\left(\mathrm{q},{ }^{3} J_{C-F}=5.5\right.$ $\mathrm{Hz}, 1 \mathrm{C}), 112.1,55.2,51.5,46.2 ;{ }^{19} \mathrm{~F}$ NMR (471 MHz, DMSO- $d_{6}$ ) $\delta-61.39$. HRMS (ESI) $\mathrm{m} / \mathrm{z}$ calcd for $\mathrm{C}_{27} \mathrm{H}_{25} \mathrm{~F}_{3} \mathrm{~N}_{5} \mathrm{O}_{2}[\mathrm{M}+\mathrm{H}]^{+}:$508.1960, found: 508.1969.

\section{$\mathrm{N}$-(5-(1H-Indol-5-yl)-2-(4-methylpiperazin-1-yl)phenyl)-6-oxo-4-(trifluoromethyl)-1,6- dihydropyridine-3-carboxamide (16c)}

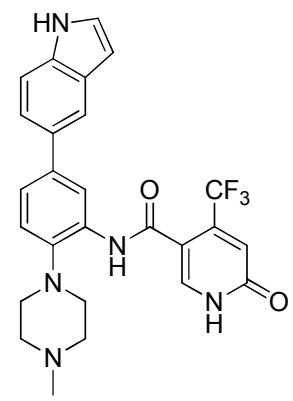

The title compound was prepared according to general procedure $\mathrm{F}$ ( $47 \mathrm{mg}, 26 \%$ yield). ${ }^{1} \mathrm{H}$ NMR $\left(500 \mathrm{MHz}, \mathrm{DMSO}-d_{6}\right) \delta 12.50$ (br s, 1H), 11.15 (br s, 1H), $9.42(\mathrm{~s}, 1 \mathrm{H}), 8.16(\mathrm{~s}, 1 \mathrm{H}), 7.99(\mathrm{~s}$, $1 \mathrm{H}), 7.75(\mathrm{~s}, 1 \mathrm{H}), 7.45(\mathrm{~d}, J=8.0 \mathrm{~Hz}, 1 \mathrm{H}), 7.38(\mathrm{~s}, 1 \mathrm{H}), 7.34(\mathrm{~d}, J=8.3 \mathrm{~Hz}, 1 \mathrm{H}), 7.25(\mathrm{~d}, J=8.3$ 
$\mathrm{Hz}, 1 \mathrm{H}), 6.84(\mathrm{~s}, 1 \mathrm{H}), 6.50$ (br s, 1H), 2.94-2.85 (m, 4H), 2.51 (br s, 4H), $2.25(\mathrm{~s}, 3 \mathrm{H}) ;{ }^{13} \mathrm{C}$ NMR $\left(125 \mathrm{MHz}, \mathrm{DMSO}-d_{6}\right) \delta 163.1,161.6,143.3,139.5,139.1\left(\mathrm{q},{ }^{2} J_{\mathrm{C}-\mathrm{F}}=32.7 \mathrm{~Hz}\right), 137.9,135.9$, $132.8,131.4,128.7,126.6,123.9,122.0,120.9,120.6,119.5,122.4$ (q, $\left.{ }^{1} J_{\mathrm{C}-\mathrm{F}}=275.2 \mathrm{~Hz}\right), 118.2$, 112.46, 112.3, 102.0, 55.4 (2), 51.8 (2), 46.23; ${ }^{19} \mathrm{~F}$ NMR (471 MHz, DMSO-d $d_{6} \delta-61.41$; HRMS (ESI) $m / z$ calcd for $\mathrm{C}_{26} \mathrm{H}_{25} \mathrm{~F}_{3} \mathrm{~N}_{5} \mathrm{O}_{2}[\mathrm{M}+\mathrm{H}]^{+}: 496.1960$, found: 496.1963 .

\section{$N$-(4-(4-Methylpiperazin-1-yl)-3'-(morpholinomethyl)-[1,1'-biphenyl]-3-yl)-6-oxo-4-} (trifluoromethyl)-1,6-dihydropyridine-3-carboxamide(16d)

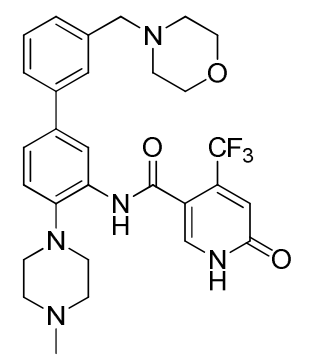

The title compound was prepared according to general procedure $\mathrm{F}$ (47 mg, 26\%yield). ${ }^{1} \mathrm{H}$ NMR $\left(500 \mathrm{MHz}, \mathrm{CDCl}_{3}\right) \delta 8.95(\mathrm{~s}, 1 \mathrm{H}), 8.64(\mathrm{~d}, J=0.9 \mathrm{~Hz}, 1 \mathrm{H}), 7.89(\mathrm{~s}, 1 \mathrm{H}), 7.55(\mathrm{~s}, 1 \mathrm{H}), 7.50(\mathrm{~d}, J$ $=7.7 \mathrm{~Hz}, 1 \mathrm{H}), 7.38-7.33(\mathrm{~m}, 2 \mathrm{H}), 7.32-7.28(\mathrm{~m}, 2 \mathrm{H}), 6.97(\mathrm{~s}, 1 \mathrm{H}), 3.72-3.68(\mathrm{~m}, 4 \mathrm{H}), 3.55$ $(\mathrm{s}, 2 \mathrm{H}), 2.97-2.90(\mathrm{~m}, 4 \mathrm{H}), 2.63(\mathrm{~s}, 4 \mathrm{H}), 2.49-2.44(\mathrm{~m}, 4 \mathrm{H}), 2.36(\mathrm{~s}, 3 \mathrm{H}) ;{ }^{13} \mathrm{C}$ NMR $(126$ $\left.\mathrm{MHz} \mathrm{CDCl}_{3}\right) \delta 163.6,161.9,140.8,140.6,140.0\left(\mathrm{q},{ }^{2} J_{C-F}=33.3 \mathrm{~Hz}, 1 \mathrm{C}\right), 139.0,138.4,138.3$, 133.7, 128.8, 128.4, 128.1, 126.2, $123.5,121.8\left(\mathrm{q},{ }^{1} J_{C-F}=275.4 \mathrm{~Hz}, 1 \mathrm{C}\right), 121.6,119.6\left(\mathrm{q},{ }^{3} J_{C-F}=\right.$ $5.3 \mathrm{~Hz}, 1 \mathrm{C}), 118.6,116.4,114.8,67.1,63.5,53.7,52.4,46.0,40.9 ;{ }^{19} \mathrm{~F}$ NMR $\left(471 \mathrm{MHz}, \mathrm{CDCl}_{3}\right)$ $\delta$-62.33.HRMS (ESI) $m / z$ calcd for $\mathrm{C}_{29} \mathrm{H}_{33} \mathrm{~F}_{3} \mathrm{~N}_{5} \mathrm{O}_{3}[\mathrm{M}+\mathrm{H}]^{+}:$556.2535, found: 556.2526.

\section{$\mathrm{N}$-(5-(6-Acetamidopyridin-3-yl)-2-(4-methylpiperazin-1-yl)phenyl)-6-oxo-4-} (trifluoromethyl)-1,6-dihydropyridine-3-carboxamide (16e)

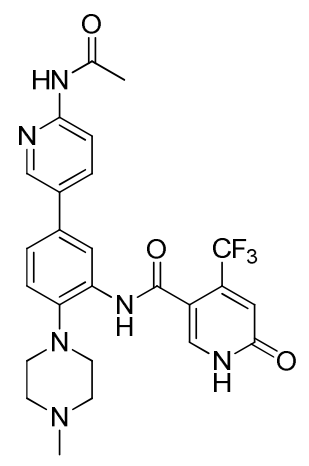

The title compound was prepared according to general procedure $\mathrm{F}$ (47 $\mathrm{mg}, 26 \%$ yield). ${ }^{1} \mathrm{H}$ NMR $\left(500 \mathrm{MHz}, \mathrm{DMSO}-d_{6}\right) \delta 10.59(\mathrm{~s}, 1 \mathrm{H}), 9.47(\mathrm{~s}, 1 \mathrm{H}), 8.54(\mathrm{~d}, J=2.3 \mathrm{~Hz}, 1 \mathrm{H}), 8.15(\mathrm{~d}, J=8.6 \mathrm{~Hz}$, $1 \mathrm{H}), 8.07(\mathrm{~d}, J=1.8 \mathrm{~Hz}, 1 \mathrm{H}), 8.00(\mathrm{~d}, J=2.4 \mathrm{~Hz}, 1 \mathrm{H}), 7.98(\mathrm{~s}, 1 \mathrm{H}), 7.49(\mathrm{dd}, J=8.3,2.1 \mathrm{~Hz}$, 1H), $7.26(\mathrm{~d}, J=8.4 \mathrm{~Hz}, 1 \mathrm{H}), 6.81(\mathrm{~s}, 1 \mathrm{H}), 2.89$ (t, $J=4.1 \mathrm{~Hz}, 4 \mathrm{H}), 2.50-2.44(\mathrm{~m}, 4 \mathrm{H}), 2.23$ (s, 
3H), $2.11(\mathrm{~s}, 3 \mathrm{H}) ;{ }^{13} \mathrm{C}$ NMR (125 MHz, DMSO- $\left.d_{6}\right) \delta 169.40,163.01,161.85,151.24,145.36$, $144.60,139.94,138.56\left(\mathrm{q},{ }^{3} J_{\mathrm{C}-\mathrm{F}}=32.6 \mathrm{~Hz}\right), 135.84,132.46,132.08,130.72,123.53,122.16(\mathrm{q}$, $\left.{ }^{1} J_{\mathrm{C}-\mathrm{F}}=275.1 \mathrm{~Hz}\right), 121.76,120.65,118.75\left(\mathrm{q},{ }^{2} J_{\mathrm{C}-\mathrm{F}}=5.1 \mathrm{~Hz}\right), 113.35,111.69,54.77,51.11$, 45.76, 23.98; ${ }^{19} \mathrm{~F}$ NMR (471 MHz, DMSO- $\left.d_{6}\right) \delta$-61.41. HRMS (ESI) $m / z$ calcd for $\mathrm{C}_{25} \mathrm{H}_{26} \mathrm{~F}_{3} \mathrm{~N}_{6} \mathrm{O}_{3}[\mathrm{M}+\mathrm{H}]^{+}:$515.2018, found: 515.2012.

\section{$\mathrm{N}$-(5-(6-Aminopyridin-3-yl)-2-(4-methylpiperazin-1-yl)phenyl)-6-oxo-4-(trifluoromethyl)-} 1,6-dihydropyridine-3-carboxamide (16f)

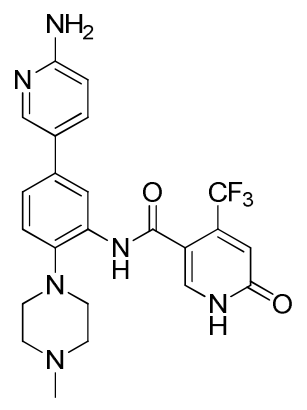

The title compound was prepared by using general procedure $\mathrm{F}$ (154 mg, 58\%yield). ${ }^{1} \mathrm{H}$ NMR $\left(500 \mathrm{MHz}, \mathrm{DMSO}-d_{6}\right) \delta 9.30(\mathrm{br} \mathrm{s}, 1 \mathrm{H}), 8.45(\mathrm{~s}, 1 \mathrm{H}), 8.16(\mathrm{~d}, J=2.5 \mathrm{~Hz}, 1 \mathrm{H}), 8.08(\mathrm{~s}, 1 \mathrm{H}), 8.04$ $(\mathrm{s}, 1 \mathrm{H}), 7.61(\mathrm{dd}, J=8.5,2.5 \mathrm{~Hz}, 1 \mathrm{H}), 7.32(\mathrm{dd}, J=8.0,2.0 \mathrm{~Hz}, 1 \mathrm{H}), 7.22(\mathrm{~d}, J=8.0 \mathrm{~Hz}, 1 \mathrm{H})$, 6.67 (br s, 1H), 6.53 (d, $J=8.5 \mathrm{~Hz}, 1 \mathrm{H}), 6.04$ (s, 2H), 2.86 (br t, 4H), 2.48 (br s, 4H), 2.23 (s, $3 \mathrm{H}) .{ }^{13} \mathrm{C}$ NMR $\left(125 \mathrm{MHz}, \mathrm{DMSO}-d_{6}\right) \delta 165.7,163.6,159.5,145.9,142.9$ (2), 135.6, 134.4, 133.4, 124.2, 122.3, 121.1, 119.9, 117.5, 111.6, 108.5 (2), 55.4 (2), 51.8 (2), 46.2. HRMS (ESI) $m / z$ calcd for $\mathrm{C}_{23} \mathrm{H}_{24} \mathrm{~F}_{3} \mathrm{~N}_{6} \mathrm{O}_{2}[\mathrm{M}+\mathrm{H}]^{+}: 473.1913$, found: 473.1909 .

$N$-(4'-Amino-4-(4-methylpiperazin-1-yl)-[1,1'-biphenyl]-3-yl)-6-oxo-4-(trifluoromethyl)-1,6dihydropyridine-3-carboxamide (16g)

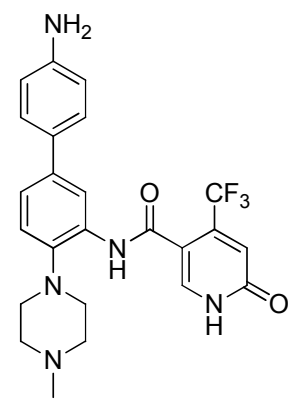

The title compound was prepared by using general procedure $\mathrm{F}$ (59 mg, 64\%yield). ${ }^{1} \mathrm{H}$ NMR $\left(500 \mathrm{MHz}, \mathrm{DMSO}-d_{6}\right) \delta 9.30(\mathrm{br} \mathrm{s}, 1 \mathrm{H}), 8.42(\mathrm{~s}, 1 \mathrm{H}), 8.06(\mathrm{~d}, J=2.0 \mathrm{~Hz}, 1 \mathrm{H}), 8.00(\mathrm{~s}, 1 \mathrm{H}), 7.31$ $7.26(\mathrm{~m}, 3 \mathrm{H}), 7.19(\mathrm{~d}, J=10.0 \mathrm{~Hz}, 1 \mathrm{H}), 6.72$ (br s, 1H), 6.66-6.62 (m, 2H), 5.20 (br s, 2H), 2.86 (br t, 4H), 2.48 (br s, 4H), $2.23(\mathrm{~s}, 3 \mathrm{H}) .{ }^{13} \mathrm{C}$ NMR (125 MHz, DMSO-d 6 ) $\delta 165.7,163.4,148.7$, 142.5, 141.6, 137.0, 133.1, 128.1, 127.6, 127.4 (2), 122.3, 120.9, 120.0, 118.2, 114.7 (2), 112.0, 
55.5 (2), 51.9 (2), 46.2; ${ }^{19} \mathrm{~F}$ NMR (471 MHz, DMSO- $d_{6}$ ) $\delta-61.15$. HRMS (ESI) $m / z$ calcd for $\mathrm{C}_{24} \mathrm{H}_{25} \mathrm{~F}_{3} \mathrm{~N}_{5} \mathrm{O}_{2}[\mathrm{M}+\mathrm{H}]^{+}: 472.1960$, found: 472.1952.

$N$-(2-(4-Methylpiperazin-1-yl)-5-(1-(2-morpholinoethyl)-1H-pyrazol-4-yl)phenyl)-6-oxo-4(trifluoromethyl)-1,6-dihydropyridine-3-carboxamide (16h)

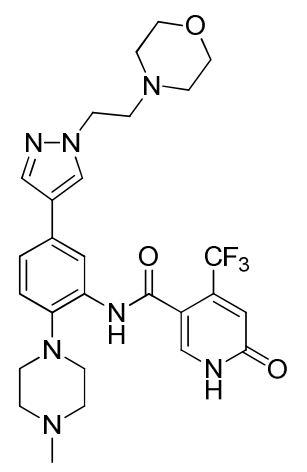

The title compound was prepared according to general procedure $\mathrm{F}$ (42 $\mathrm{mg}, 68 \%$ yield). ${ }^{1} \mathrm{H}$ NMR $(500 \mathrm{MHz}, \mathrm{MeOD}) \delta 8.20(\mathrm{~d}, J=1.6 \mathrm{~Hz}, 1 \mathrm{H}), 8.01(\mathrm{~s}, 1 \mathrm{H}), 7.98(\mathrm{~s}, 1 \mathrm{H}), 7.80(\mathrm{~s}, 1 \mathrm{H}), 7.38(\mathrm{dd}, J$ $=8.3,2.0 \mathrm{~Hz}, 1 \mathrm{H}), 7.25(\mathrm{~d}, J=8.3 \mathrm{~Hz}, 1 \mathrm{H}), 6.92(\mathrm{~s}, 1 \mathrm{H}), 4.29(\mathrm{t}, J=6.5 \mathrm{~Hz}, 2 \mathrm{H}), 3.68-3.64$ (m, 4H), $2.96(\mathrm{t}, J=4.7 \mathrm{~Hz}, 4 \mathrm{H}), 2.82(\mathrm{t}, J=6.5 \mathrm{~Hz}, 2 \mathrm{H}), 2.68(\mathrm{~s}, 4 \mathrm{H}), 2.52-2.47(\mathrm{~m}, 4 \mathrm{H}), 2.38$ $(\mathrm{s}, 3 \mathrm{H}) ;{ }^{13} \mathrm{C}$ NMR $(126 \mathrm{MHz}, \mathrm{MeOD}) \delta 164.8,164.4,143.3,141.4\left(\mathrm{q},{ }^{2} J_{C-F}=33.2 \mathrm{~Hz}, 1 \mathrm{C}\right)$, $139.8,137.5,134.1,130.8,128.9,123.8,123.7,123.4\left(\mathrm{q},{ }^{1} J_{C-F}=274.7 \mathrm{~Hz}, 1 \mathrm{C}\right), 122.2,120.3(\mathrm{q}$, $\left.{ }^{3} \mathrm{~J}_{\mathrm{C}-\mathrm{F}}=4.5 \mathrm{~Hz}, 1 \mathrm{C}\right), 114.8,67.9,59.2,56.3,54.7,52.6,50.3,46.0 ;{ }^{19} \mathrm{~F}$ NMR $(471 \mathrm{MHz}, \mathrm{MeOD})$ $\delta$-63.80. HRMS (ESI) $\mathrm{m} / z$ calcd for $\mathrm{C}_{27} \mathrm{H}_{33} \mathrm{~F}_{3} \mathrm{~N}_{7} \mathrm{O}_{3}[\mathrm{M}+\mathrm{H}]^{+}: 560.2597$, found: 560.2595 . 


\section{NMR Spectra of Select Compounds}

Spectra are displayed in the following order: ${ }^{1} \mathrm{H},{ }^{13} \mathrm{C},{ }^{19} \mathrm{~F}$

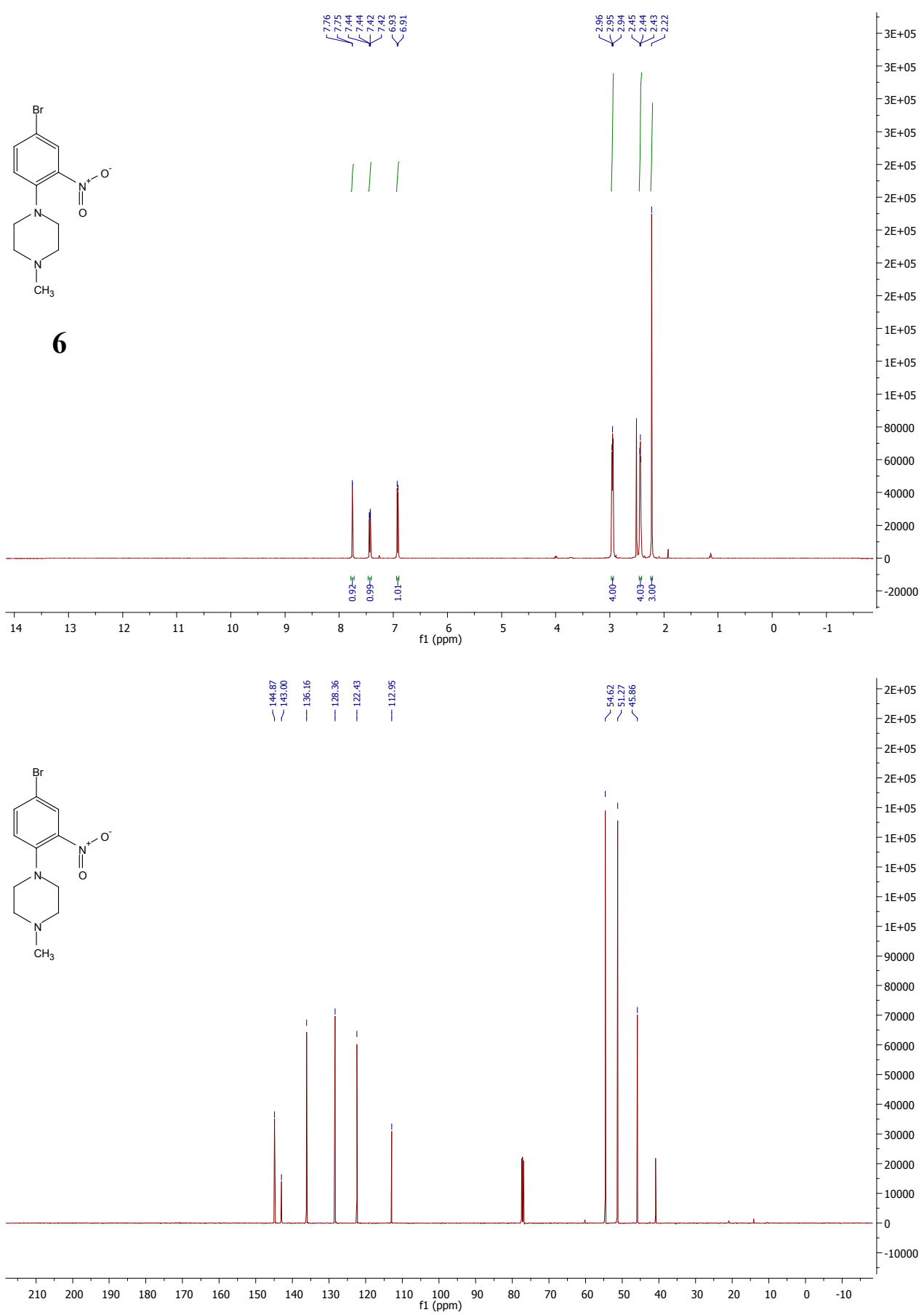




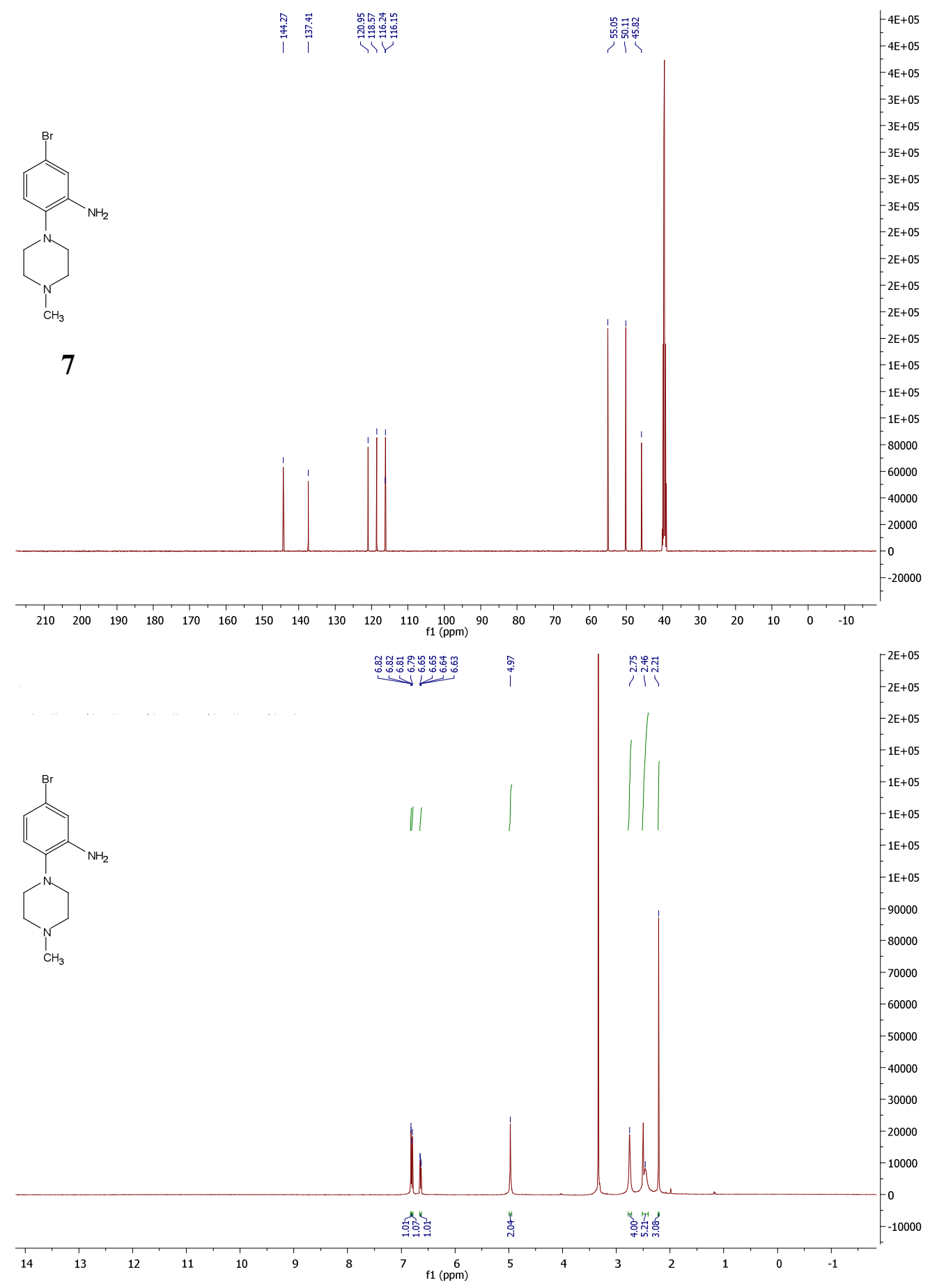




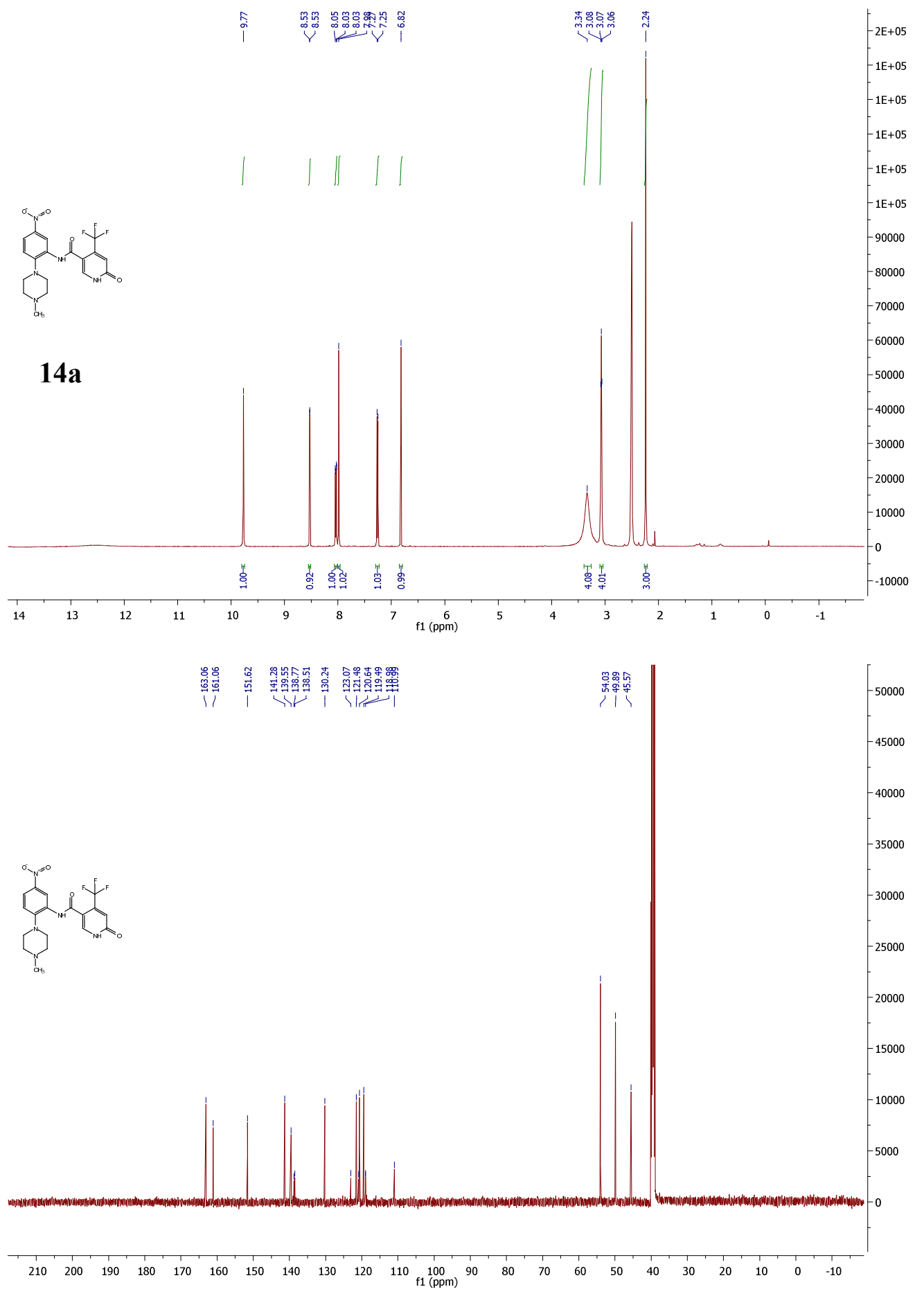




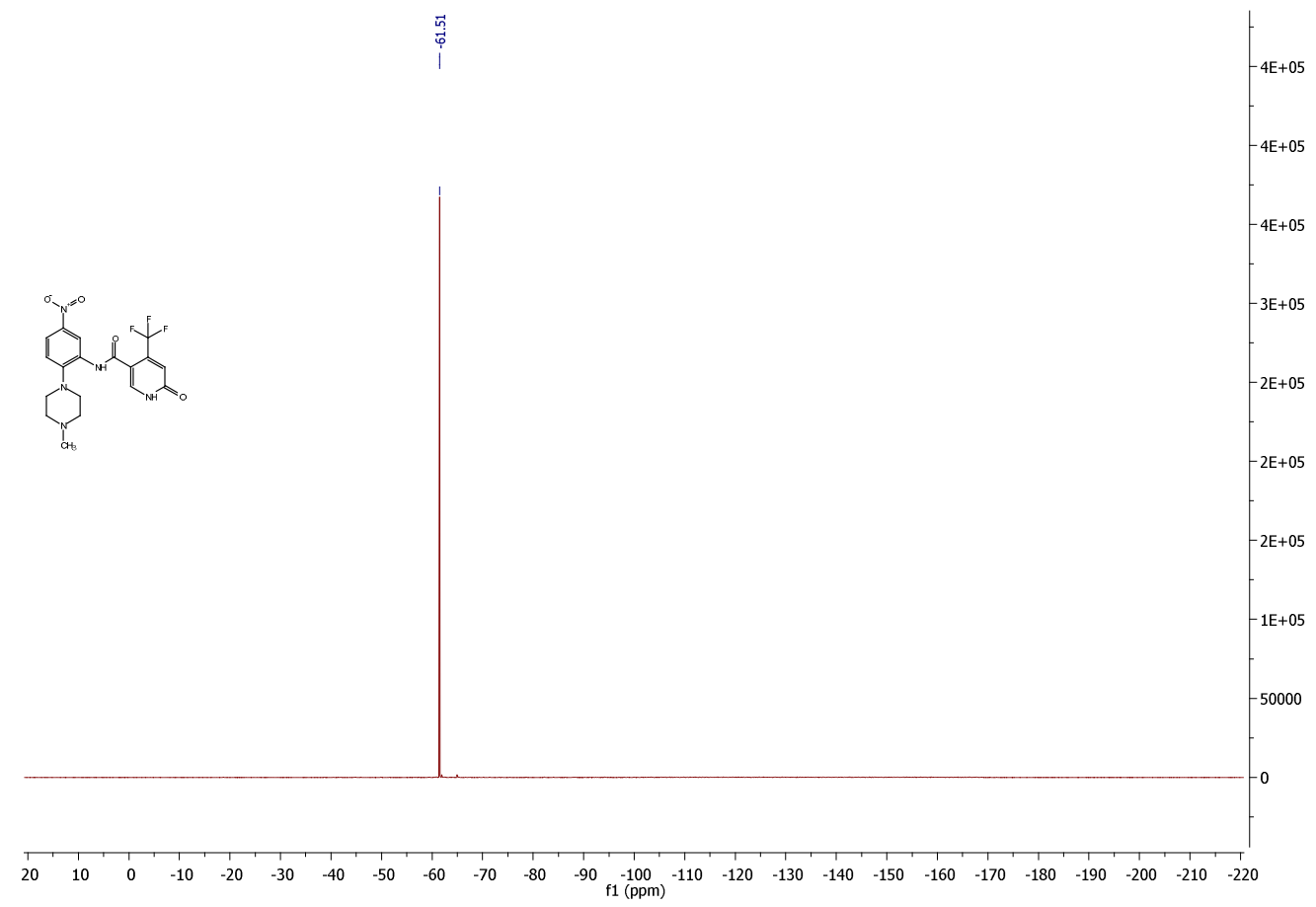




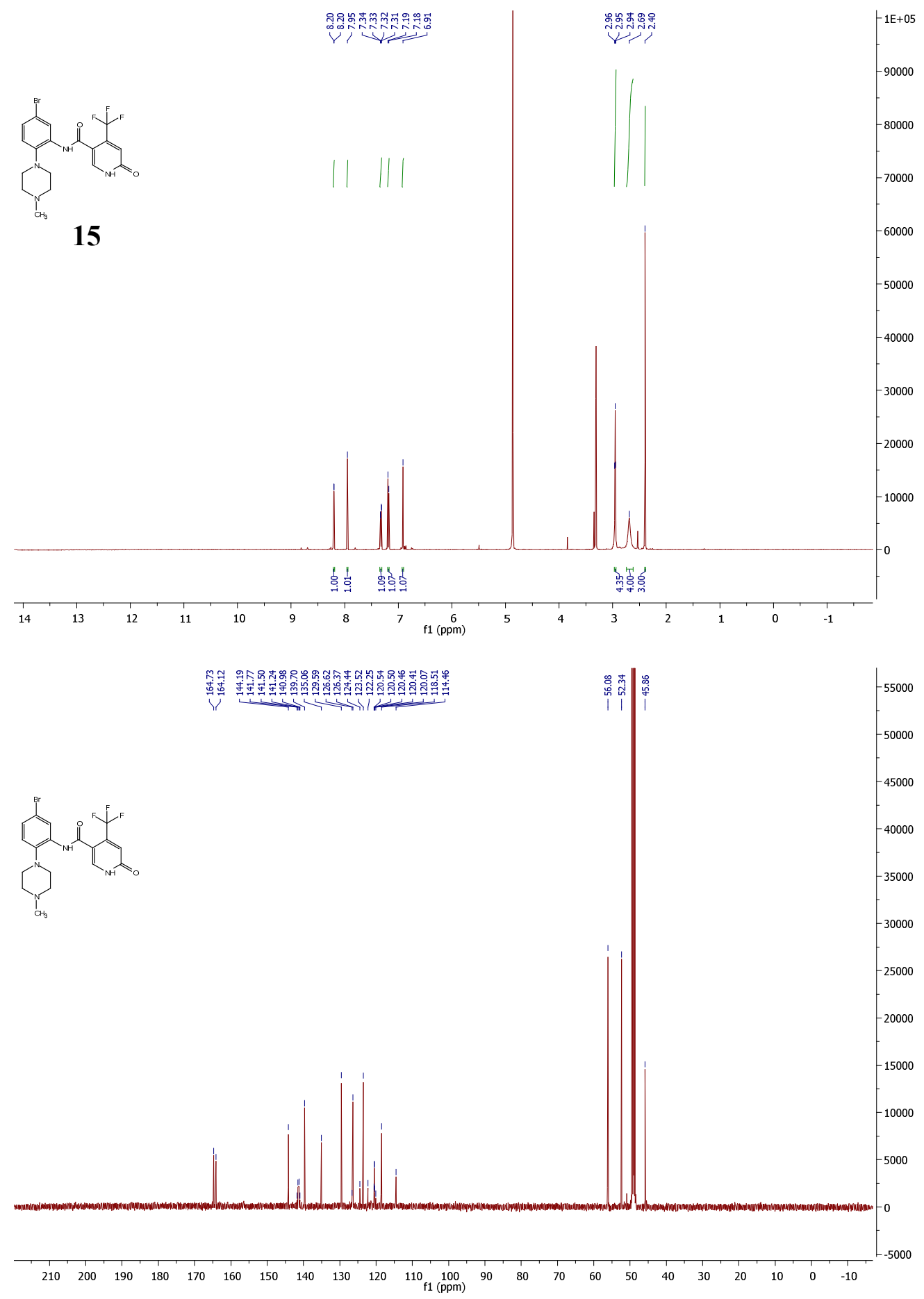




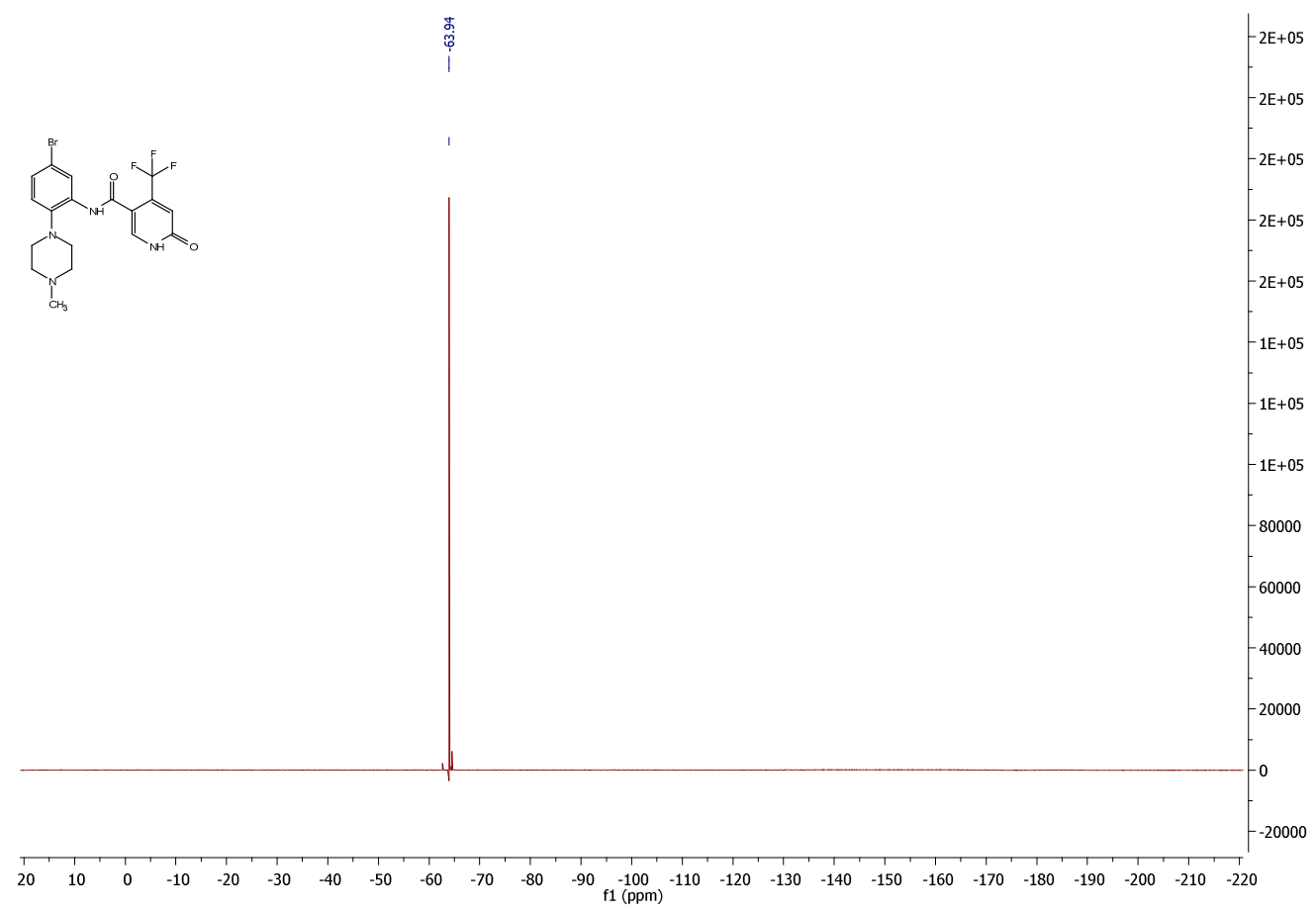



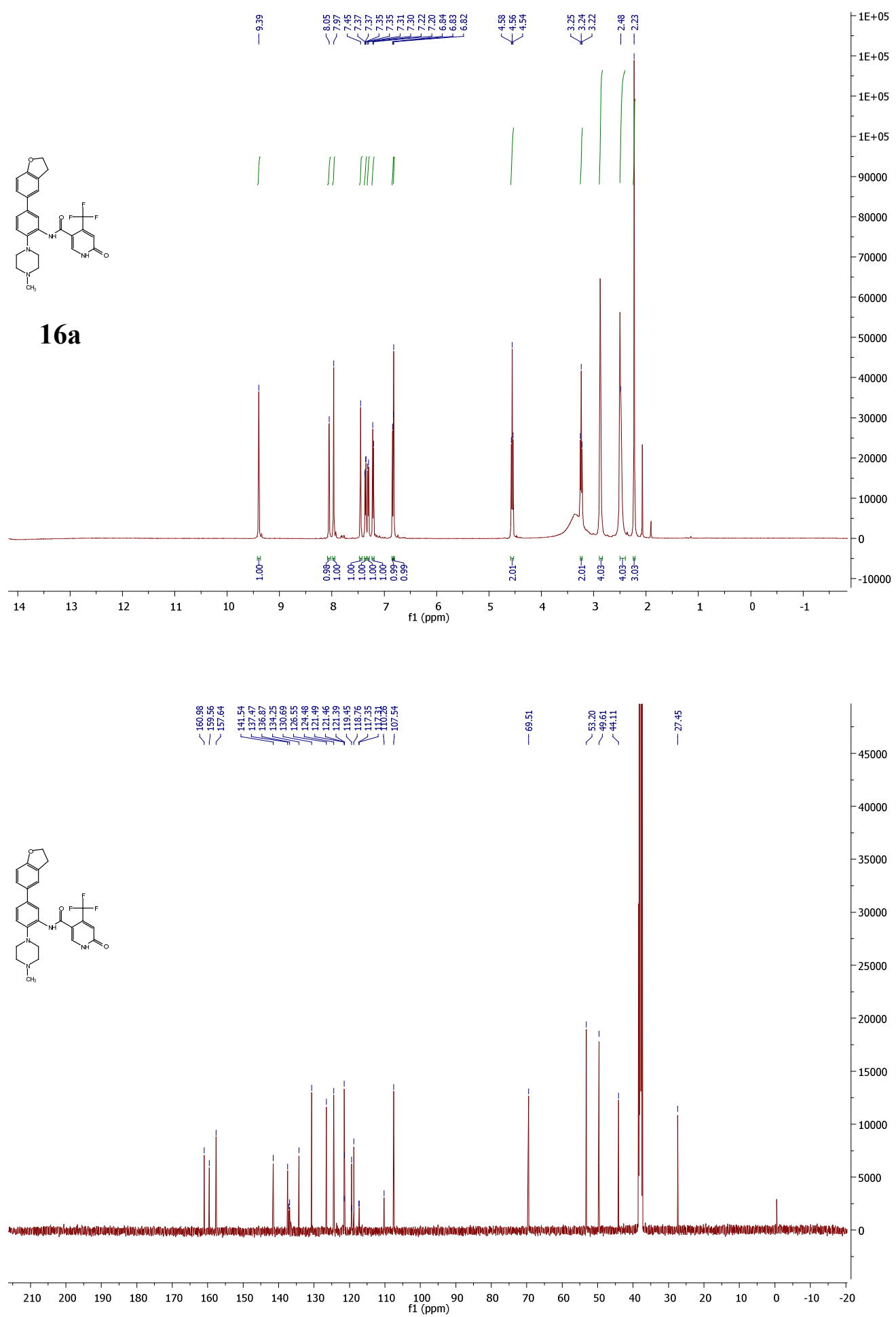


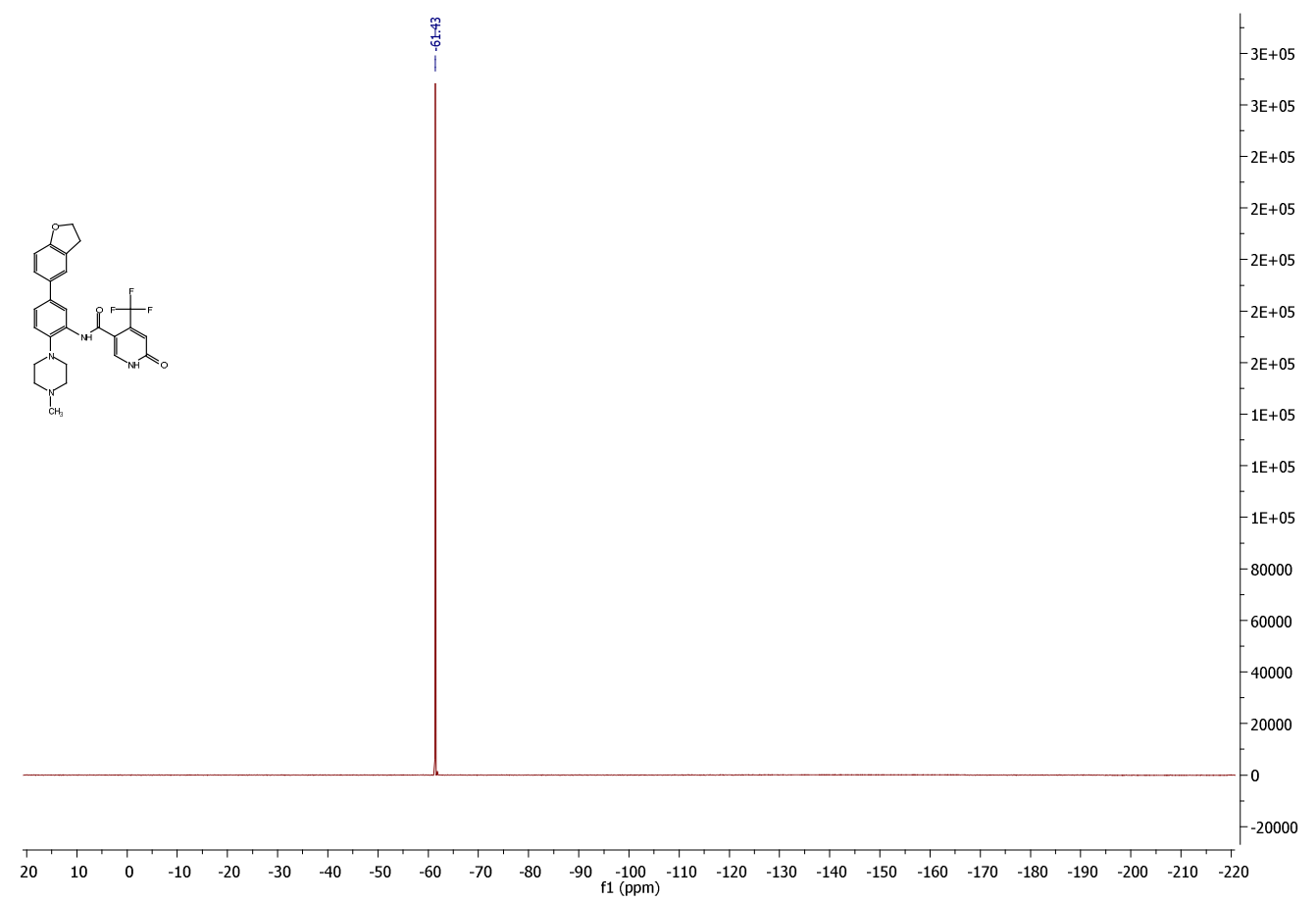



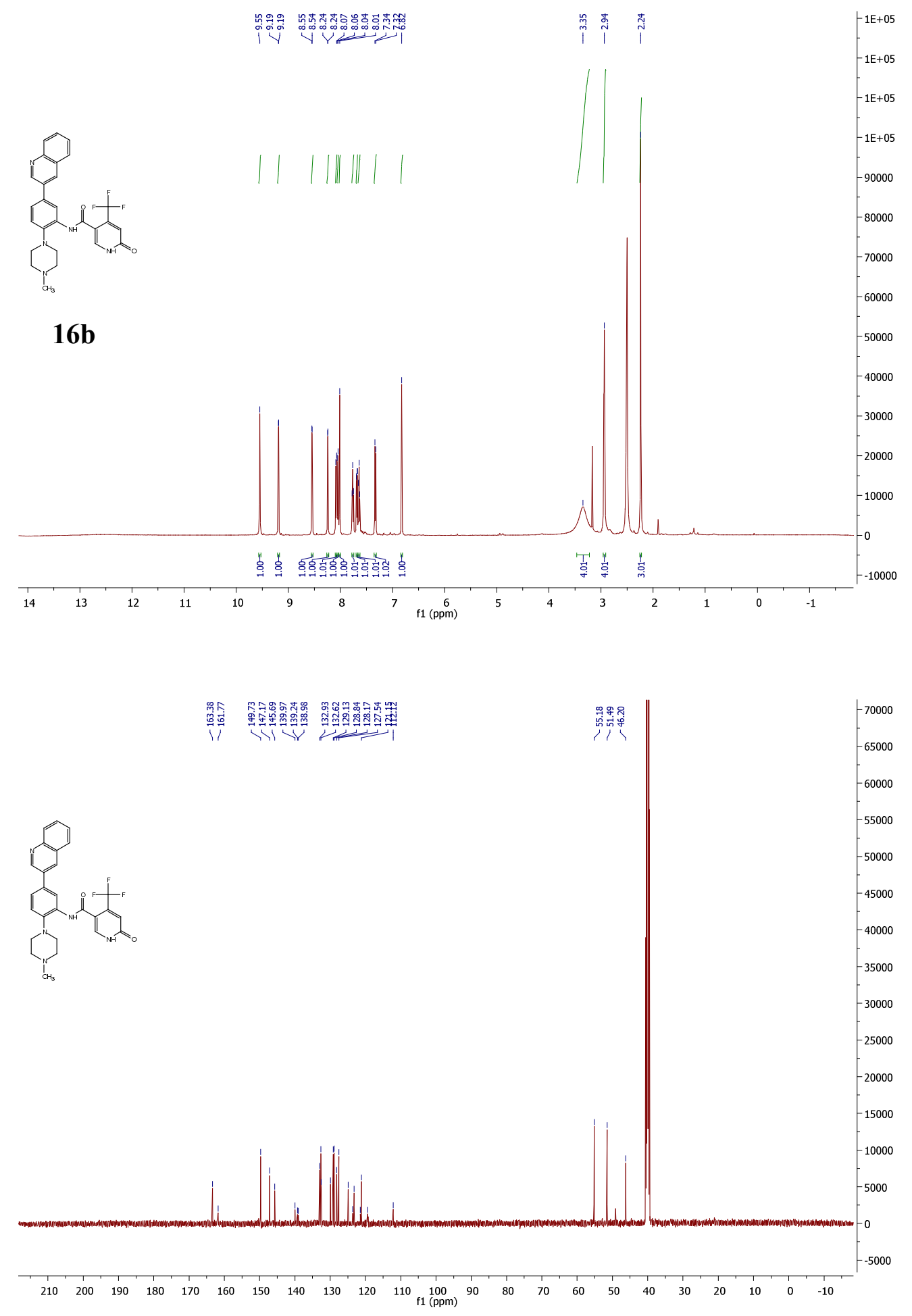


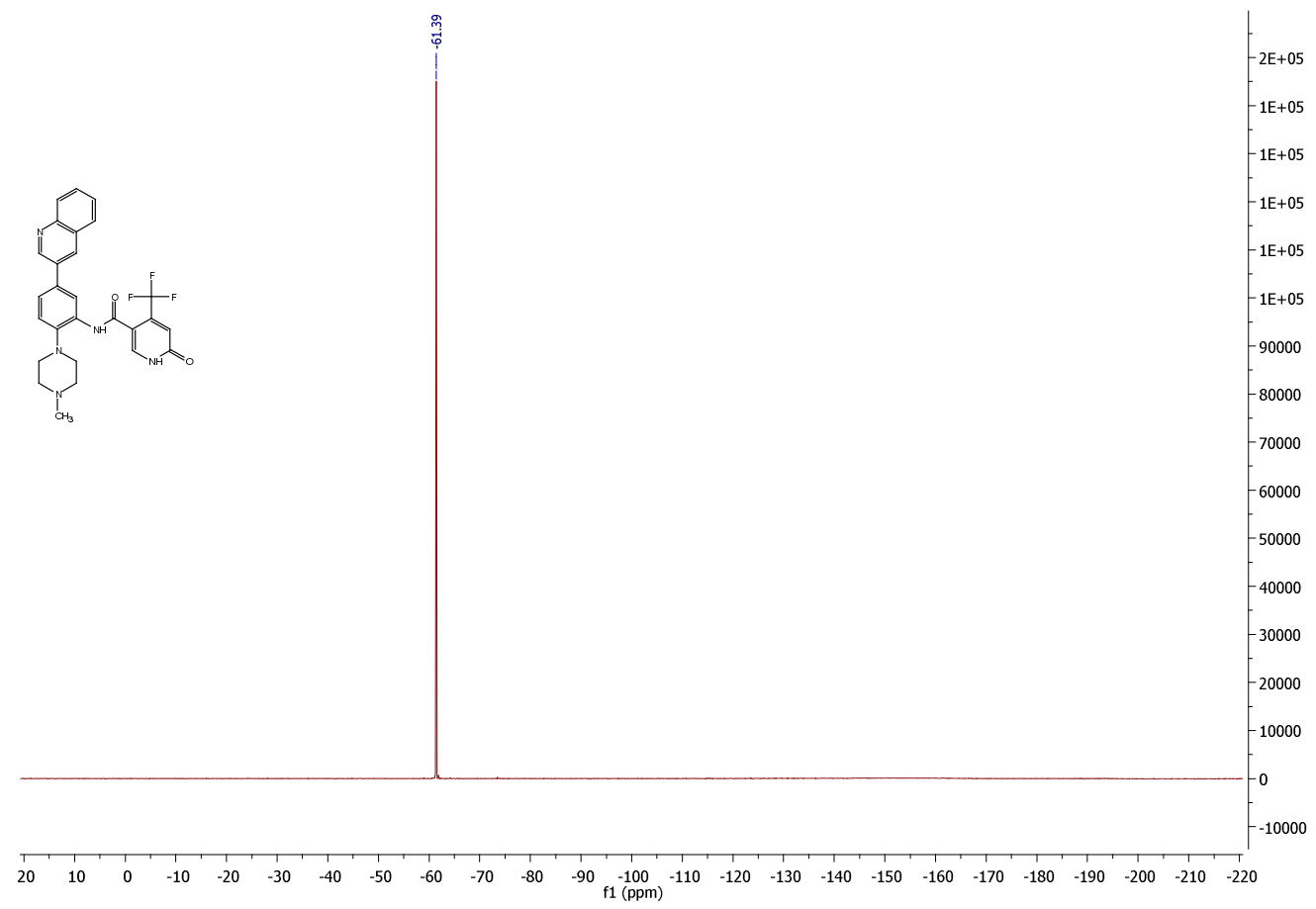




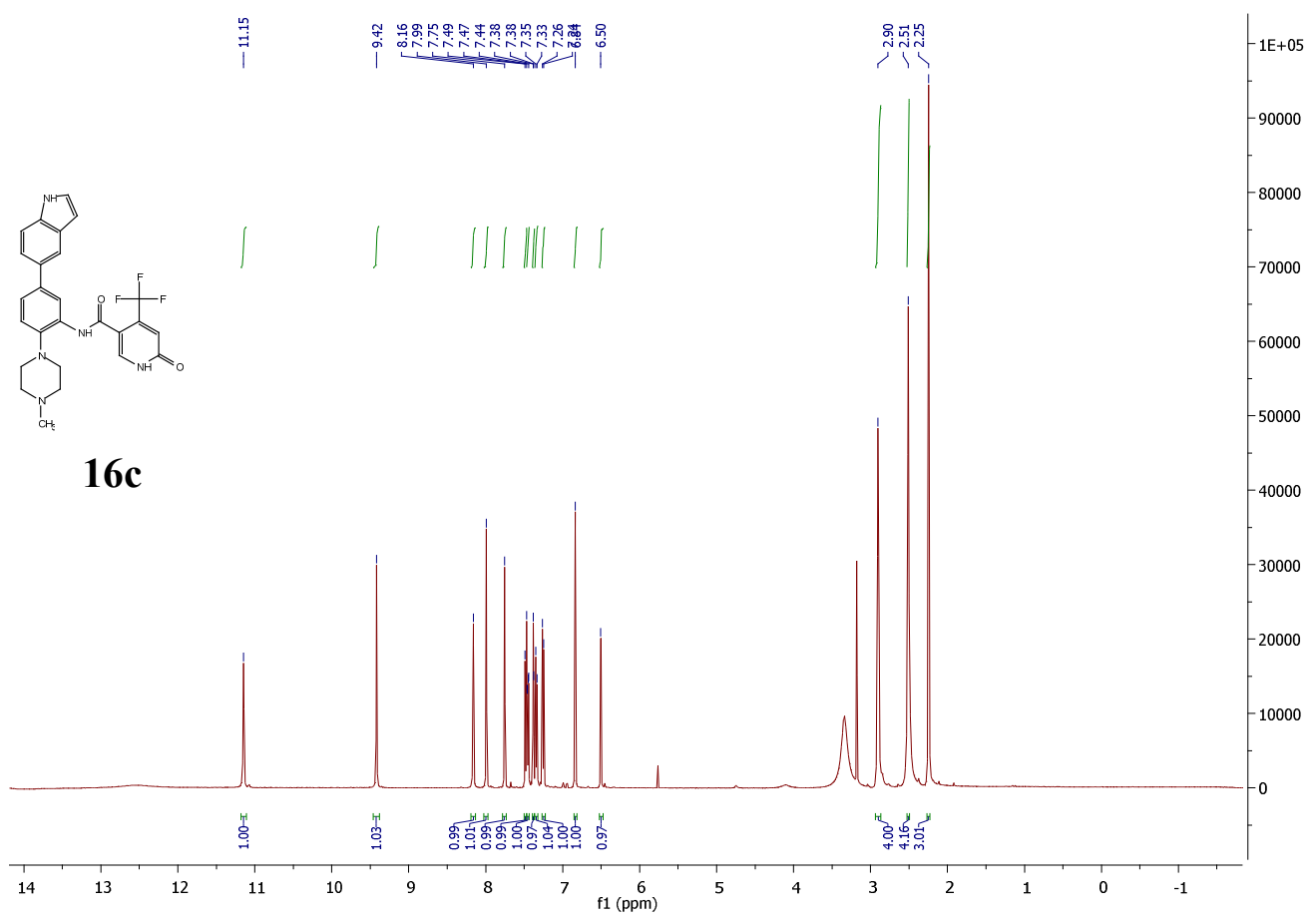

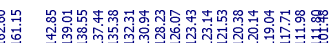

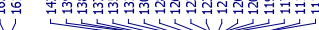

(1)

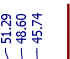

(1)

$-50000$

50000

40000

35000

30000

25000

$-20000$

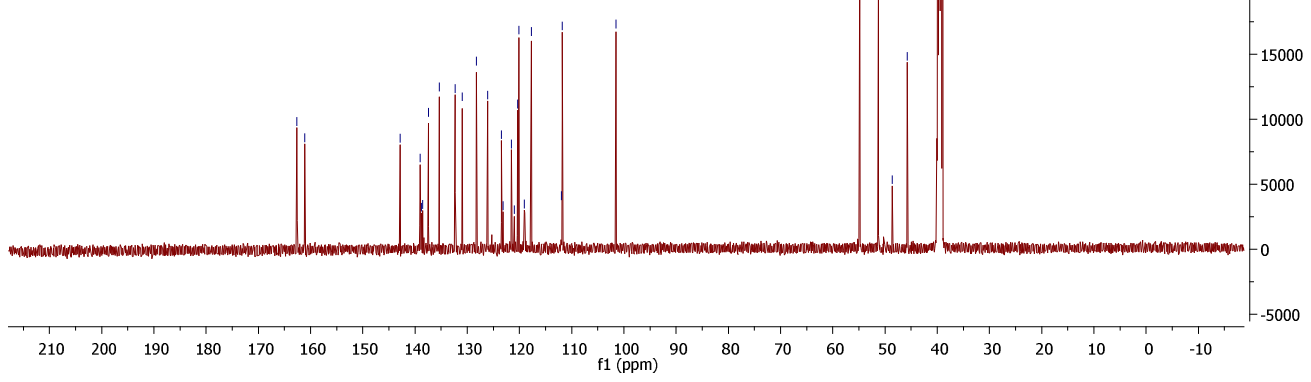

$\begin{array}{lllllllllllllllllllllll}210 & 200 & 190 & 180 & 170 & 160 & 150 & 140 & 130 & 120 & 110 & \underset{\mathrm{f} 1(\mathrm{ppm})}{100} & 90 & 80 & 70 & 60 & 50 & 40 & 30 & 20 & 10 & 0 & -10\end{array}$ 


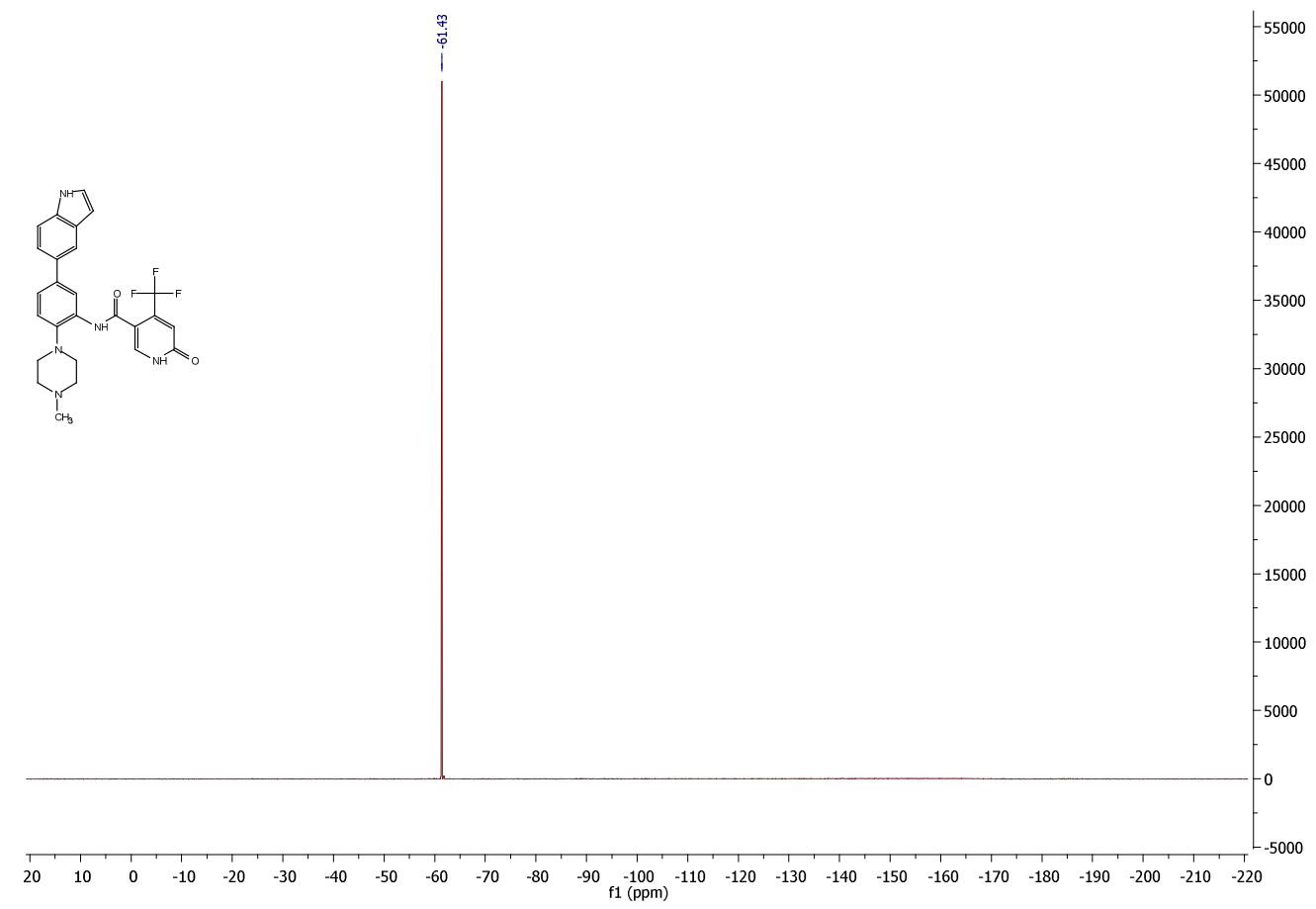




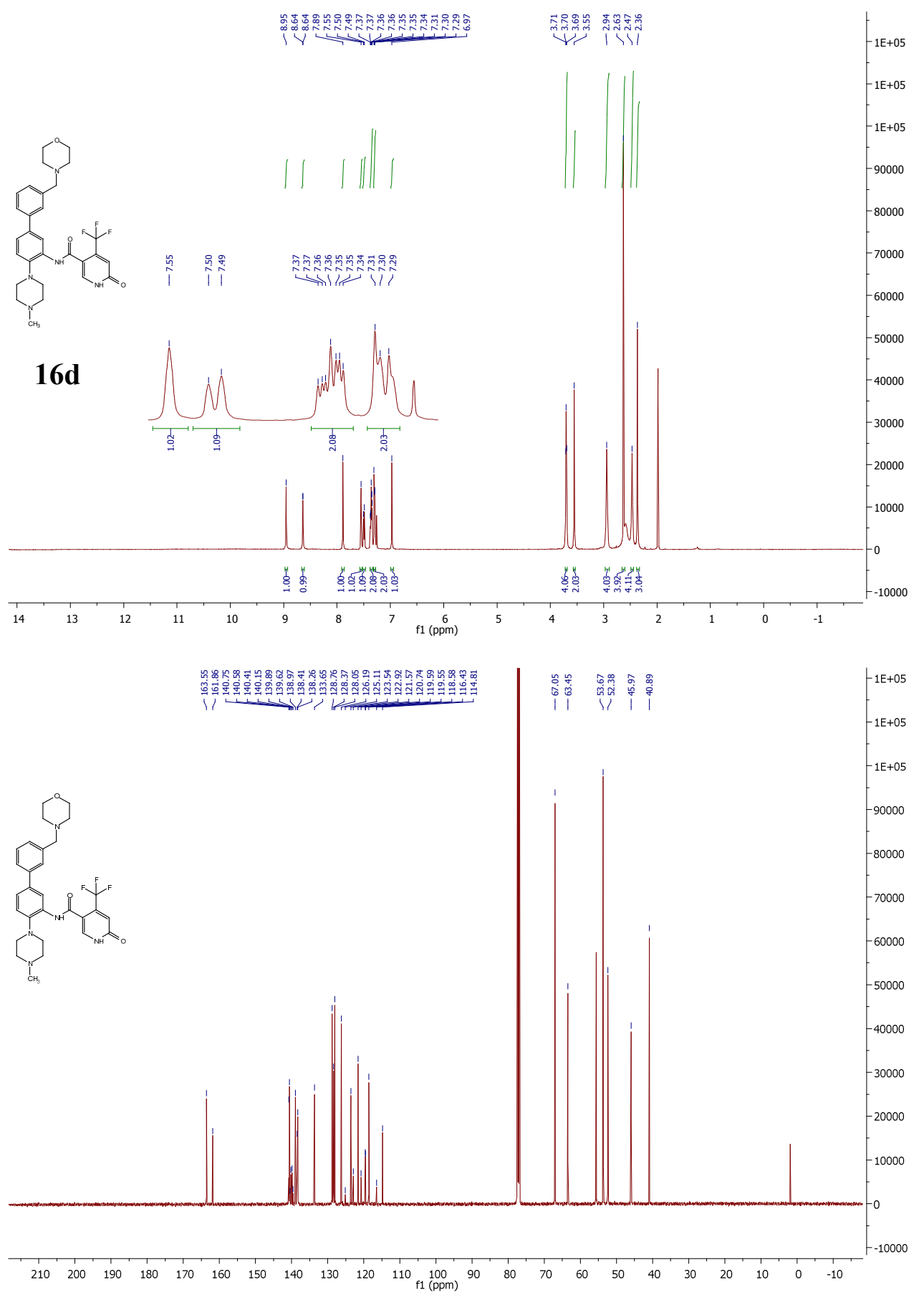




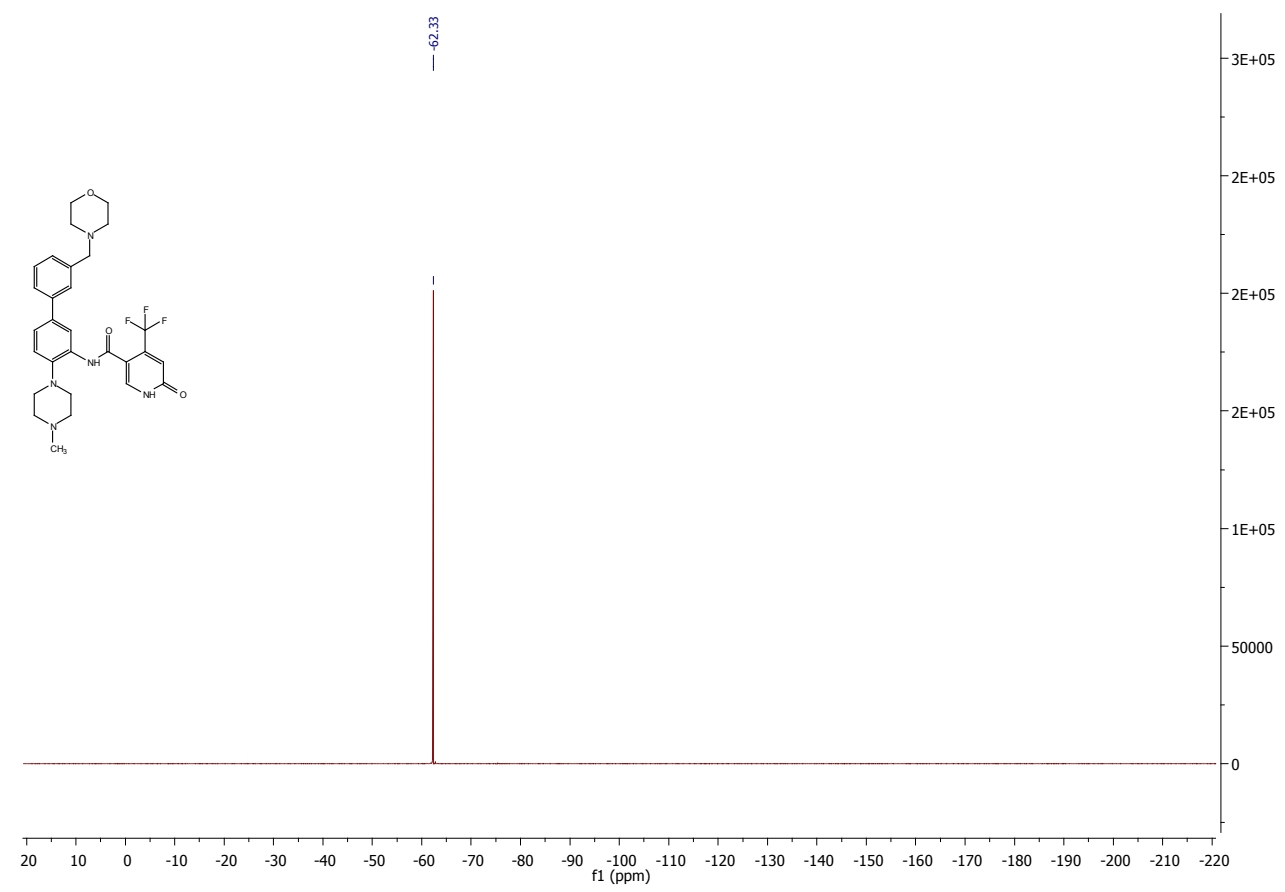




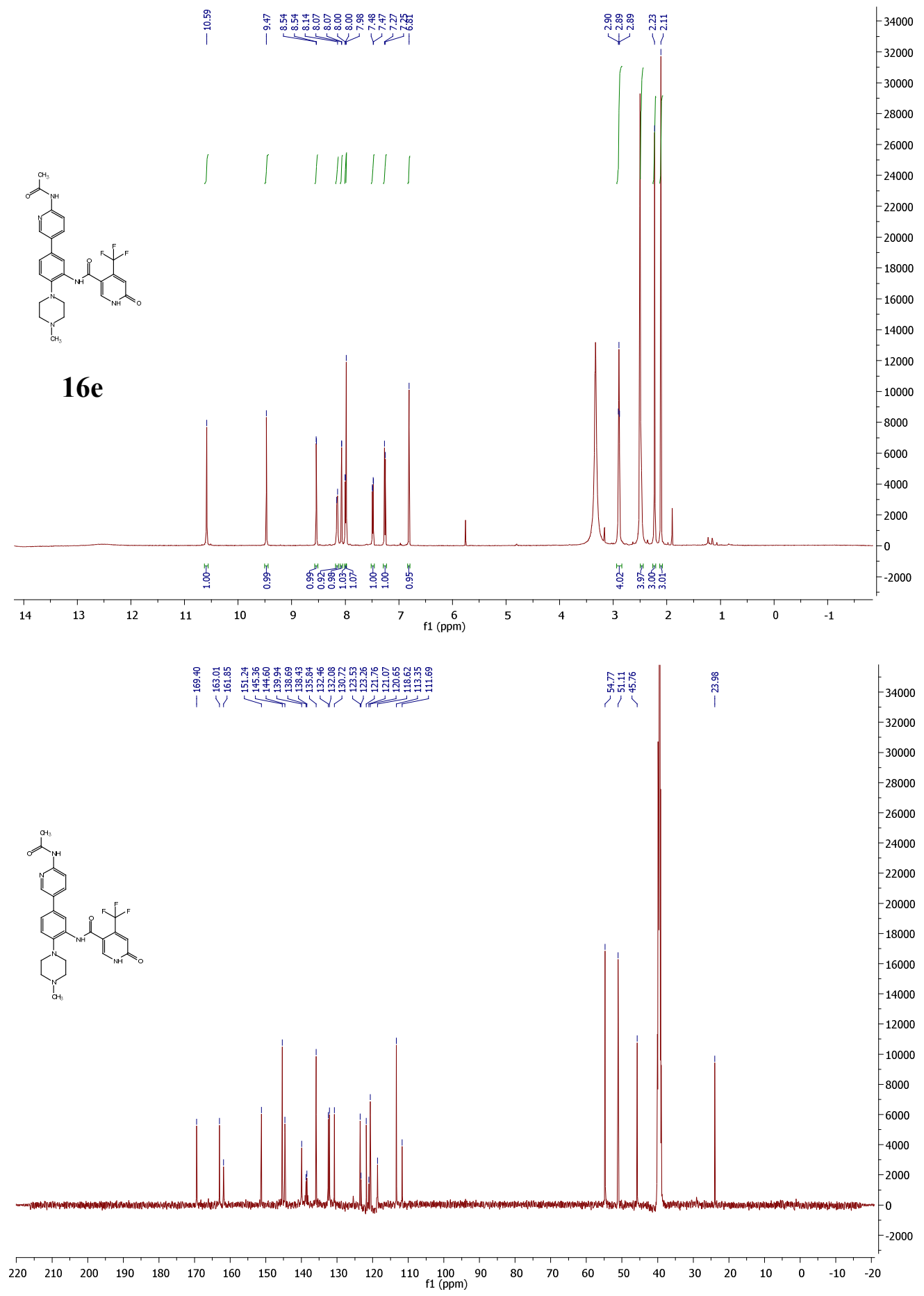




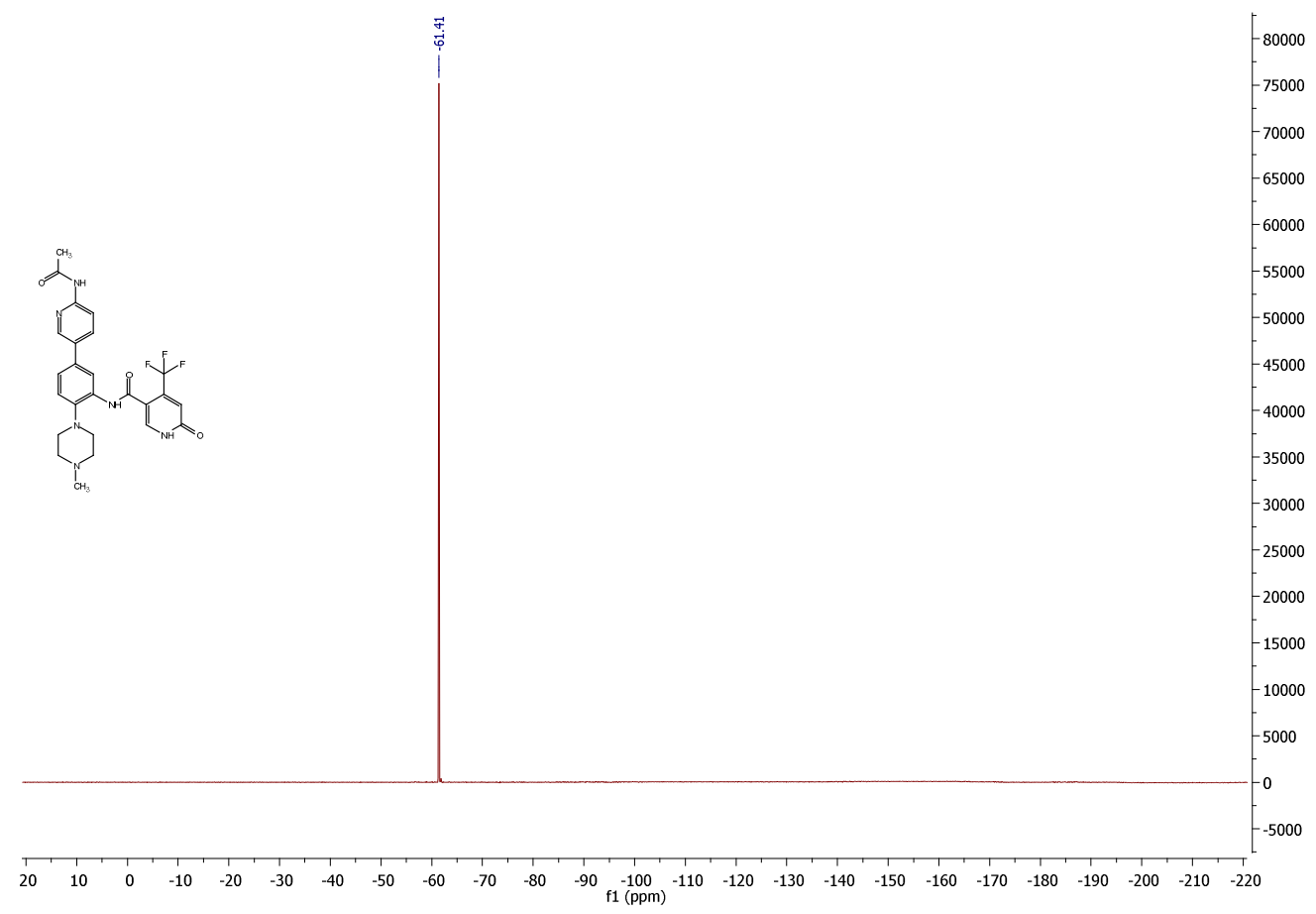



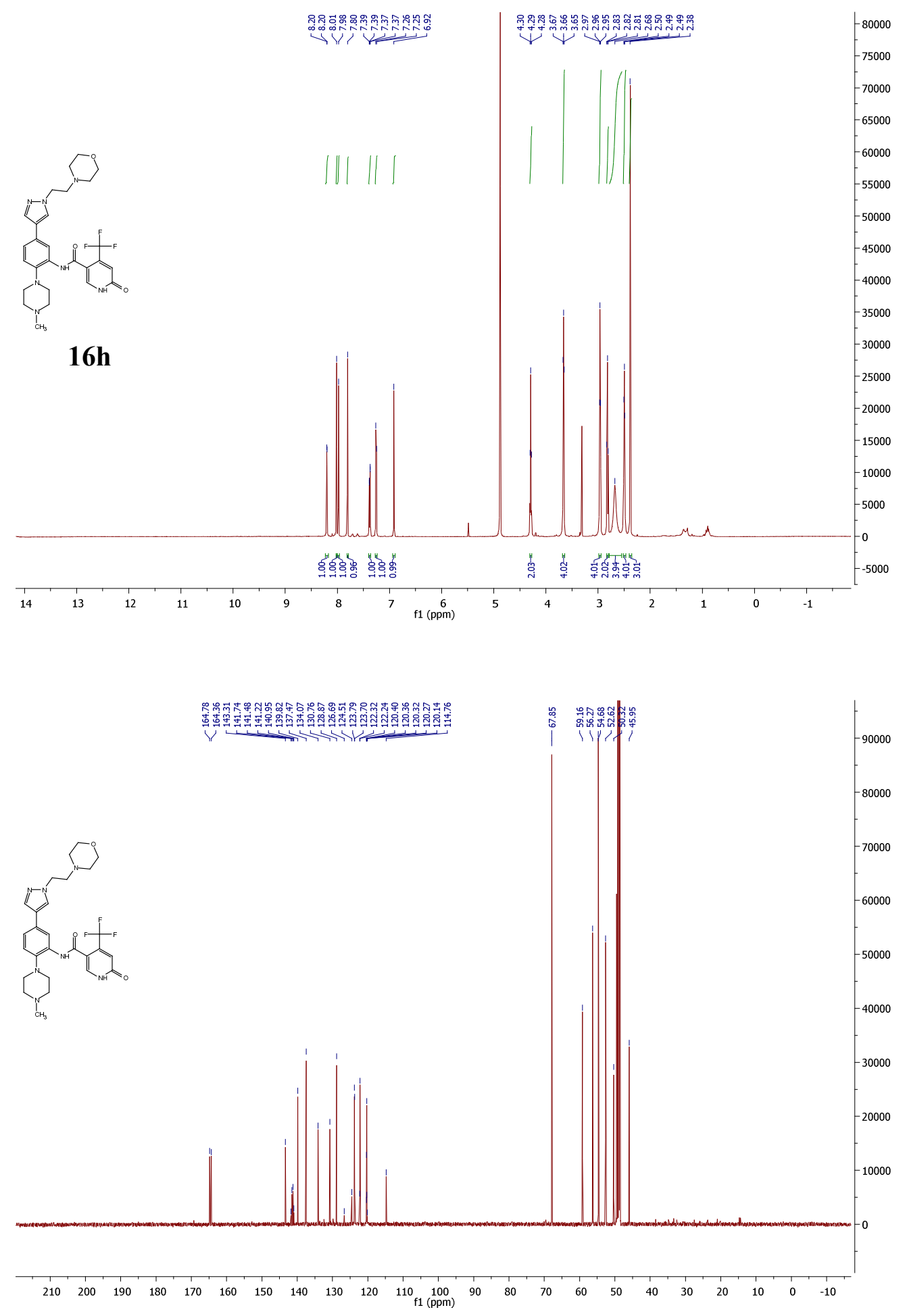


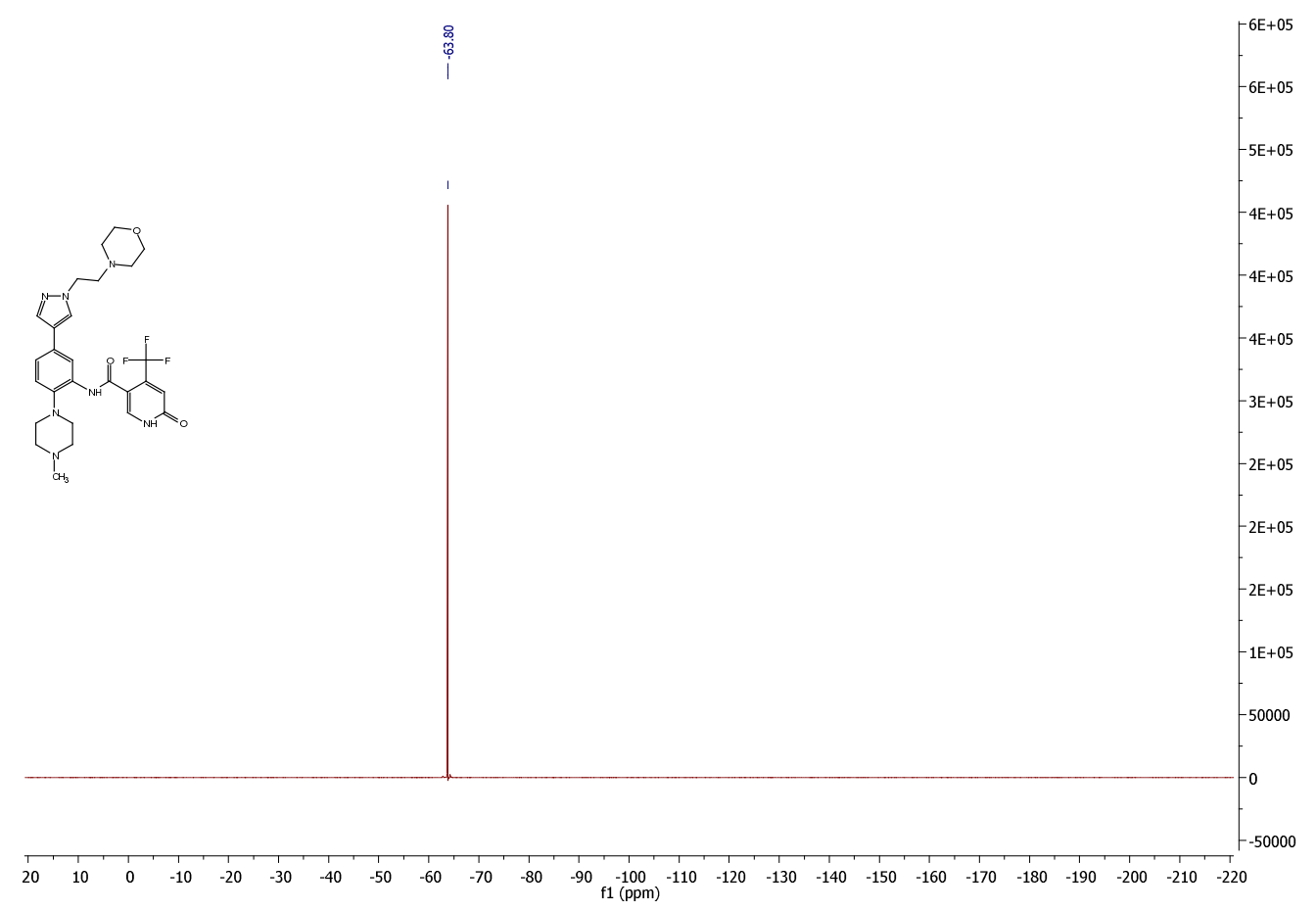




\section{Focused Library Design and Molecular Docking}

Focused library design and reaction-based virtual enumeration was performed with Accelrys Pipeline Pilot (currently, BIOVIA, http:/www.3ds.com/products-services/biovia/). Structures, vendor information, and prices of all commercially available building blocks were assembled in a flat SD file based on the database table dumps from eMolecules Plus (https://www.emolecules.com/info/building-blocks). These available building blocks were fed into Pipeline Pilot Markush substructure searches to yield all commercially available benzoyl and acid halides, benzoic acids and esters, and heterocyclic carboxylic acids. The lists were then used to virtually enumerate all (benz)amides accessible via commercially available reagents. OICR HTS Filters were used to reduce the number of enumerated products by eliminating compounds with undesirable calculated physical properties (MW, PSA, calculated octanol-water partition coefficient, $\log \mathrm{P}$, number of aromatic rings, number of H-bond acceptors and donors, number of rotatable bonds, individual halogens counts, positively and negatively charged groups counts). As a result, about 10,200 (benz)amides were enumerated: 1,200 based on available acid halides and 9,000 based on available acids/esters. The obtained library was prepared with the ligprep procedure from Schrödinger, Inc. Accordingly, the molecules were ionized to $\mathrm{pH} 7$ with Epik, specific chiralities were retained while all other chiral centers were enumerated, and no tautomers were generated. The resulting structures were energy minimized with OPLS_2005 force field. To avoid docking instability and to obtain the best possible results during the docking stage with Glide, 10 different conformers were generated for each molecule with the ConfGen Mixed torsional/Low-mode sampling procedure using 1,000,000 steps and a $21 \mathrm{~kJ} / \mathrm{mol}$ energy window for saving structures. The protein grid calculation was done based on the WDR5-4 cocrystal structure (PDB code $3 \mathrm{SMR}$, resolved to $1.8 \AA$ ) with one H-bond constraint defined with the side chain of S91. Docking was performed with the Glide docking program using the SP scoring function (http://www.schrodinger.com). Each compound was subject to post-docking minimization using a set of 100 ligand poses. Out of all the poses generated for multiple conformers, one best docking pose was retained for each compound. The obtained SP Glide docking scores were used to rank the top 2,000 virtual compounds that were visually inspected. The 50 best looking analogs were selected and prioritized for synthesis.

\section{Cloning, Expression, and Purification of Human WDR5}

The DNA fragment encoding human WDR5 (residues 1-334) was amplified by PCR and subcloned into pET28-LIC vector, downstream of the poly-histidine coding region. The protein was expressed in E. coli BL21 (DE3)-V2R-pRARE2 strain by addition of $1 \mathrm{mM}$ isopropyl-1-thio-Dgalactopyranoside (IPTG) and incubated overnight at $15{ }^{\circ} \mathrm{C}$. Harvested cells were re-suspended in $20 \mathrm{mM}$ Tris buffer ( $\mathrm{pH} 7.5$ ) supplemented with $500 \mathrm{mM} \mathrm{NaCl}, 5 \mathrm{mM}$ imidazole, and 5\% glycerol. The cells were lysed chemically, followed by sonication at a frequency of 8.5 (10 sec on/10 sec off) for $4 \mathrm{~min}$. After clarification of the crude extract by high-speed centrifugation, the lysate was loaded onto DE52 and passed onto a Ni-NTA column. The column was washed and eluted sequentially with $20 \mathrm{mM}$ Tris ( $\mathrm{pH} 7.5$ ), $500 \mathrm{mM} \mathrm{NaCl}, 5 \%$ glycerol, $30 \mathrm{mM}$ and $250 \mathrm{mM}$ imidazole. Thrombin was added while the protein was being dialyzed against $20 \mathrm{mM}$ Tris buffer ( $\mathrm{pH} 7.5$ ), $2.5 \mathrm{mM} \mathrm{CaCl}_{2}$, and $500 \mathrm{mM} \mathrm{NaCl}$. To remove the cut his-tag and his-tagged protein, dialyzed protein solution was passed through a Ni-NTA column. Flow through was dialyzed again against $20 \mathrm{mM}$ Tris buffer $(\mathrm{pH} 7.5), 2.5 \mathrm{mM} \mathrm{CaCl}_{2}$, and $500 \mathrm{mM} \mathrm{NaCl}$. Pure protein (> 
$95 \%$ ) was further concentrated to higher than $20 \mathrm{mg} / \mathrm{mL}$, and stored at $-80{ }^{\circ} \mathrm{C}$ after flash freezing.

\section{Fluorescence Polarization (FP) Binding Assays}

H3 (1-15) (ARTKQTARKSTGGKA) and 9-Ala-FAM ((Ac)-ARAEVHLRK-(Ahx-Ahx)-K(5,6FAM)) peptides for WDR5 were synthesized, $N$-terminal-labeled with isothiocyanatefluorescein, and purified by Tufts University Core Services (Boston, MA). Compound binding assays were performed at a constant labeled peptide concentration of 30 or $20 \mathrm{nM}$ for $\mathrm{H} 3$ (1-15) and 9-Ala-FAM respectively. WDR5 concentrations of $0.3 \mu \mathrm{M}$ for $\mathrm{H} 3$ (1-15) and $0.05 \mu \mathrm{M}$ for 9Ala-FAM were used. For both the H3 (1-15) and 9-Ala-FAM peptides, $80 \mathrm{mM}$ sodium phosphate buffer ( $\mathrm{pH} 6.5), 20 \mathrm{mM} \mathrm{KCl}$, and $0.008 \%$ Triton X-100 was used. For the H3 (1-15) peptide, FP assays were measured in $10 \mu \mathrm{l}$ aliquots in 384-well Axygen plates using a Synergy 4 microplate reader (BioTek) with an excitation wavelength of $485 \mathrm{~nm}$ and emission wavelength of $528 \mathrm{~nm}$. For the 9-Ala-FAM peptide, FP assays were measured in $125 \mu 1$ aliquots in 96 well Microfluor plates using a ViewLux instrument (Perkin Elmer) with an excitation wavelength of $480 \mathrm{~nm}$ and an emission wavelength of $540 \mathrm{~nm}$. To determine $K_{\text {disp }}$ values, the data were fit to a hyperbolic function using Sigma Plot software (Systat Software). The $K_{\text {disp }}$ values represent the average of quadruplicate measurements.

\section{Crystallization and Structure Determination}

Purified WDR5 protein $(10 \mathrm{mg} / \mathrm{ml})$ was mixed with each compound at a 1:5 molar ratio of protein to compound and crystallized using the sitting-drop vapor-diffusion method at $20{ }^{\circ} \mathrm{C}$ by adding $1 \mu \mathrm{l}$ of protein solution to $1 \mu \mathrm{l}$ of the reservoir solution containing $25 \%$ PEG [poly(ethylene glycol)] 3350, 0.1 M ammonium sulfate 0.1 M BisTris, pH 6.5 (compound 9d), 28\% PEG 2000 monomethyl ether, 0.1 M BisTris, pH 6.5 (compound 9e), 20\% PEG 5000 monomethyl ether, 0.1 M BisTris, $\mathrm{pH} 6.5$ (compound 9h) and 25\% PEG3350, $0.1 \mathrm{M}$ ammonium sulfate, $0.1 \mathrm{M}$ BisTris, pH 6.5 (compound 9o), respectively. Crystals were soaked in the corresponding mother liquor supplemented with $20 \%$ ethylene glycol as cryoprotectant before freezing in liquid nitrogen. Diffraction data for crystals of the WDR5-compound complexes were collected on a Rigaku FR-E SuperBright instrument. The program suite HKL3000 was used to integrate and scale the datasets. All WDR5 co-crystal structures were determined by molecular replacement using coordinates from PDB entry $2 \mathrm{O} 9 \mathrm{~K}$ as the search template. The graphic program Coot32 was used for manual model refinement and visualization. Refmac533 was used to refine the model. MolProbity was used to validate the refined structure. The structures have been deposited into the PDB under codes 3SMR, 4IA9, 5EAR, 5EAP, 5EAL, 5EAM, and 4QL1. Crystal diffraction data and refinement statistics for the structures of WDR5-9d, 9e, 9h and 9o complexes are shown in Supplementary Table 1 (below). 
Supplementary Table 1 - Data Collection and Refinement Statistics (Molecular Replacement)

\begin{tabular}{|c|c|c|c|c|}
\hline & WDR5-9d & WDR5-9e & WDR5-9h & WDR5-9o \\
\hline \multicolumn{5}{|l|}{ Data collection } \\
\hline Space group & P1 & $\mathrm{C} 2$ & P1 & P1 \\
\hline \multicolumn{5}{|l|}{ Cell dimensions } \\
\hline$a, b, c(\AA)$ & $46.6,53.6,64.7$ & $97.2,48.2,63.4$ & $47.2,61.0,64.1$ & $46.9,54.8,64.0$ \\
\hline$\alpha, \beta, \gamma\left({ }^{\circ}\right)$ & $107.9,90.9,109.7$ & $90.0,108.0,90.0$ & $110.7,90.4,109.5$ & $107.2,90.2,112.6$ \\
\hline Resolution ( $\AA$ ) & $\begin{array}{l}50.00-1.80(1.83- \\
1.80)^{*}\end{array}$ & $\begin{array}{l}50.00-1.73(1.76- \\
1.73)^{*}\end{array}$ & $\begin{array}{l}50.00-1.80(1.83- \\
1.80)^{*}\end{array}$ & $\begin{array}{l}50.00-1.80(1.83- \\
1.80)^{*}\end{array}$ \\
\hline$R_{\text {sym }}$ or $R_{\text {merge }}$ & $4.2(20.7)$ & $7.9(45.2)$ & $7.1(61.8)$ & $10.5(43.7)$ \\
\hline$I / \sigma I$ & $31.5(6.4)$ & $19.7(2.0)$ & $20.2(2.1)$ & $12.5(2.1)$ \\
\hline Completeness (\%) & $94.1(89.8)$ & $99.2(92.5)$ & $94.2(90.5)$ & $96.5(77.9)$ \\
\hline Redundancy & $4.0(4.0)$ & $4.1(3.6)$ & $3.9(4.0)$ & $3.2(3.0)$ \\
\hline \multicolumn{5}{|l|}{ Refinement } \\
\hline Resolution $(\AA)$ & $50.00-1.72$ & $50.00-1.72$ & $50.00-1.80$ & $50.00-1.80$ \\
\hline No. reflections & 47564 & 28238 & 53439 & 49117 \\
\hline$R_{\text {work }} / R_{\text {free }}$ & $16.8 / 19.6$ & $21.3 / 24.2$ & $18.9 / 22.0$ & $20.1 / 22.5$ \\
\hline \multicolumn{5}{|l|}{ No. atoms } \\
\hline Protein & 4633 & 2370 & 4697 & 4779 \\
\hline Ligand/ion & 66 & 32 & 66 & 64 \\
\hline Water & 542 & 97 & 497 & 329 \\
\hline \multicolumn{5}{|l|}{$B$-factors } \\
\hline Protein & 18.3 & 27.5 & 21.9 & 20.5 \\
\hline Ligand/ion & 17.0 & 18.7 & 18.4 & 21.8 \\
\hline Water & 30.1 & 32.1 & 33.6 & 29.6 \\
\hline \multicolumn{5}{|l|}{ R.m.s. deviations } \\
\hline Bond lengths $(\AA)$ & 0.007 & 0.008 & 0.008 & 0.008 \\
\hline Bond angles $\left(^{\circ}\right)$ & 1.237 & 1.299 & 1.256 & 1.323 \\
\hline \multirow{2}{*}{\multicolumn{5}{|c|}{$\begin{array}{l}\text { Ramachandran plot } \\
\% \\
\text { residues }\end{array}$}} \\
\hline & & & & \\
\hline Favored & 96.2 & 95.9 & 95.9 & 95.2 \\
\hline Allowed & 3.8 & 4.1 & 4.1 & 4.8 \\
\hline
\end{tabular}

*Highest-resolution shell is shown in parentheses.

\section{Pharmacokinetics}

All PK assessments were performed by InterVivo Solutions (Mississauga, Ontario, Canada). Compound 16d was administered to mice (female NOD-SCID) at $3 \mathrm{mg} / \mathrm{kg}$ IV $(n=3)$ and 30 $\mathrm{mg} / \mathrm{kg}$ IP $(n=3)$, along with an undosed control $(n=3)$. Blood samples were collected from all mice at 5, 15, 30 min, 1, 2, 4, 6, and $24 \mathrm{~h}$. Plasma was separated from blood by centrifugation and stored at $-80{ }^{\circ} \mathrm{C}$ until analysis. The pharmacokinetic parameters $\mathrm{C}_{\max }, \mathrm{T}_{\max }, \mathrm{t}_{1 / 2}, \mathrm{AUC}, \mathrm{Cl}$, and $\mathrm{V}_{\mathrm{D}}$ were evaluated. 